\title{
Sandia National Laboratories Analysis Code Data Base
}

\author{
Carl W. Peterson \\ Sandia National Laboratories \\ Albuquerque, New Mexico 87185
}

\begin{abstract}
Sandia National Laboratories' mission is to solve important problems in the areas of national defense, energy security, environmental integrity, and industrial technology. The Laboratories' strategy for accomplishing this mission is to conduct research to provide an understanding of the important physical phenomena underlying any problem, and then to construct validated computational models of the phenomena which can be used as tools to solve the problem. In the course of implementing this strategy, Sandia's technical staff has produced a wide variety of numerical problem-solving tools which they use regularly in the design, analysis, performance prediction, and optimization of Sandia components, systems and manufacturing processes. This report provides the relevant technical and accessibility data on the numerical codes used at Sandia, including information on the technical competency or capability area that each code addresses, code "ownership" and release status, and references describing the physical models and numerical implementation.
\end{abstract}

\section{MASTER}




\section{Acknowledgment}

The editor would like to thank the Sandia points-of-contact for providing the summary information contained in this report. 


\section{DISCLAIMER}

This report was prepared as an account of work sponsored by an agency of the United States Government. Neither the United States Government nor any agency thereof, nor any of their employees, make any warranty, express or implied, or assumes any legal liability or responsibility for the accuracy, completeness, or usefulness of any information, apparatus, product, or process disclosed, or represents that its use would not infringe privately owned rights. Reference herein to any specific commercial product, process, or service by trade name, trademark, manufacturer, or otherwise does not necessarily constitute or imply its endorsement, recommendation, or favoring by the United States Government or any agency thereof. The views and opinions of authors expressed herein do not necessarily state or reflect those of the United States Government or any agency thereof. 


\section{DISCLAIMER}

Portions of this document may be illegible in electronic image products. Images are produced from the best available original document. 


\section{Contents}

Introduction $\ldots \ldots \ldots \ldots \ldots \ldots \ldots \ldots \ldots \ldots \ldots \ldots \ldots \ldots \ldots \ldots \ldots \ldots \ldots$

Fluid Mechanics and Heat Transfer Codes $\ldots \ldots \ldots \ldots \ldots \ldots \ldots \ldots \ldots \ldots \ldots$

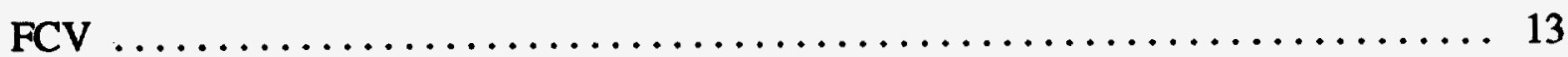

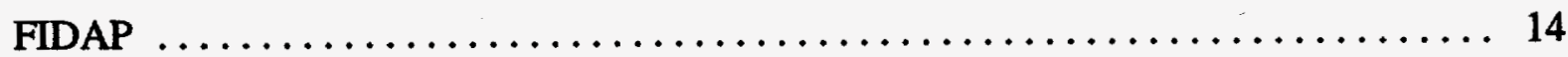

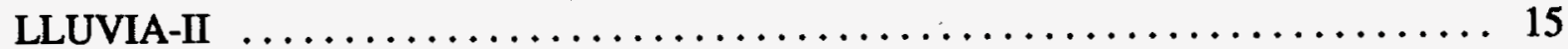

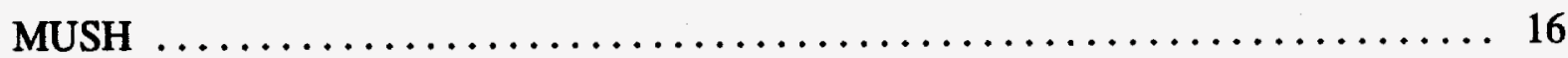

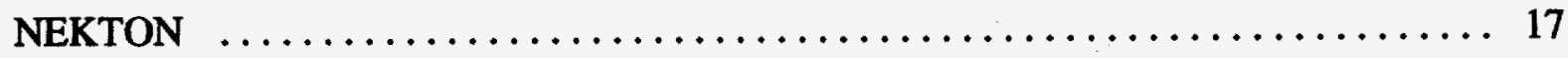

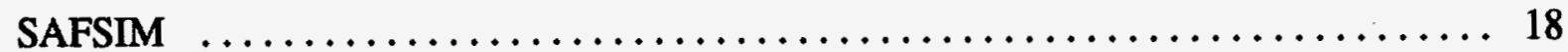

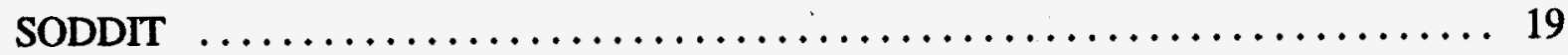

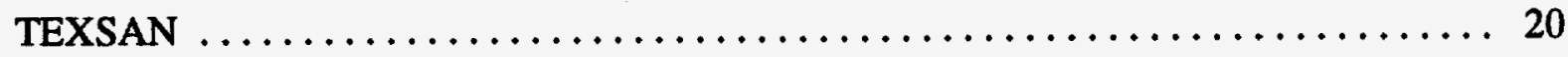

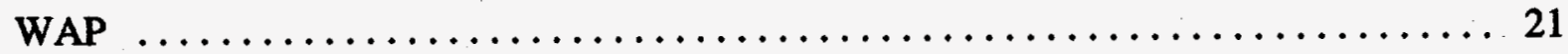

Thermal and Thermal/Structural Analysis Codes $\ldots \ldots \ldots \ldots \ldots \ldots \ldots \ldots \ldots$

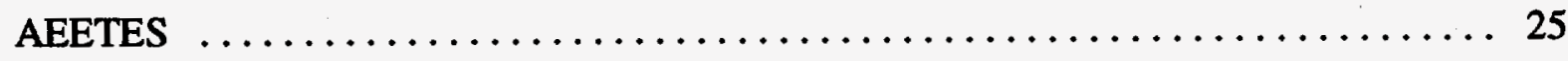

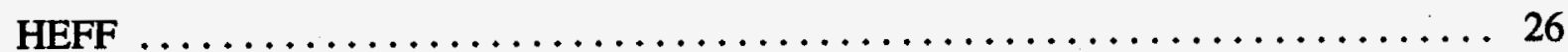

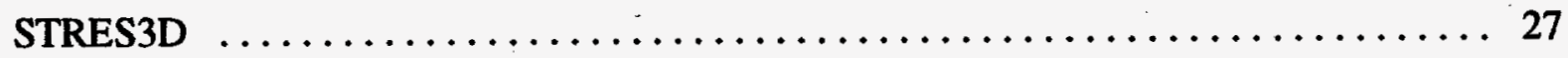

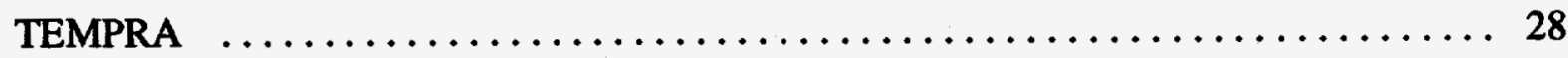

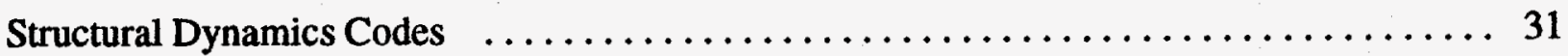

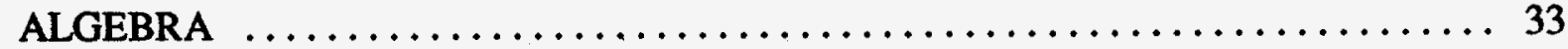

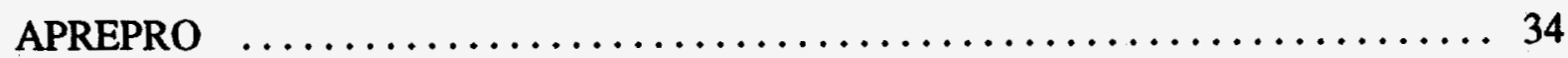

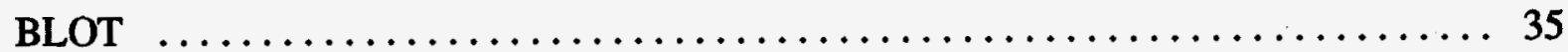

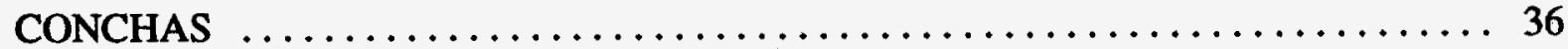

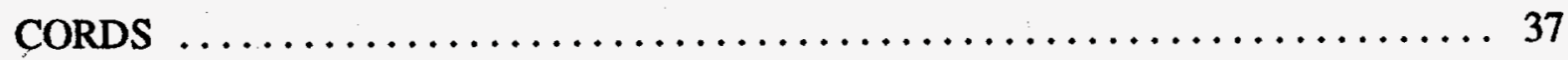

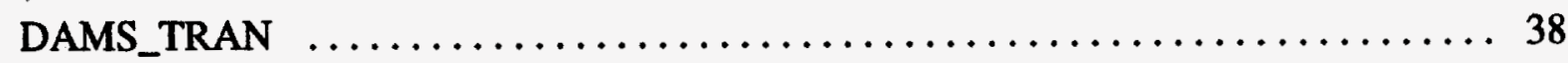

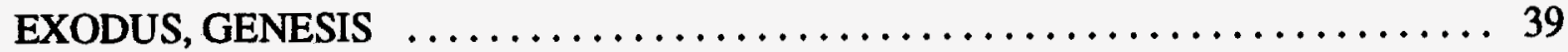

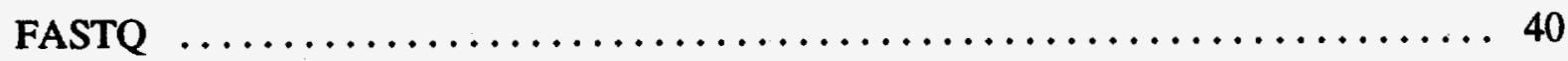

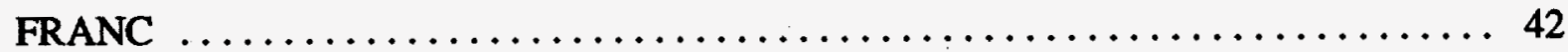

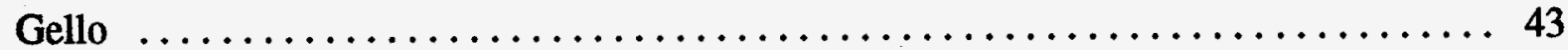

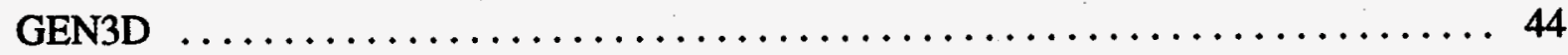

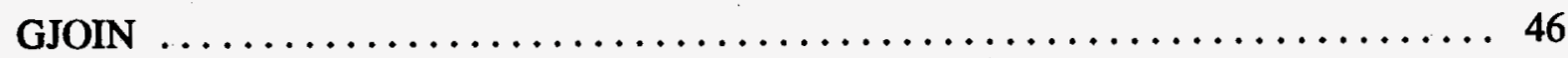

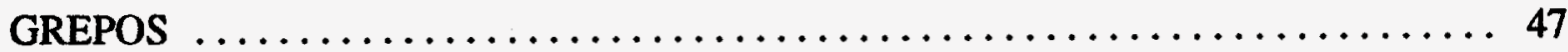

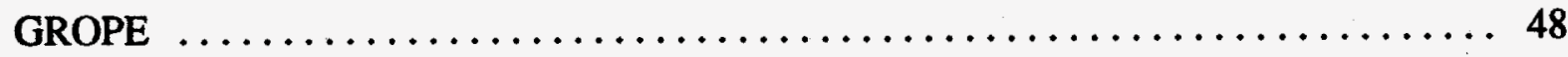




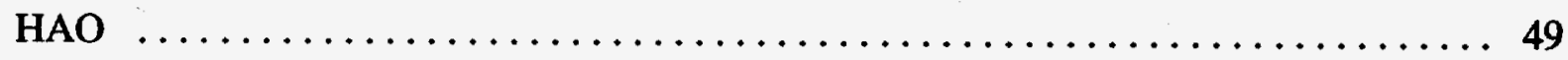

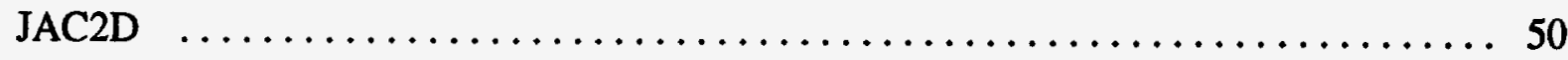

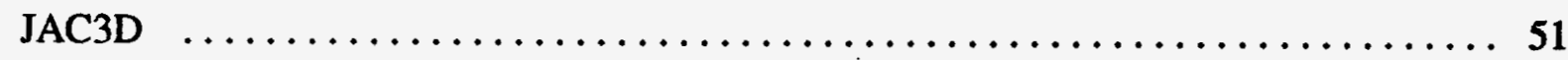

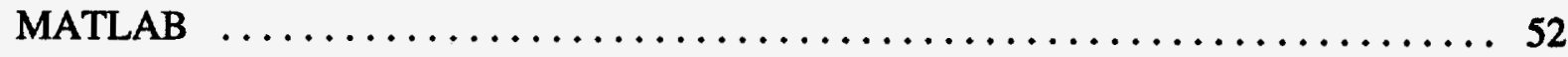

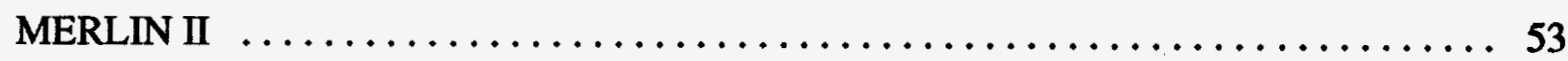

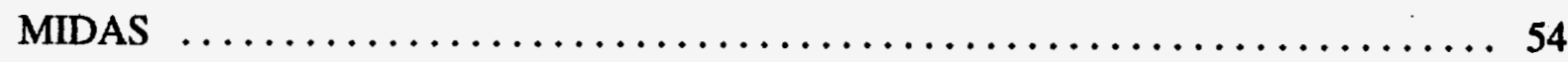

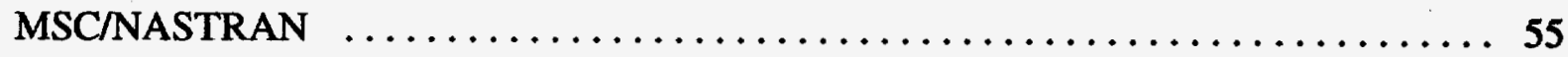

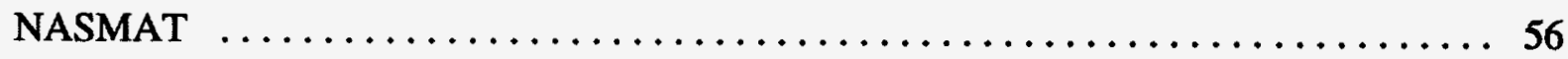

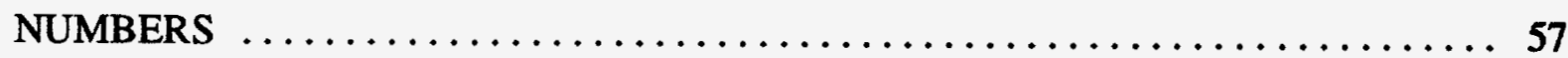

OBSERVER/SYSTEM REALIZATION TOOLBOX $\ldots \ldots \ldots \ldots \ldots \ldots \ldots \ldots . \ldots$

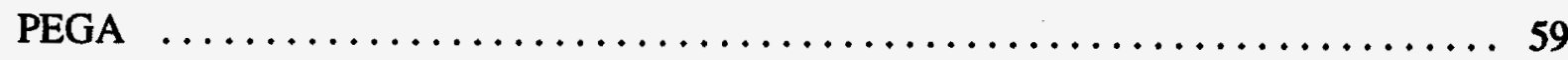

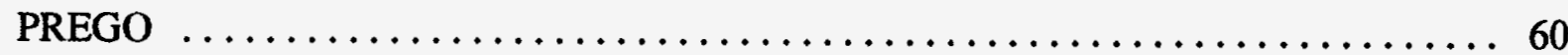

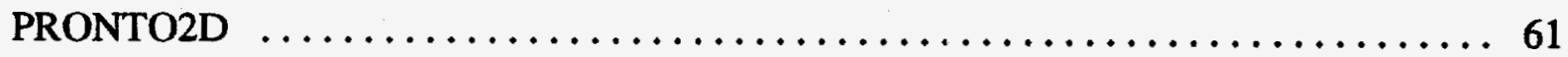

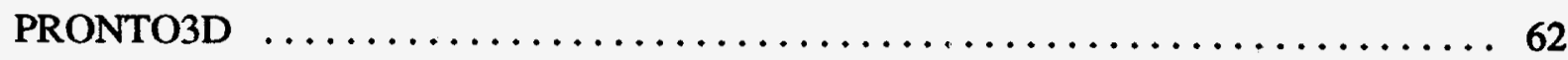

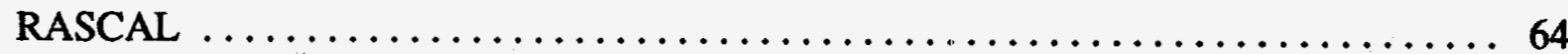

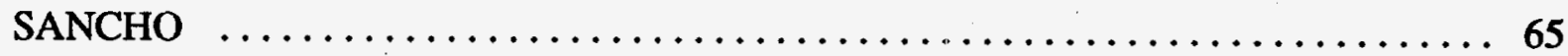

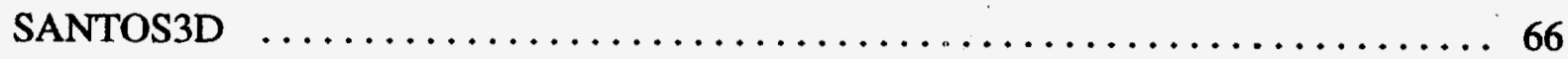

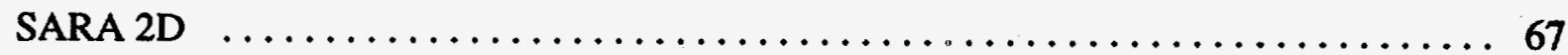

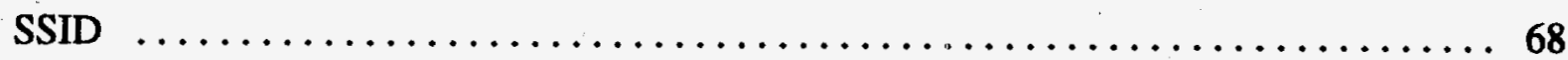

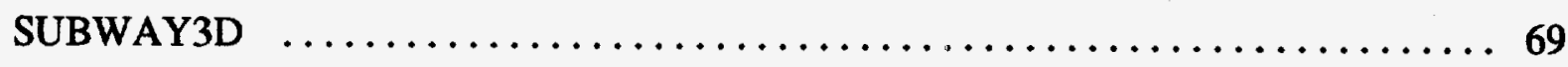

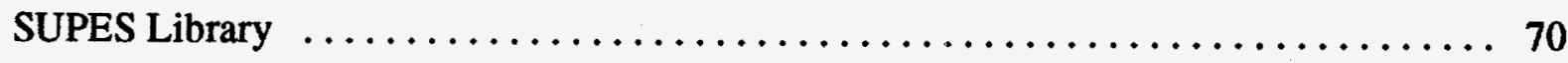

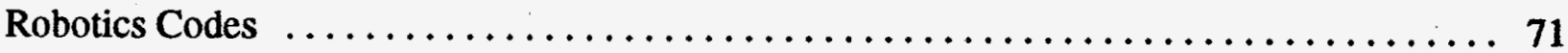

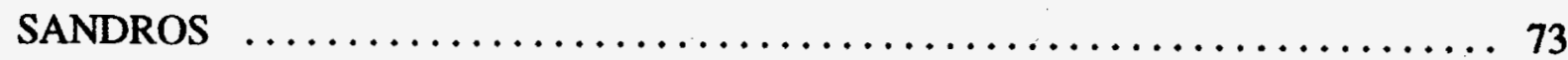

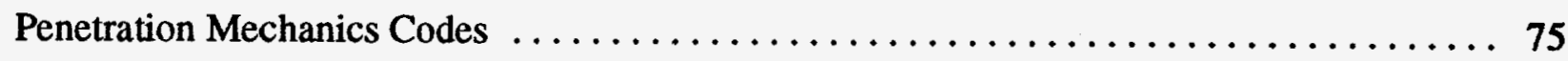

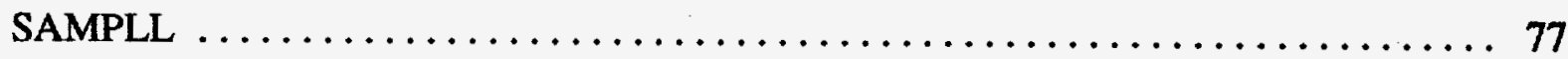

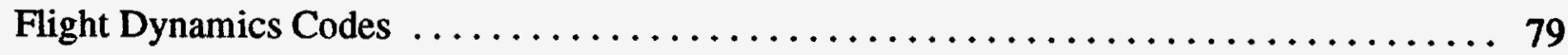

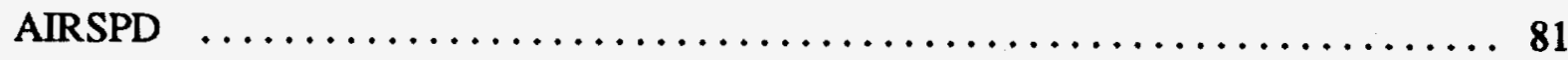

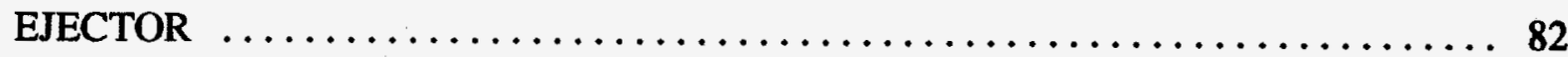

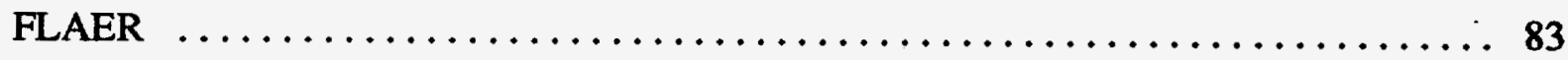

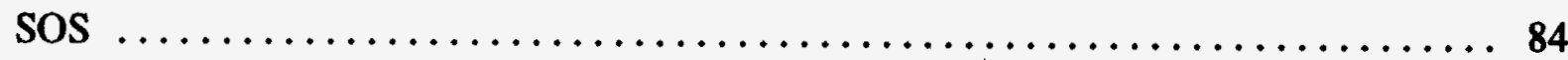

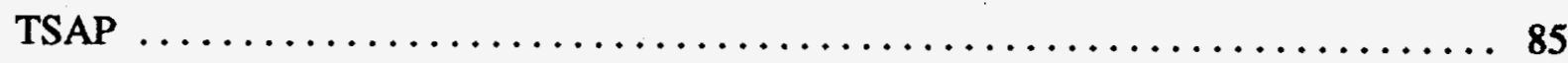

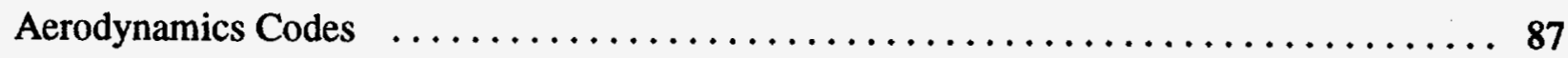

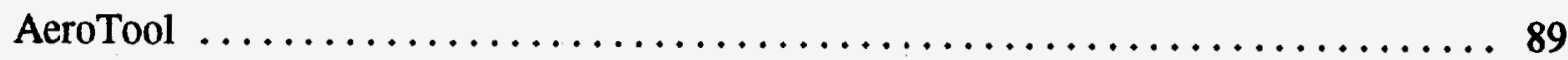

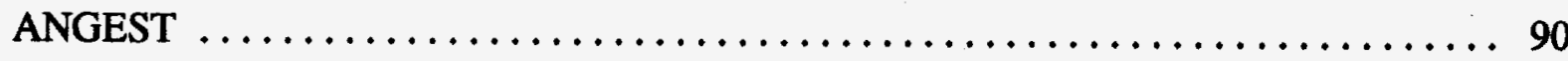




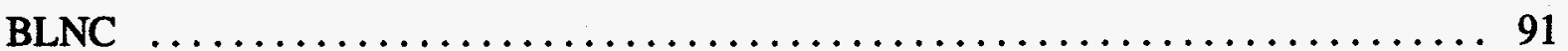

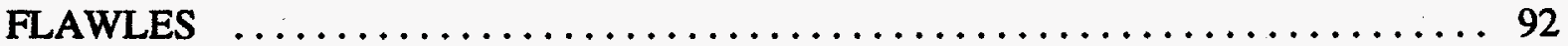

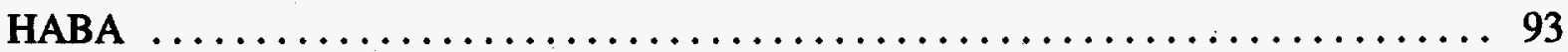

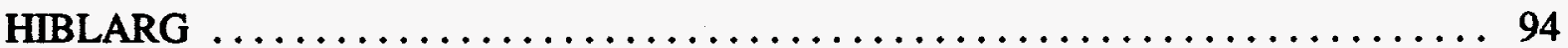

MISSILE DATCOM $\ldots \ldots \ldots \ldots \ldots \ldots \ldots \ldots \ldots \ldots \ldots \ldots \ldots \ldots \ldots \ldots, \ldots 5$

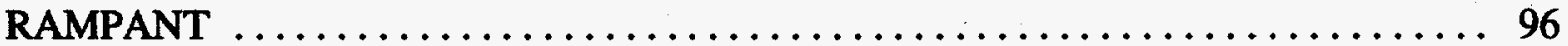

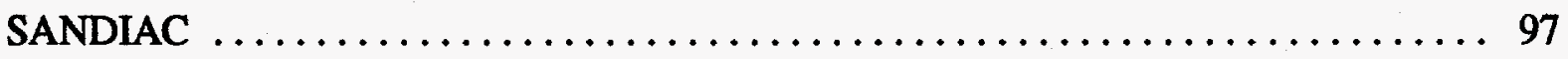

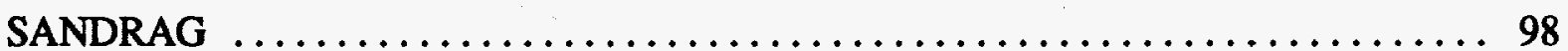

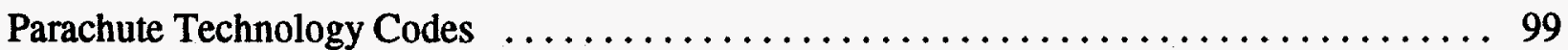

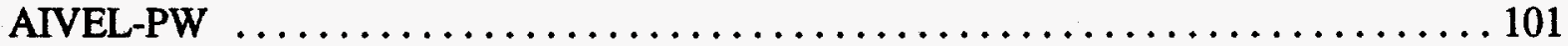

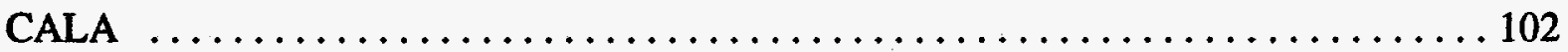

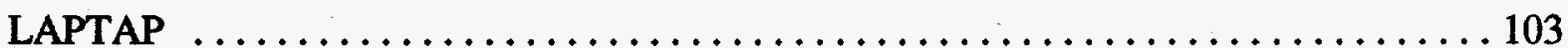

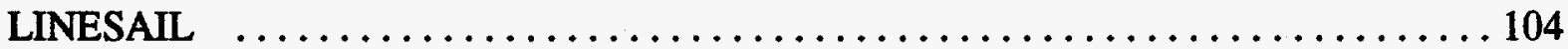

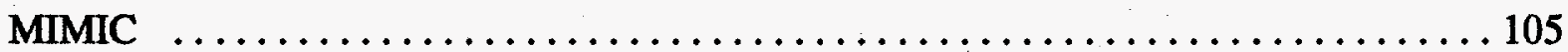

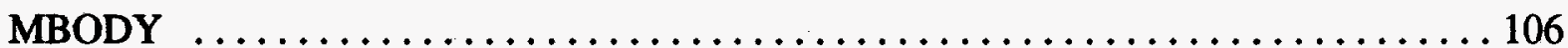

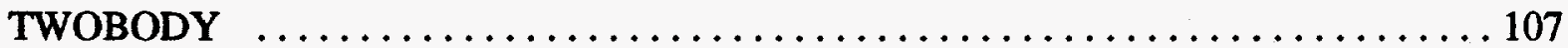

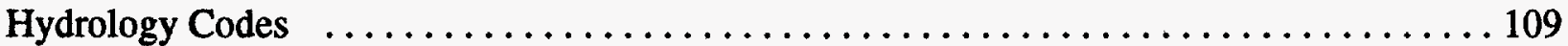

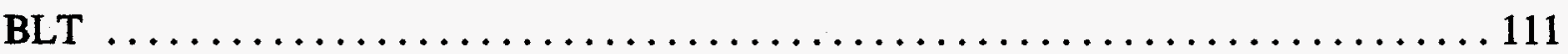

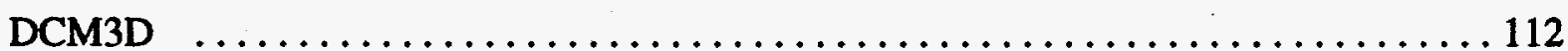

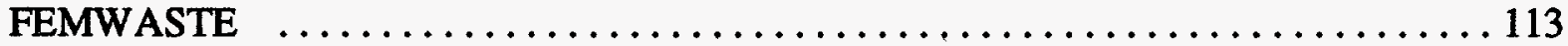

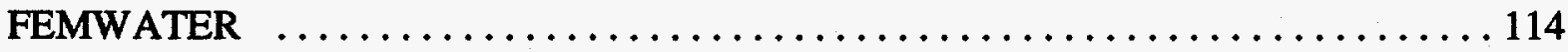

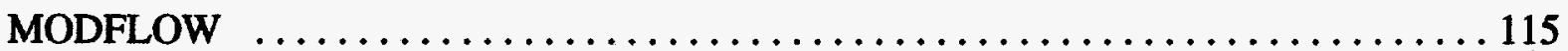

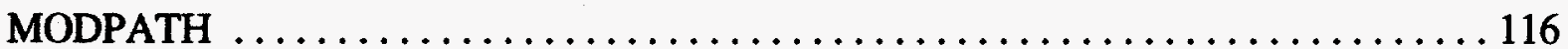

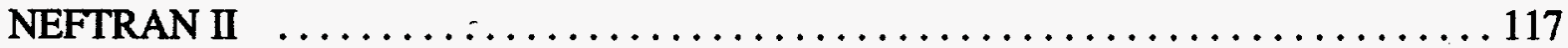

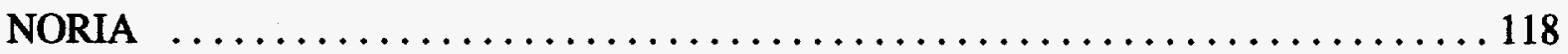

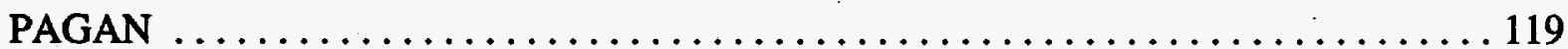

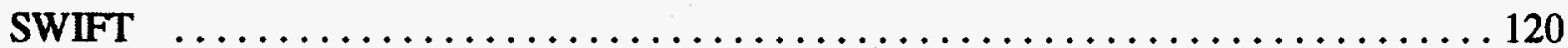

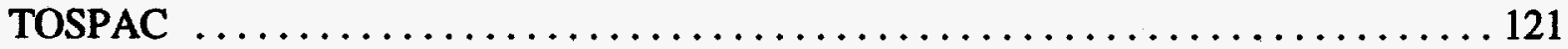

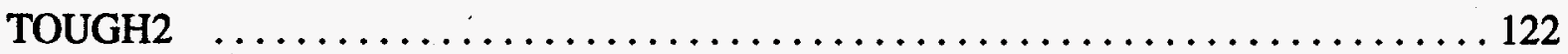

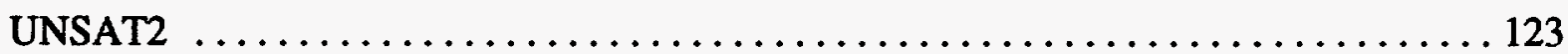

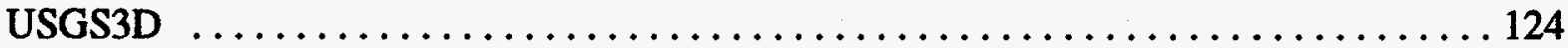

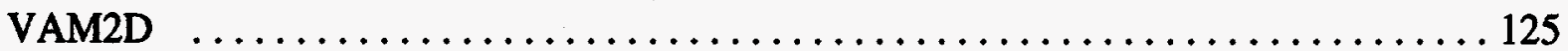

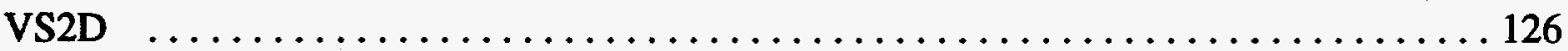

Geostatistics Codes ........................................... 127 


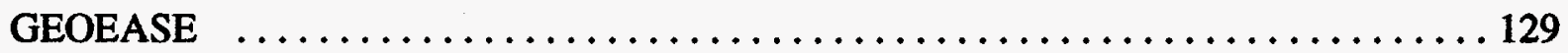

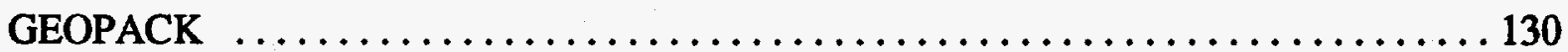

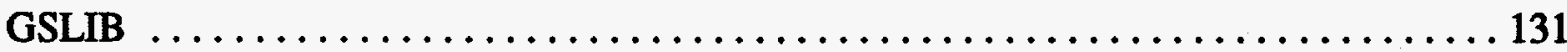

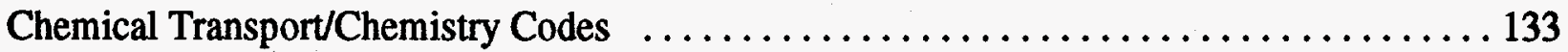

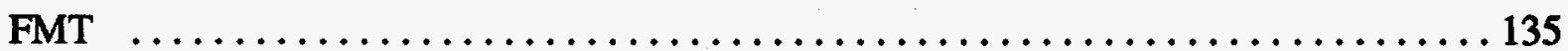

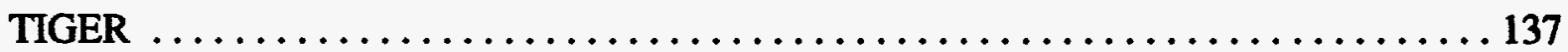

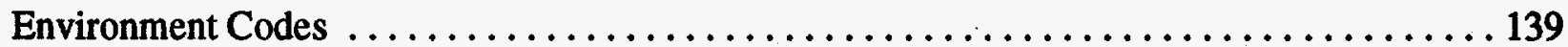

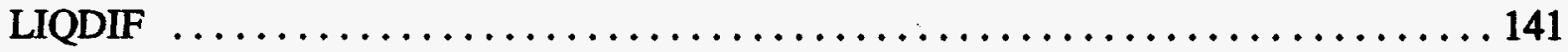

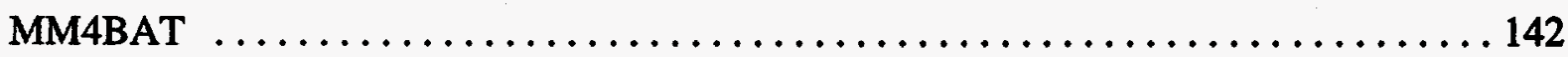

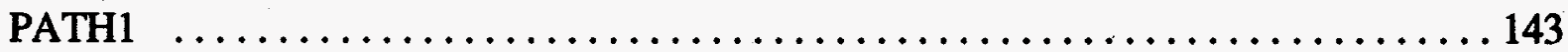

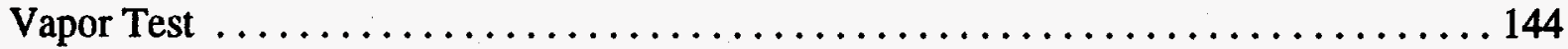

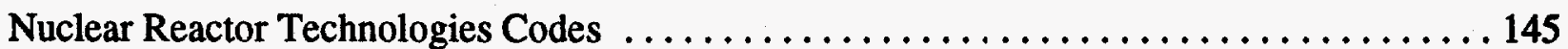

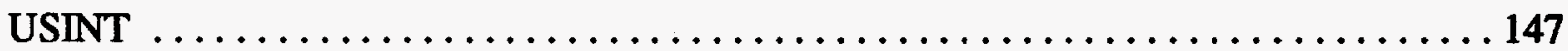

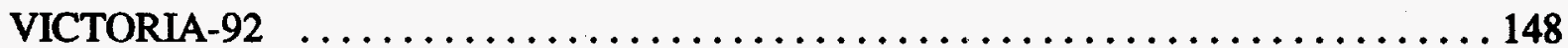

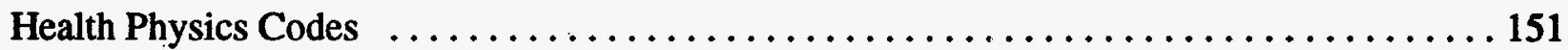

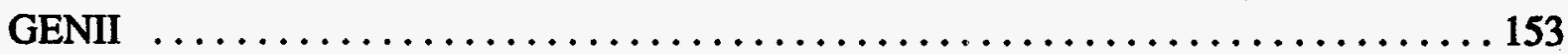

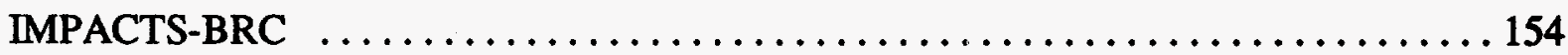

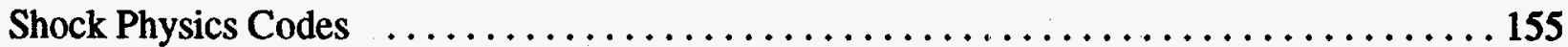

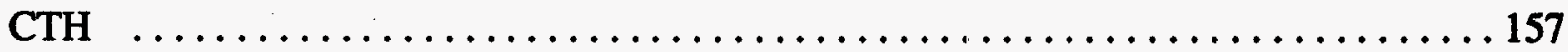

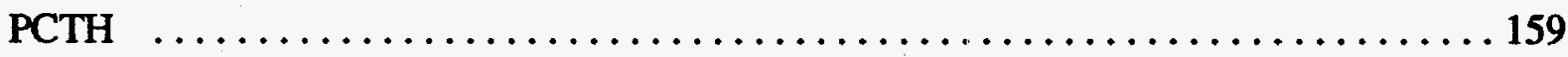

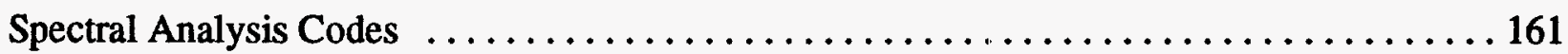

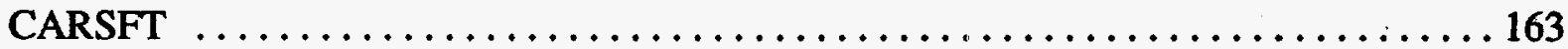

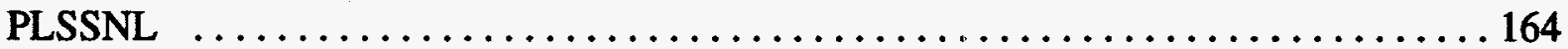

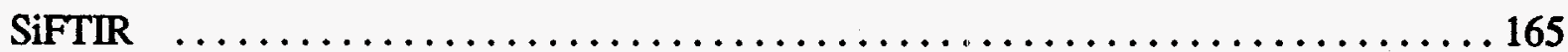

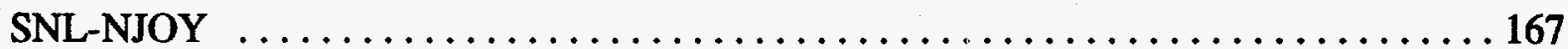

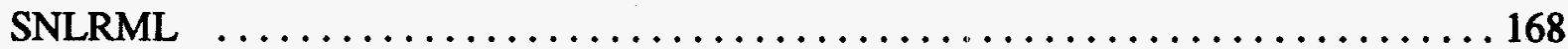

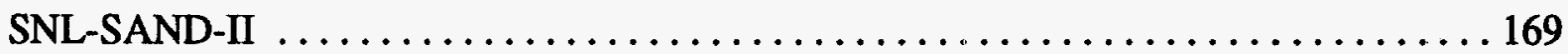

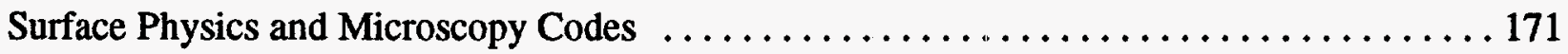

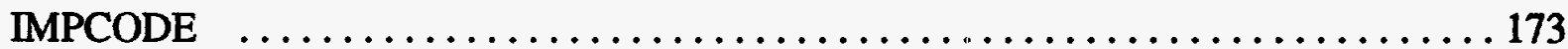

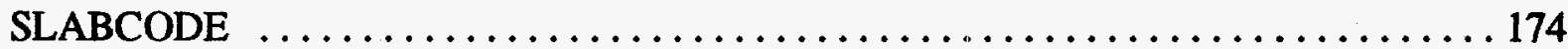

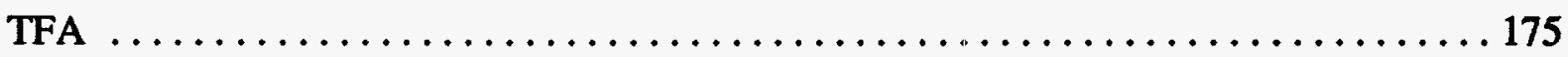

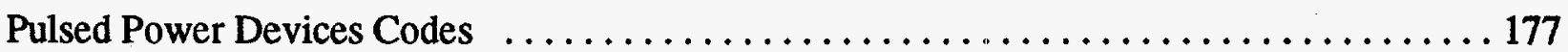




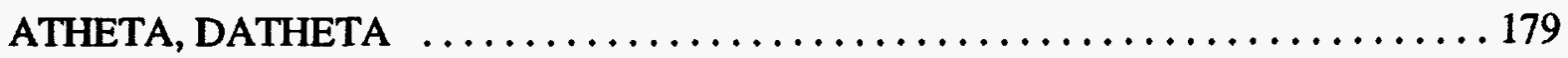

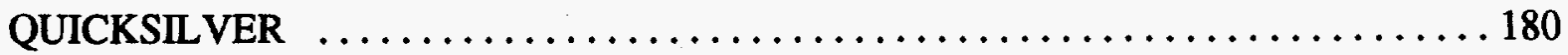

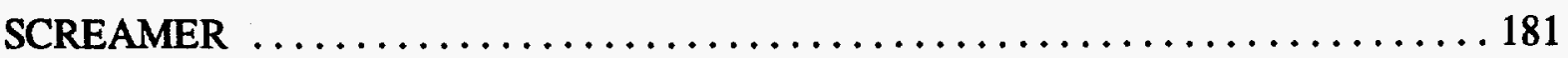

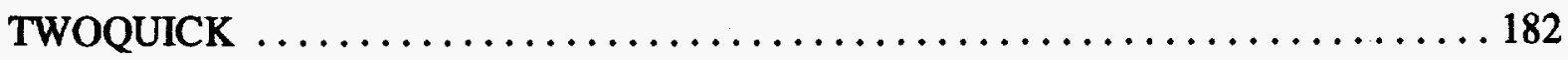

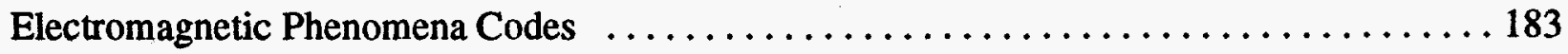

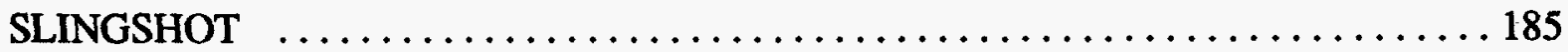

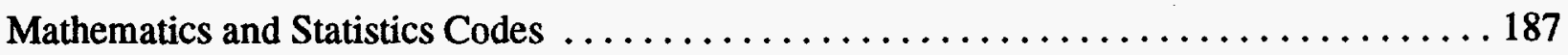

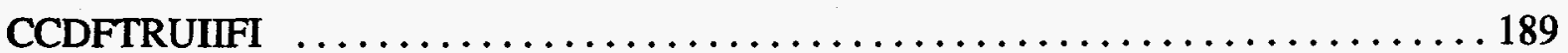

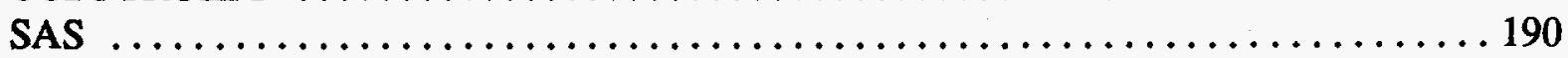

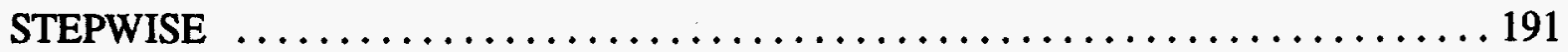

Weapons Effectiveness Simulation Codes . . . . . . . . . . . . . . . . . . . 193

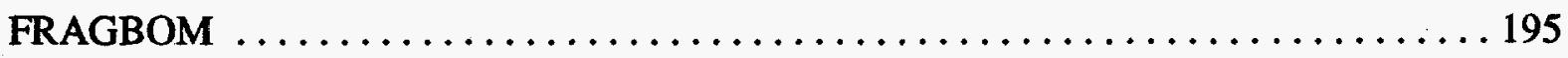

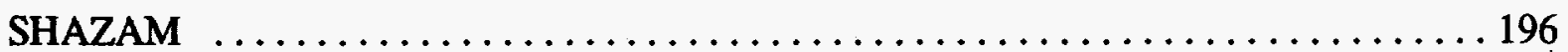

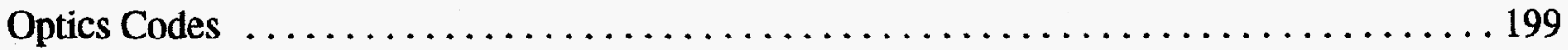

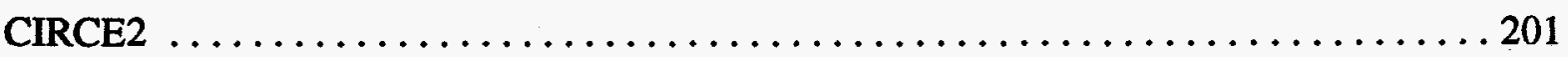




\section{Introduction}

Sandia National Laboratories' mission is to solve important problems in the areas of national security, industrial competitiveness, energy resources, science and technology, and environmental quality. Such complex, diverse problems have required Sandia to develop an exceptionally strong technology base spanning a wide variety of disciplines in the physical and engineering sciences. The Laboratories' strategy for accomplishing our mission is to use this technology base to provide an understanding of the important physical phenomena underlying any problem, and then to construct validated computational models of the phenomena which can be used as tools to solve the problem. This approach to problem-solving reflects our conviction that validated computational tools operating on advanced computers can reduce the time and expense required to solve the problems compared to relying heavily upon experiential and design-by-test methods.

In the course of implementing this strategy, Sandia's technical staff has produced a wide variety of numerical problem-solving tools which they use regularly in the design, performance prediction, and optimization of Sandia components, systems and manufacturing processes. The codes are constantly being improved to provide new or better phenomenological models, broader ranges of applicability, and greater accuracy; they are never "finalized," they are always changing. As a result, it is difficult for other Sandians and people outside the laboratory to know that these powerful numerical design tools exist, let alone what their capabilities are.

The purpose of this report is to provide for people outside Sandia's computational engineering community a general data base on the numerical codes used at Sandia. The report contains information on the technical competency and capability area that each code addresses, code "ownership" and release status, and references describing the physical models and numerical implementation. Each data sheet was prepared by the Sandia point-of-contact and submitted only if the point-of-contact wanted to disseminate information about the code. Codes which are early in the development cycle or are being phased out of use are not included in this data base. Not all codes listed in this data base were developed at Sandia (some are commercial codes, others were imported from other government agencies), and not all Sandia codes in this listing are available to the public or will be marketed outside of Sandia. Because current codes are changed, new codes come and older codes go, this listing will be updated periodically.

The remainder of this report contains summary information on each Sandia code, grouped by technical competency and capability area. 
Fluid Mechanics and Heat Transfer Codes 
This page intentionally left blank 


\section{Sandia National Laboratories Analysis Code Data Base}

Code Name: FCV (Finite Control Volume)

Technical Competency/Capability Area:

Heat conduction in 2-D planar and axi-symmetric geometries

Sandia Point of Contact:

BennieF.Blackwell, 1514,MS-0826,(505)845-8844,FAX (505)844-4523; bfblack@sandia.gov;

Roy E.Hogan, Jr. 1513, MS-0835, (505) 845-9585, FAX (505) 844-8251, rehogan@sandia.gov

Technical Description of What the Code Does:

FCV solves the transient heat conduction equation for 2-D planar and axisymmetric geometries using unstructured mesh of 3 node triangles and 4 node quadrilaterals. The spatial differencing uses a finite control volume procedure and the time differencing uses an implicit procedure. The algebraic equations are solved using a direct solver for a sparselbanded matrix. Boundary conditions include specified (time dependent) temperature, convection based on transfer coefficient times temperature difference, aerodynamic heating based on transfer coefficient times enthalpy difference, and radiation exchange. Internal radiation cavities are allowed; this requires input of configuration factors.

\section{Original Developer of the Code:}

B. F. Blackwell and R. E. Hogan of Sandia National Laboratories

Release Status: Still in development but has been released to friendly users

\section{References:}

B. F. Blackwell and R. E. Hogan, "Numerical Solution of 2-D Axisymmetric Heat Conduction Problems Using a Finite Control Volume Technique," AIAA 91-1353, presented at AIAA 26th Thermophysics Conference, Honolulu, Hawaii, June 24-26, 1991. To be published in Journal of Thermophysics and Heat Transfer.

\section{Computer Language: FORTRAN}

\section{Computer Platform:}

Sun Work Station, double precision (earlier versions have run on VAX and CRAY machines)

Related Codes: Compatible with FASTQ mesh generator in ABAQUS format

Key Words: Heat Conduction, Aerodynamic Heating 
Code Name: FIDAP

Technical Competency/Capability Area:

Laminar or turbulent flows, Newtonian or non-Newtonian, porous pedia flows, flows with coupled mass or heat transport, steady state or transient flows, creeping flows, forced and free convection problems, flows driven by body forces, periodic, separating, or recirculating flows, flows with free or moving surfaces, surface tension driven thermal flows, solidification and melting, radiation transport, conjugate flow and heat transport.

Sandia Point of Contact:

Randall P. Schunk,.1511, MS-0827, (505) 844-5992, FAX (505) 844-4523 prschun@sandia.gov

Technical Description of What the Code Does:

Finite element method for incompressible mass, momentum, and energy transport including turbulence, non-Newtonian fluids, etc. in steady or transient mode for 2- and 3-D geometries. Range of solution methods including Picard, Newton, Quasi-Newton, and iterative solvers available.

Original Developer of the Code: Fluid Dynamics International Inc.

Release Status: Commercially available, version 6.1 (not distributed by Sandia)

References:

FIDAP Users Manual, Fluid Dynamics International Inc.

Computer Language: FORTRAN

Computer Platform: Sandia: Cray, Stardent. Also availabie for Alliant, Apollo, CDC, Convex, Decstation, HP9000, IBM, Iris, Sun and Vax

Related Codes: FIDAP includes preprocessor FIPREP, mesh generator FIMESH, and postprocessor FIPOST.

Key Words: Finite elements, incompressible, heat transport, mass transport, non-Newtonian, steady, unsteady turbulent, fluid dynamics 


\section{Sandia National Laboratories Analysis Code Data Base}

Code Name: LLUVIA-II

Technical Competency/Capability Area:

Single phase flow of water through partially saturated porous media

Sandia Point of Contact:

Roger R. Eaton, 1511, MS-0835, (505) 844-4063 FAX (505) 844-4523, rreaton@sandia.gov

Technical Description of What the Code Does:

LLUVIA-II is a program designed for the efficient solution of two-dimensional, transient flow of liquid water through partially saturated, porous media. The code solves the time-dependent Richards equation using the method-of-lines procedure.

Original Developer of the Code:

Roger R. Eaton and Polly Hopkins, Sandia National Laboratories

Release Status: $\quad$ LLUVIA-II has been released to Org. 6112

\section{References:}

R. R. Eaton and P. L. Hopkins, "LLUVIA-II: A Program for Two-Dimensional, Transient Flow Through Partially Saturated Porous Media," SAND90-2416, Sandia National Laboratories, Albuquerque, NM, 1992

Computer Language: FORTRAN

Computer Platform: SUN computer

Related Codes: $\quad$ LLUVIA - One-dimensional version of LLUVIA-II

Key Words: Porous media 


\section{Sandia National Laboratories Analysis Code Data Base}

Code Name: MUSH, "MUSHY Zone Simulator"

Technical Competency/Capability Area:

Metal solidification simulation for casting, welding, remelting processes.

Sandia Point of Contact:

Lee A. Bertram, 8743, MS-9043, (510) 294-1545, FAX: (510) 294-1459, labertr@sandia.gov

\section{Technical Description of What the Code Does:}

MUSH solves the Local Solute Redistribution Equation for volume fraction liquid in a solidifying metal cylinder, for which the macroheating, including fluid flow of the melt, is known (by ZAP, WAP or other macroscale code simulation). Given a coarsening rule for the solidification processes, permeabilities are assigned and interdendritic pressure and a Darcy flow are calculated. Final macro- and micro-segregation are calculated from this flow and the LSRE.

Original Developer of the Code: Lee A. Bertram, Sandia

Release Status: Research code

\section{References:}

Lee A. Bertram, "Flow Effects on the Solidification Environment in a GTA Spot Weld," to appear in Trans. ASME-J Mater. Tech, 1992.

\section{Computer Language: Fortran}

Computer Platform: SUN

\section{Related Codes:}

Postprocessors: PZW/CBIN to plot contours of fraction liquid, solute concentration, pressure. Symbionts: WAP, ZAP, ZAPP quasisteady axisymmetric macroscale solidification codes.

Key Words:

Axisymmetric, solidification, mushy zones, LSRE, Flemings-Mehrabian formulation 


\section{Sandia National Laboratories Analysis Code Data Base}

\section{Code Name: NEKTON}

\section{Technical Competency/Capability Area:}

Time-accurate simulations in general geometries of incompressible fluid flow, conductive and convective heat transfer, and diffusive and convective transport of scalars.

Sandia Point of Contact:

John R.Torczynski, 1512, M/S 0834, (505) 845-8991,FAX(505) 844-8251,jrtorcz@cfd.sandia.gov

\section{Technical Description of What the Code Does:}

NEKTON simulates any combination of the following: the motion of an incompressible fluid, conductive and convective heat transfer, and diffusive and convective transport of arbitrary scalars, such as concentrations of chemical species. Material properties can be functions of time, space, flow properties, temperature, and transported scalars. Complex free surfaces, moving and deforming geometries, and melting/solidifying interfaces are also treated. Mixing-length and $k-e$ turbulence models are available. NEKTON represents the field variables using spectral elements (high-order finite elements) and as such can simulate complex two-dimensional, axi-symmetric, and three-dimensional geometries. Geometries and meshes can be defined using PRENEK, the pre-processor for NEKTON, or imported from other codes. NEKTON generally solves the equations of motion in a time-accurate fashion although steady solution techniques are available for certain problems. Temporal and spatial variations of field quantities are determined using POSTNEK, the post-processor for NEKTON.

\section{Original Developer of the Code: A. T. Patera, MIT; S. A. Orszag, Princeton}

\section{Release Status:}

NEKTON is a commercially available code currently developed by Nektonics (Cambridge, MA) and marketed and supported by Fluent Inc. (Lebanon, NH). The current full release is version 2.8 , with version 2.85 scheduled for November 16, 1992. Source is available under certain licensing arrangements.

\section{References:}

1. A. T. Patera, "A Spectral Element Method for Fluid Dynamics: Laminar Flow in a Channel Expansion," J. Comput. Phys. 54, 468-488 (1984).

2. NEKTON User's Guide, Version 2.8 (Nektonics, Cambridge MA, 1991).

Computer Language: NEKTON is written in a combination of FORTRAN and $C$

\section{Computer Platform:}

NEKTON has been ported to the following platforms: Cray (unicos), various workstations (unix), Vax (vms), and various parallel computers.

\section{Related Codes:}

NEKTON uses the code PRENEK as a pre-processor and the code POSTNEK as a post-processor.

Key Words: Incompressible flow, heat transfer, species transport, free surface, moving boundaries, phase change, spectral element, time accurate, parallel processing 


\section{Sandia National Laboratories Analysis Code Data Base}

Code Name: SAFSIM: System Analysis Flow SIMulator

Technical Competency/Capability Area:

Fluid Mechanics, Heat Transfer, Reactor Dynamics, System Modeling

Sandia Point of Contact:

Dean Dobranich, 1513,M/S 0835, (505) 845-0446, FAX(505) 844-8251, ddobran@sandia.gov

\section{Technical Description of What the Code Does:}

SAFSIM is a general-purpose computer program (being developed at Sandia National Laboratories) with sufficient versatility to allow the simulation of almost any flow system, from a backyard sprinkler system to a nuclear propulsion system. SAFSIM solves the steady and transient equations governing fluid mechanics and heat transfer based on a one-dimensional finite element approach. SAFSIM"s major strength is its ability to predict the integrated performance of complex systems. Thus, flow systems can be "tested" on the computer before hardware is developed. SAFSIM is currently being used to assess the operational performance of proposed nuclear thermal rockets.

Original Developer of the Code: Dean Dobranich, Sandia, Department 1513

Release Status:

SAND document describing input released publicly; evaluation copies of code sent to NASA, $B \& W$, Rockwell International, ORNL, and several Universities.

\section{References:}

Dean Dobranich, "SAFSIM Input manual -- A Computer Program for the Engineering Simulation of Flow Systems," SAND92-0694

\section{Computer Language: FORTRAN}

\section{Computer Platform:}

Independent of platform; developed on a PC using Lahey FORTRAN; also run on a VAX, Sun and HP workstations

Related Codes: None

Key Words:

Fluid Mechanics, Heat Transfer, Reactor Dynamics, System Modeling, Finite element analysis tool. 


\section{Sandia National Laboratories Analysis Code Data Base}

Code Name: SODDIT (Sandia One-Dimensional Direct and Inverse Thermal)

Technical Competency/Capability Area: Direct and inverse heat conduction problems Sandia Point of Contact:

Bennie F. Blackwell, 1514,MS-0826, (505)845-8844 FAX(505) 844-4523; bfblack@ sandia.gov;

\section{Technical Description of What the Code Does:}

Solves one-dimensional heat conduction equation with sources for planar, cylindrical, and spherical geometries using a finite control volume procedure for spatial differencing and implicit time differencing. The mesh generator is built into the code and it allows a nonuniform mesh using a geometric progression. Temperature dependent thermal properties are entered in tabular form. Internal radiation/convection gaps and contact resistances are allowed. General convection/ radiation boundry conditions are permitted including aerodynamic heating based on enthalpy difference as a driving potential. Two ablation options exist: 1) specified (fixed) ablation temperature with heat of ablation and 2) dimensionless mass loss rate as a function of temperature and pressure.

For non-ablating problems, inverse problems can be solved in which surface heat flux is estimated from interior temperature measurement using the future temperature method of Beck.

Original Developer of the Code: Ben Blackwell, Sandia National Laboratory

Release Status: Has been released to government laboratories and defense contractors

\section{References:}

1. B. F. Blackwell, R. W. Douglass and H. Wolf, "A User's Manual for the Sandia One-Dimensional Direct and Inverse Thermal (SODDIT) Code," SAND85-2478, Sandia National Laboratories, May 1987. Contains extensive series of benchmark problems.

2. B. F. Blackwell, "Numerical Prediction of One-Dimensional Ablation Using a Finite Control Volume Procedure with Exponential Differencing," Numerical Heat Transfer, vol. 14, pp. 17. $34,1988$.

\section{Computer Language: FORTRAN \\ Computer Platform:}

Sun Work Station with double precision (earlier versions have run on VAX and CRAY machines and other people have converted the code to run on PC's)

Related Codes: None

Key Words: Heat conduction, ablation, inverse problems 


\section{Sandia National Laboratories Analysis Code Data Base}

Code Name: TEXSAN (Texas-Sandia Thermal-Hydraulic Analysis Program)

Technical Competency/Capability Area: Fluid Mechanics and Heat Transfer

Sandia Point of Contact:

Steven E. Gianoulakis,1513, (505) 844-0450, M/S 0835 FAX (505) 844-8251, segiano.sandia.gov Technical Description of What the Code Does:

TEXSAN solves the coupled Navier-Stokes and energy equations on an arbitrary domain. Physical phenomena that can be modeled include conduction, convection, and radiation heat transfer, buoyancy induced and forced laminar flows. TEXSAN uses a hybrid finite element finite difference method to solve the discretized steady or unsteady transport equations in two or three dimensions.

Original Developer of the Code:

The University of Texas at Austin under contract to Sandia National Laboratories.

Release Status: Available.

\section{References:}

1. S. E. Gianoulakis, "A Hybrid Finite Element Finite Difference Method for Multi-Mode Heat Transfer in Complex Geometries", PhD Dissertation, The University of Texas at Austin, May, 1992.

2. S. P. Burns, D. E. Klein, "Validation of the TEXSAN Thermal-Hydraulic Analysis Program," Proceedings of the Third International Conference on High Level Radioactive Waste Management, Las Vegas, NV, April 12-16, 1992, pp 799-804.

3. N. N. Brown, S. P. Burns, S. E. Gianoulakis, D. E. Klein, "Thermal-Hydraulic Software Development for Nuclear Waste Transportation Cask Design and Analysis," presented at the National Heat Transfer Conference, Minneapolis, MN, July 28-31, 1991, Paper \#91-HT-2.

\section{Computer Language: FORTRAN}

Computer Platform: Cray Y-MP8/864, VAX 6410, and Unix Workstations

Related Codes: Pre-and Post processing is accomplished with PATRAN

Key Words: Thermal-Hydraulic, Heat Transfer, Navier-Stokes, Multi-dimensional 


\section{Sandia National Laboratories Analysis Code Data Base}

Code Name: WAP "Weld Analysis Program"

Technical Competency/Capability Area:

Metal solidification simulation for casting, welding, remelting processes

Sandia Point of Contact:

Lee A. Bertram, 8743, M/S 9043, (510) 294-1545; FAX (510) 294-3410; labertr@sandia.gov

Technical Description of What the Code Does:

WAP solves the macroscale heat transfer problem for a melting/solidifying metal cylinder subjected to rather general axisymmetric heating, including fluid flow of the melt. The fluid flow is driven by surface tension, Lorentz (electromagnetic) forces of AC or DC sources, buoyancy due to thermal solutal gradients, and surface shear stresses of other (e.g., frictional) sources. Metal evaporation, radiation, convection and pressure-dependent contact conduction are available as cooling boundary conditions. The method is fully-consistent (electromagnetically, mass, energy) finite volume formulation, with explicit time integration.

Original Developer of the Code: Lee A. Bertram, Sandia National Laboratories

\section{Release Status:}

Copy released to Ray Berry, INEL, for In-situ Vitrification of Wastes Simulation; research code.

\section{References:}

1. Lee A. Bertram and K. W. Mahin, "Fluid Flow in Metal Processing: A Welding Simulation," presented at Fluids Engineering Seminar and published in Proceedings; Editors J. H. Kim, J. M. Hyun and C. O. Lee, p.545, Hemisphere, NY (1991.

2. Lee A. Bertram and M. P. Kanouff, "A Proposed Standard Problem Definition for the Calculation of Heat and Fluid Flow in a GTA Weld Pool," published in Modeling of Casting, Welding and Advanced Solidification Processes; Editors M. Rappaz, M. R. Ozgu and K. W. Mahin, p.733, TMMMS, Warrendale, PA (1991).

\section{Computer Language: Fortran}

Computer Platform: SUN, CRAY, VAX

Related Codes:

Postprocessors: PZW/CBIN to diagnose energy budgets and plot contours of flow and temperature. PEM/CBIN to plot electromagnetic fields - voltage, current streamlines, curl of Lorentz force, Joule heating rate. 
Symbiont: MUSH, a Local Solute Redistribution Equation (SERE) based quasisteady axisymmetric solidification code to simulate averaged mushy zones. ZAP and ZAPP (for SMpC) are arcmelting simulators using many of the same modules; they provide macroscale solutions for that solidification processes.

\section{Key Words:}

Axisymmetric, transient, finite volume, melting and solidification, welding, arc welding, GTA, TIG. 
Thermal and Thermal/Structural Analysis Codes 
This page intentionally left blank 


\section{Sandia National Laboratories Analysis Code Data Base}

Code Name: AEETES

Technical Competency/Capability Area: Thermal Analysis of Solar Reflux Receivers Sandia Point of Contact:

Roy E.Hogan, Jr., 1513, M/S 0835, (505) 845-9585,FAX(505) 844-8251, rehogan@sandia.gov

Technical Description of What the Code Does:

AEETES simulates steady-state thermal performance of axisymmetric solar receivers with either axisymmetric or asymmetric incident solar fluxes. It accommodates either two-dimensional axisymmetric (rings) or three-dimensional (quadrilaterals) computational elements. AEETES accounts for the radiative and convective energy transfer within the receiver cavity, the conductive and convective energy transfer from the receiver housing, and the energy transfer to the receiver working fluid. AEETES computes the surface temperatures within the receiver and the receiver thermal efficiency. Complex receiver geometries are easily specified with combinations of planar, conical, cylindrical, and spherical sections. An interactive preprocessor is available for creating and modifying AEETES input files.

Both the solar and the infrared radiative transfer within the receiver cavity are modeled using variations of the net-radiation method which assumes the cavity surfaces are diffuse and gray within the solar and the infrared bands. Conduction heat transfer is modeled using a thermal resistance formulation. Correlations for the convective heat losses from the receiver cavity are available as input options.

Original Developer of the Code:

Roy E. Hogan, Jr., Department 1513, P.O. Box 5800, Sandia National Laboratories, Albuquerque, $N M, 87185$

Release Status: Available

\section{References:}

1. R. E. Hogan, "AEETES -- A Solar Reflux Receiver Thermal Performance Numerical Model," Solar Energy, accepted 1992.

2. R. E. Hogan, "AEETES -- A Solar Reflux Receiver Thermal Performance Numerical Model," SAND91-1280, Sandia National Laboratories, Albuquerque, NM, in progress, 1992.

Computer Language: FORTRAN

Computer Platform: SUN workstations and $\mathrm{PCs}$

Related Codes: $\quad$ CIRCE2, REWICK, and WICKPROP

Key Words: Solar, Thermal Analysis, Reflux Receivers, Coupled Conduction and Enclosure Radiation 


\section{Sandia National Laboratories Analysis Code Data Base}

Code Name: HEFF

Technical Competency/Capability Area: Rock Mass Analysis

\section{Sandia Point of Contact:}

Joe A. Fernandez, 7583, M/S 1348, (505) 848-0462;FAX (505) 848-0398, jaferna@ sandia.gov

\section{Technical Description of What the Code Does:}

Boundary-element code for predicting stresses, displacements, and temperatures in the vicinity of an opening in a linear, elastic, homogeneous medium. HEFF is based on the fictious stress method. The thermal model is a closed-form solution for a line heat source in an infinite medium. Input includes initial conditions, material properties, heat source parameters, and problem geometry.

Original Developer of the Code: Agapito \& Associates

Release Status: Research Code

References:

SAND87-7075

Computer Language: FORTRAN 77

Computer Platform: $P C$

Related Codes: None

Key Words: Thermal modeling, fictious stress modeling 


\section{Sandia National Laboratories Analysis Code Data Base}

Code Name: STRES3D

Technical Competency/Capability Area: Rock Mass Analysis

Sandia Point of Contact:

Eric Ryder ,6313,M/S 1325, (505) 848-0779; FAX(505) 848-0739, eeryder@sandia.gov

Technical Description of What the Code Does:

Thermomechanical analysis code for predicting transient temperatures, stresses, and displacements in infinite and semi-infinite conducting, homogeneous, elastic media. The code is based on thermoelastic analytic solutions for point heat sources in an infinite body. Semi-infinite bodies are treated by superposition of source and sink terms, coupled with relief of surface shear stresses by numerical integration.

Original Developer of the Code: St. John J.F.T. Agapito Asso

Release Status: Research code

References:

SAND89-7023, "Documentation and Verification of STRES3D"

Computer Language: Fortran 77

Computer Platform: PC-type

Related Codes: None

Key Words: Thermomechanical, thermoelastic 


\section{Sandia National Laboratories Analysis Code Data Base}

Code Name: TEMPRA (Thermal Evaluation and Matching Program for Risk Applications

Technical Competency/Capability Area: Simplified thermal analysis of complex systems Sandia Point of Contact:

Allen S. Benjamin, 6411, M/S 0405, (505) 845-8418; FAX(505) 844-8867, asbenja@sandia.gov

\section{Technical Description of What the Code Does:}

TEMPRA is a thermal analysis code which evaluates the response of complex systems to a wide range of thermal environments and predicts the timing of internal failures. It contains the following features which make it particularly suitable for applications, such as probabilistic risk assessments, where a large number of calculations are required using simplified models:

It is extremely fast-running and unconditionally stable. These characteristics are achieved through the use of lumped-element modeling together with full-linearization of the governing nonlinear equations and semi-implicit time integration.

It is robust for all types of thermal boundary conditions, including those which are highly directional as well as highly variable with time.

It contains fully integrated numerical models for many phenomena of interest in the evaluation of system responses, including thermal conduction, radiation, convection, chemical reaction, and material decomposition.

It calculates the timing of important events such as component failures or the ignition of explosives, and if uncertainty distributions are provided, it calculates pairwise event probabilities (i.e., the probability that one event occurs before another).

It contains a benchmarking option, in which the user may specify that certain parameters are adjustable. A special algorithm determines values for these parameters which optimize agreement of TEMPRA results with a set of benchmarking results (i.e., results obtained from more detailed models or from experimental data).

\section{Original Developer of the Code:}

Allen S. Benjamin, Sandia National Laboratories, Organization 6411

\section{Release Status:}

TEMPRA is a research code being used for probabilistic risk assessments of nuclear weapon systems. It has not been distributed outside Sandia. While it has been thoroughly checked and verified to be free of errors, it has not been subjected to formal $Q A$ procedures.

\section{References:}

D. D. Carlson, et al., "Probabilistic Risk Assessment Methods for Nuclear Weapon System Applications", SAND91-0323, Vols. 1 and 2, June 1991. 


\section{Computer Language: FORTRAN}

\section{Computer Platform:}

TEMPRA is operational on distributed VAX systems and on the CRAY-YMP at Sandia.

\section{Related Codes:}

PATRAN and P/THERMAL have been used to provide geometric input and benchmarking thermal response data to TEMPRA

\section{Key Words:}

Thermal analysis, temperature response, thermal failure analysis, conduction, convection, radiation, chemical reaction, simplified models, lumped-element models, probabilistic risk assessments. 
This page intentionally left blank 


\section{Structural Dynamics Codes}


This page intentionally left blank 


\section{Sandia National Laboratories Analysis Code Data Base}

Code Name: ALGEBRA

Technical Competency/Capability Area: Structural Mechanics

Sandia Point of Contact:

Frank J. Mello, 1516, MS0437; (505) 844-5357, FAX (505) 844-9297; fjmello@ sandia.gov

\section{Technical Description of What the Code Does:}

The ALGEBRA program allows the user to manipulate data from a finite element analysis before it is plotted. The finite element output data is in the form of variable values (e.g., stress, strain, and velocity components) in an EXODUS database. The ALGEBRA program evaluates user-supplied functions of the data and writes the results to an output EXODUS database which can be read by plot programs.

Original Developer of the Code: Amy P. Gilkey, Sandia National Laboratories

Release Status: Available to government agencies and contractors, university research groups.

\section{References:}

A. P. Gilkey, "ALGEBRA - A Program that Algebraically Manipulates the Output of a Finite Element Analysis (EXODUS Version)," SAND88-1431, Sandia National Laboratories, Albuquerque, New Mexico, August 1988

Computer.Language: ANSI Standard FORTRAN-77

Computer Platform:

Code is written in as portable a form as possible and has been ported to several UNIX systems including Cray, HP, Sun, Dec, Stardent, Convex, and SGI platforms.

\section{Related Codes:}

All SEACAS analysis codes CONCHAS, SANCHO, PRONTO2D, PRONTO3D, JAC2D, and JAC3D provide input to ALGEBRA. Output of ALGEBRA is used by BLOT.

Key Words: Finite elements 


\section{Sandia National Laboratories Analysis Code Data Base}

Code Name: $A P R E P R O$

Technical Competency/Capability Area: Structural Mechanics

Sandia Point of Contact:

Gregory D. Sjaardema, 1518, M/S0437, (505) 844-2701; FAX (505) 844-9297, gdsjaar@sandia.gov

\section{Technical Description of What the Code Does:}

APREPRO is a translator that reads a text file containing both general text and algebraic expressions. It echoes the general text to the output file, along with the results of the algebraic expressions. The syntax used in Aprepro is such that all expressions between the delimiters ' $?$ ' and ' $\}$ ' are evaluated and all other text is simply echoed to the output file.

Original Developer of the Code: Gregory D. Sjaardema, Sandia National Laboratories

Release Status: Available to government agencies and contractors, university research groups.

\section{References:}

Gregory D. Sjaardema, "APREPRO: An Algebraic Preprocessor for Parameterizing Finite Element Analyses," SAND92-2291, Sandia Natinal Laboratories, Albuquerque, New Mexico, December 1992.

Computer Language: ANSI Standard C, yacc and lex modules also required.

\section{Computer Platform:}

Code is written in as portable a form as possible and has been ported to several UNIX systems including Cray, HP, Sun, Dec, Stardent, Convex, and SGI plafforms.

\section{Related Codes:}

Aprepro serves as an interface to facilitate input to other codes. Any SEACAS code could be considered a related code.

Key Words: .Text translation, parameterization 


\section{Sandia National Laboratories Analysis Code Data Base}

Code Name: $B L O T$

Technical Competency/Capability Area: Structural Mechanics

Sandia Point of Contact:

Larry A. Schoof, 1425, M/S 0441, (505) 844-5156 FAX (505) 844-9297, laschoo@sandia.gov

\section{Technical Description of What the Code Does:}

BLOT is a graphics program for post-processing of finite element analyses output in the EXODUS database format. It is command driven with free-format input and can drive any graphics device supported by the Sandia Virtual Device Interface. BLOT produces mesh plots with various representations of the analysis output variables. The major mesh plot capabilities are deformed mesh plots, line contours, filled (painted) contours, vector plots of two/three variables (e.g., velocity vectors), and symbol plots of scalar variables (e.g., discrete cracks). Pathlines of analysis variables can also be drawn on the mesh. BLOT's features include element selection by material, element birth and death, multiple views for combining several displays on each plot, symmetry mirroring, and node and element numbering. BLOT can also produce X-Y curve plots of the analysis variables. BLOT generates time-versus-variable plots or variable-versus-variable plots. It also generates distance-versus-variable plots at selected time steps where the distance is the accumulated distance between pairs of nodes or element centers.

Original Developer of the Code: Amy P. Gilkey, John H. Glick, R. J. Meyers, Sandia National Laboratories.

Release Status: Available to government agencies and contractors, university research groups.

References:

1. Amy P. Gilkey and John H. Glick, "BLOT-A Mesh and Curve Plot Program for the Output of a Finite Element Analysis," SAND88-1432, Sandia National Laboratories, Albuquerque, New Mexico, August 1991.

2. R. J. Meyers, "Updates to the postprocessing program BLOT," memo to distribution dated August 21, 1990, Sandia National Laboratories, Albuquerque, NM.

\section{Computer Language: ANSI Standard FORTRAN-77}

\section{Computer Platform:}

Code is written in as portable a form as possible. Machine-specific routines are limited in number and are grouped together to minimize the time required to adapt them to a new system. BLOT has been ported to several UNIX systems including Cray, HP, Sun, Dec, Stardent, Convex, and SGI platforms

\section{Related Codes:}

BLOT produces graphic visualization for the analysis codes CONCHAS, SANCHO, PRONTO2D, PRONTO3D, JAC2D, and JAC3D. ALGEBRA can be used to modify input to BLOT. Requires the Sandia Virtual Device Interface (SVDI).

Key Words: graphics, plotting, visualization, finite element analysis 


\section{Sandia National Laboratories Analysis Code Data Base}

Code Name: CONCHAS

Technical Competency/Capability Area: Structural Mechanics

Sandia Point of Contact:

Marilyn K. Smith, 1425,M/S 0441, (505) 844-3082; FAX (505) 844-9297, mksmith@sandia.gov

Technical Description of What the Code Does:

CONCHAS is a linear finite element structural analysis code which is specialized for axisymmetric structures. Loads and responses are limited to those symmetric about a plane which includes the symmetric axis of the structure. CONCHAS will perform eigenanalysis, static analysis, and dynamic analysis. The element library includes consistent-mass shell, solid and beam elements, nonlinear springs, and concentrated masses. Pre-and post-processing is available with the separately supported utilities BLOT, PATRAN, and FASTQ.

Original Developer of the Code: William C. Mills-Curran and Dennis P. Flanagan, Sandia National Laboratories

Release Status: Available to government agencies and contractors, university research groups.

\section{References:}

W. C. Mills-Curran and D. P. Flanagan, "CONCHAS Users Manual," SAND88-1006, Sandia National Laboratories, Albuquerque, New Mexico, June 1989.

Computer Language: ANSI Standard FORTRAN-77

\section{Computer Platform:}

Code is written in as portable a form as possible and has been ported to several Unix systems including Cray, HP, Sun, Dec, Stardent, Convex, and SGI.

Related Codes:

GEN3D, GJOIN, GREPOS, GROPE, and NUMBERS, with Aprepro interface, can provide modifications to the finite element mesh generated by FASTQ to construct the input finite element model. Output of analysis codes can be modified by ALGEBRA before running the postprocessing graphics code BLOT.

Key Words: Finite element analysis, linear structural analysis, axisymmetric structures 


\section{Sandia National Laboratories Analysis Code Data Base}

Code Name: $C O R D S$

Technical Competency/Capability Area: Test/Analysis Correlation (Modal)

Sandia Point of Contact:

Edward L.Marek, 1434, (505) 844-3966; FAX (505) 844-9297; elmarek@ sandia.gov

Technical Description of What the Code Does:

CORDS - Correlation using Design Sensitivity - performs test/analysis correlation calculations based on sensitivity data. Design sensitivities are obtained from the finite element code NASTRAN. These are used to determine optimal parameter updates to the finite element model to reconcile modal frequencies and/or shape coefficients with experimental data.

Original Developer of the Code: SDRD (Structural Dynamics Research Corp.)

Release Status: Version 4

References: CORDS, Version 4, User's Guide, SDRC, Inc., 1992

Computer Language: Fortran

Computer Platform: HP 700 Unix Workstation, Cray YMP

Related Codes: NASTRAN, Matlab, PEGA

Key Words: System identification, structural identification, model update, test/analysis correlation, test/analysis reconciliation, modal analysis, structural dynamics 


\section{Sandia National Laboratories Analysis Code Data Base}

Code Name: DAMS_TRAN

Technical Competency/Capability Area: Structural Dynamics, Modal Analysis

Sandia Point of Contact:

Clark Dohrmann, 1434, M/S 0439, (505) 844-8058 FAX(505) 844-9297, crdohrma@sandia.gov

\section{Technical Description of What the Code Does:}

DAMS_TRAN is a collection of software tools developed for performing structural dynamic analysis by modal superposition. A key element of the code is a translator which permits the efficient transfer of modal data from a NASTRAN finite element analysis to the MATLAB computing environment. A collection of tools developed in MATLAB are available for calculating such quantities as frequency response functions, modal assurance criteria, and mode indicator functions. In addition to its computational capabilities, DAMS-TRAN provides a convenient environment for performing pre-test analysis. This environment allows the analyst and test engineer to sit down together at a workstation and determine how to carry out a modal or vibration test.

Original Developer of the Code: Clark Dohrmann, Ed Marek, 1434, Sandia National Laboratories

Release Status: Beta

\section{References:}

C. R. Dohrmann, memo dated January 7, 1993, "DAMS (Dynamic Analysis by Modal Superposition) Process"

Computer Language: Fortran

Computer Platform: Currently used on HP700 workstations running MATLAB

Related Codes: NASTRAN, MATLAB, MIDAS

Key Words: Modal analysis, vibration testing, finite element analysis, translators 


\title{
Sandia National Laboratories Analysis Code Data Base
}

\author{
Code Name: EXODUS, GENESIS
}

Technical Competency/Capability Area: Structural Mechanics

Sandia Point of Contact:

Marilyn K. Smith, 1425,M/S 0441, (505) 844-3082; FAX (505) 844-9297, mksmith@sandia.gov

Technical Description of What the Code Does:

EXODUS and GENESIS are pre- and post-processing codes which interface to Sandia's suite of structural mechanics codes. EXODUS defines a binary file format which is used for finite element analysis pre-and postprocessing. It includes data to define the finite element mesh and label both boundary condition and load application points. EXODUS accommodates multiple element types and is sufficiently general to service many different analysis codes. It also provides a very general format for analysis results. A benefit of combining the mesh definition data and the results data in the same file is that the user is assured that the results data are consistent with the model. EXODUS is currently in use by the entire range of SEACAS codes (including preprocessors, translators, linear and nonlinear analyses, and postprocessors) and is finding applications in codes outside SEACUS.

Original Developer of the Code: William C. Mills-Curran, Amy P. Gilkey, Dennis P. Flanagan, Sandia National Laboratories

Release Status: Available with other SEACAS codes.

\section{References:}

1. W. C. Mills-Curran, A. P. Gilkey, and D. P. Flanagan, "EXODUS: A Finite Element File Format for Pre-and Post-processing," SAND87-2977, Sandia National Laboratories, Albuquerque, New Mexico, September 1988.

2. L. M. Taylor, D. P. Flanagan and W. C. Mills-Curran, "The GENESIS Finite Element Mesh File Format," SAND86-0910, Sandia National Laboratories, Albuquerque, NM May 1986.

Computer Language: ANSI Standard FORTRAN-77

\section{Computer Platform:}

Code is written in as portable a form as possible and has been ported to several UNIX systems including Cray, HP, Sun, Dec, Stardent, Convex, and SGI platforms.

Related Codes: All SEACAS codes.

Key Words: Database, finite element analysis 


\section{Sandia National Laboratories Analysis Code Data Base}

Code Name: FASTQ

Technical Competency/Capability Area: Structural Mechanics

Sandia Point of Contact:

Ray J.Meyers,M/S 0441, 1425,(505) 844-5173;FAX (505) 844-9297,rjmeyer@sandia.gov

\section{Technical Description of What the Code Does:}

The FASTQ code is an interactive two-dimensional finite element mesh generation program. It is designed to provide a powerful and efficient tool to both reduce the time required of an analyst to generate a mesh, and to improve the capacity to generate good meshes in arbitrary geometries. It is based on a mapping technique and employs a set of higher-order primitives which have been developed for automatic meshing of commonly encountered shapes (i.e. the triangle, semi-circle, etc.) and conditions (i.e. mesh transitioning from coarse to fine mesh size). FASTQ has been designed to allow user flexibility and control. The user interface is built on a layered command level structure. Multiple utilities are provided for input, manipulation, and display of the geometric information, as well as for direct control, adjustment, and display of the generated mesh. Enhanced boundary flagging has been incorporated and multiple element types and output formats are supported. FASTQ includes the paving algorithm which meshes arbitrary two-dimensional geometries with an all quadrilateral mesh

Original Developer of the Code: T. C. Blacker, Sandia National Laboratories

Release Status: Available to government agencies and contractors, university research groups.

\section{References:}

1. T. D. Blacker, "FASTQ Users Manual, Version 2.1," SAND88-1326, Sandia National Laboratories, Albuquerque, NM July 1988.

This paper presents a new mesh generation technique, paving, which meshes arbitrary twodimensional geometries with an all-quadrilateral mesh. Paving allows varying element size distributions on the boundary as well as the interior of a region. The generated mesh is well formed (i.e. nearly square elements, elements perpendicular to boundaries, etc.) and geometrically pleasing (i.e. mesh contours tend to follow geometric contours of the boundary). In this paper we describe the theory behind this algorithmic/heuristic technique, evaluate the performance of the approach and present examples of automatically generated meshes.

2. T. C. Blacker and M. B. Stephenson, "Paving: A New Approach to Automated Quadrilateral Mesh Generation," International Journal for Numerical Methods in Engineering, Volume 32, pp. 811-847, 1991. 
Computer Language: ANSI Standard FORTRAN-77

\section{Computer Platform:}

Code is written in as portable a form as possible and has been ported to several UNIX systems, including Cray, HP, Sun, Dec, Stardent, Convex, and SGI platforms.

\section{Related Codes:}

FASTQ finite element mesh is input to analysis codes CONCHAS, SANCHO, PRONTO2D, $P R O N T O 3 D, J A C 2 D$, and JAC3D. The finite element mesh can be converted to a three-dimensional mesh by GEN3D for three-dimensional analysis codes, and models can be further refined using GJOIN, GREPOS, GROPE, and NUMBERS.

Key Words: Mesh generation, finite elements, paving 


\section{Sandia National Laboratories Analysis Code Data Base}

Code Name: FRANC: Flexible Robot ANimation Code

Technical Competency/Capability Area: Multi-flexible-body dynamics/controls/animation

Sandia Point of Contact:

G. Richard Eisler, 1434, M/S 0439,(505) 844-4838; FAX (505) 844-9297,greisle@sandia.gov

Technical Description of What the Code Does:

Animates the motion of structurally flexible robotic manipulators for user-specified and effector trajectories. Allows the rapid redesign of the structure and its physical properties and the controller algorithm. Manipulator dynamics available for unlimited number of structurally-flexible link-joint combinations executing three-dimensional motions. Realistic graphical animation and robot assemblage provided through the use of the AVS (Advanced Visualization Systems) graphics library. Modular (and interchangeable) packages available for assemblage, dynamics, control, trajectory planning, and animation.

Original Developer of the Code: Department 1434 (under LDRD sponsorship)

Release Status: Unclassified

References:

1. Rosenthal, D. E., "An Order in Formulation for Robotic Systems," The Journal of the Astronautical Sciences, Vol 38, Oct-Dec 1990, pp 511-529

2. “AVS Tutorial Guide, Release 4,” Advanced Visual Systems, Inc., Waltham, Mass., May 1992

Computer Language: $C, C++$

Computer Platform: HP, Silicon-Graphics

Related Codes:

Key Words: Flexible robotics, animation, multi-body dynamics 


\section{Sandia National Laboratories Analysis Code Data Base}

Code Name: Gello

Technical Competency/Capability Area: $\quad$ Simulation of Polyelectrolyte Gels as Active Materials

Sandia Point of Contact:

Daniel J. Segalman 1434,M/S 0439, (505) 844-0972; FAX (505) 844-9297 djsegal@ sandia.gov

Walter R. Witkowski, 1434, M/S 0439 (505) 844-3869; FAX 844-9297, wrwitko@ sandia.gov

\section{Technical Description of What the Code Does:}

Gello solves a coupled set of mass transport and mechanical stress displacement relationships describing the dynamic behavior of polyelectrolyte gels. A finite element scheme is used to solve the complete continuum mathematical description in a decoupled fashion: the solid elasticity and mass transport equations are solved sequentially. In the elasticity equations the solid is treated as incompressible, neo-Hookean material although it is permitted to expand in the diffusion portion of the code. Only plane strain deformations are considered.

The gel is caused to swell and contract under external environmental changes through modulation of solvent and ion composition. Results are put out in the Sandia EXODUS II format.

Original Developer of the Code: Daniel Segalman and Walter R. Witkowski, 1434

Release Status: Research Code

\section{References:}

1. D. J. Segalman, W. R. Witkowski, R.Rao, D. B. Adolf and M. Shahinpoor, "Finite Element Simulation of the $2 D$ Collapse of a Polyelectrolyte Gel Disk" in Proceedings of the 1993 North American SPIE Smart Structures and Materials Conference.

2. D. J. Segalman, W. R. Witkowski, D. B. Adolf and M. Shahinpoor, "Theory and Application of Electrically Controlled Polymeric Gels", published in Smart Materials and Structures, Vol. 1, 1992, pp. 95-100.

Computer Language: $C++$

Computer Platform: Unix

Related Codes: $B L O T, F A S T Q$

\section{Key Words:}

Polyelectrolyte gels, artificial muscles, transient behavior, neo-Hookean mechanics, moving boundary finite element, coupled mass transport and solid deformation mechanics 


\section{Sandia National Laboratories Analysis Code Data Base}

Code Name: GEN3D

Technical Competency/Capability Area: Structural Mechanics

Sandia Point of Contact:

Gregory D. Sjaardema, 1518, M/S 0437, (505) 844-2701, FAX(505) 844-9297, gdsjaard@sandia.gov

\section{Technical Description of What the Code Does:}

GEN3D is a three-dimensional mesh generation program. The three-dimensional mesh is generated by mapping a two-dimensional mesh into three-dimensions according to one of four types of transformations: translating, rotating, mapping onto a spherical surface, and mapping onto a cylindrical surface. The generated three-dimensional mesh can then be reoriented by offsetting, reflecting about an axis, and revolving about an axis. GEN3D can be used to mesh geometries that are axisymmetric or planar, but, due to three-dimensional loading or boundary conditions, require a three-dimensional finite element mesh and analysis. More importantly, it can be used to mesh complex three-dimensional geometries composed of several sections when the sections can be defined in terms of transformations of two-dimensional geometries. The code GJOIN is then used to join the separate sections into a single body. GEN3D reads and writes two-dimensional and three-dimensional mesh databases in the GENESIS database format; therefore, it is compatible with the preprocessing, postprocessing, and analysis codes used by the Engineering Analysis Department at Sandia National Laboratories, Albuquerque, NM.

Original Developer of the Code: Amy P. Gilkey and Gregory D. Sjaardema, Sandia National Laboratories

Release Status: Available to government agencies, contractors, and university research groups

\section{References:}

1. A. P. Gilkey and G. D. Sjaardema, "GEN3D: A GENESIS Database 2D to 3D Transformation Program," SAND89-0485, Sandia National Laboratories, Albuquerque, New Mexico, March, 1989

This memo describes the changes that have been made to the GEN3D program since the man-ual (SAND89-0485) was published. The changes include: (1) new mesh generation options: spline, project, twist, interval, and rotcen transformations; (2) new mesh modification options: change material, change sideset, and change nodeset; (3) new mesh orientation option: scale; and (4) miscellaneous changes.

2. G. D. Sjaardema, "Updates to the mesh generation program GEN3D," memo to distribution dated April 11, 1990, Sandia National Laboratories, Albuquerque, New Mexico.

Computer Language: ANSI Standard FORTRAN-77 


\section{Computer Platform:}

Code is written in as portable a form as possible and has been ported to several UNIX systems including Cray, HP, Sun, Dec, Stardent, Convex, and SGI platforms.

\section{Related Codes:}

GEN3D converts FASTQ two-dimensional mesh to three-dimensional mesh for the analysis codes CONCHAS, SANCHO, PRONTO2D, PRONTO3D, JAC2D, and JAC3D.

Key Words: Mesh generation, finite elements 


\section{Sandia National Laboratories Analysis Code Data Base}

Code Name: GJOIN

Technical Competency/Capability Area: Structural Mechanics

Sandia Point of Contact:

Gregory D. Sjaardema, 1518, M/S 0437, (505) 844-2701, FAX(505) 844-9297, gdsjaard@sandia.gov

Technical Description of What the Code Does:

GJOIN is a computer program which is used to merge two or more GENESIS databases into a single GENESIS database.

Original Developer of the Code: Gregory D. Sjaardema, Sandia National Laboratories

Release Status: Available to government agencies and contractors, university research groups.

\section{References:}

G. D. Sjaardema, "GJOIN: A Program for Merging Two or More GENESIS Databases," SAND 92-2290, Sandia National Laboratories, Albuquerque, New Mexico, December 1992.

Computer Language: ANSI Standard FORTRAN-77

\section{Computer Platform:}

Code is written in as portable a form as possible and has been ported to several UNIX systems including Cray, HP, Sun, Dec, Stardent, Convex, and SGI platforms.

\section{Related Codes:}

GJOIN is one of the group of preprocessor codes--GEN3D, GJOIN, GREPOS, GROPE, and NUMBERS, useful for manipulating finite element models for input to the analysis codes CONCHAS, SANCHO, PRONTO2D, PRONTO3D, JAC2D, and JAC3D.

Key Words: Mesh generation, finite elements 


\title{
Sandia National Laboratories Analysis Code Data Base
}

\author{
Code Name: GREPOS
}

Technical Competency/Capability Area: Structural Mechanics

Sandia Point of Contact:

Gregory D. Sjaardema, 1518, M/S 0437, (505) 844-2701, FAX (505) 844-9297,

gdsjaard@sandia.gov

\section{Technical Description of What the Code Does:}

GREPOS is a mesh utility program that repositions or modifies the configuration of a $2 D$ or $3 D$ mesh. GREPOS can be used to change the orientation and size of a $2 D$ or $3 D$ mesh; change the material block, nodeset, and sideset IDs; or "explode" the mesh to facilitate viewing of the various parts of the model. GREPOS also updates the EXODUS QA and information records to help track the codes and files used to generate the mesh. GREPOS reads and writes $2 D$ and $3 D$ mesh databases in the GENESIS database format; therefore, it is compatible with the preprocessing, postprocessing, and analysis codes in SEACAS.

Original Developer of the Code: Gregory D. Sjaardema, Sandia National Laboratories

Release Status: Available to government agencies and contractors, university research groups.

\section{References:}

G. D. Sjaardema, "GREPOS: A GENESIS Database Repositioning Program," SAND90-0566, Sandia National Laboratories, Albuquerque, New Mexico, April 1990.

Computer Language: ANSI Standard FORTRAN-77

\section{Computer Platform:}

Code is written in as portable a form as possible and has been ported to several UNIX systems including Cray, HP, Sun, Dec, Stardent, Convex, and SGI platforms.

\section{Related Codes:}

GREPOS is one of the group of preprocessor codes-GEN3D, GJOIN, GREPOS, GROPE, and NUMBERS, useful for manipulating finite element models for input to the analysis codes CONCHAS, SANCHO, PRONTO2D, PRONTO3D, JAC2D, and JAC3D.

Key Words: Mesh generation, finite elements 


\section{Sandia National Laboratories Analysis Code Data Base}

Code Name: GROPE

Technical Competency/Capability Area: Structural Mechanics

Sandia Point of Contact:

Gregory D. Sjaardema, 1518, M/S 0437, (505) 844-2701, FAX (505) 844-9297, gdsjaard@sandia.gov

Technical Description of What the Code Does:

Grope is a program that examines the input to a finite element analysis (which is in the GENESIS database format) or the output from an analysis (in the EXODUS database format). Grope allows the user to examine any value in the database. The display can be directed to the user's terminal or to a print file.

Original Developer of the Code: Amy P. Gilkey, Sandia National Laboratories

Release Status: Available to government agencies and contractors, university research groups.

\section{References:}

1. Gregory D. Sjaardema, "GROPE: A GENESIS/EXODUS Database Examination Program," SAND92-2289, Sandia National Laboratories, Albuquerque, New Mexico, December 1992.

2. A. P. Gilkey, "GROPE - A GENESIS/EXODUS Database Examination Program," RS1523/88/ 02, Sandia National Laboratories, Albuquerque, New Mexico.

Computer Language: ANSI Standard FORTRAN-77

\section{Computer Platform:}

Code is written in as portable a form as possible and has been ported to several UNIX systems including Cray, HP, Sun, Dec, Stardent, Convex, and SGI platforms.

Related Codes:

GROPE is one of the group of preprocessor codes--GEN3D, GJOIN, GREPOS, GROPE, and NUMBERS--which is useful for manipulating finite element models for input to the analysis codes CONCHAS, SANCHO, PRONTO2D, PRONTO3D, JAC2D, and JAC3D.

Key Words: Mesh generation, finite elements 


\section{Sandia National Laboratories Analysis Code Data Base}

Code Name: HAO: Homotopy Algorithms for Optimal Projection of Uncertain Systems

Technical Competency/Capability Area: Robust Control Design

Sandia Point of Contact:

James J. Allen, 2741, M/S 0557, (505) 844-6764; FAX(505) 844-9297 jjallen@ sandia.gov

Technical Description of What the Code Does:

This Pro-Matlab toolbox implements homotopy solution techniques that allow the design of reduced order $\mathrm{H}_{2}$ optimal or Maximum Entropy controllers. These robust control methods are frequently used in structural control design. Homotopy methods directly solve the coupled Riccati and Lyapunov equations for Optimal Projection or Maximum Entropy. These algorithms rely on the first and second derivatives of the cost functional with respect to a parameter vector describing the controller. Although the methods in this toolbox do not allow the design of reduced order Maximum Entropy controllers, it is sometimes possible to significantly reduce the order of a full-order Maximum Entropy controllers using suboptimal controller reduction techniques.

Original Developer of the Code:

Harris Corporation, Government Aerospace Systems Division, Melbourne, Florida

Release Status: Software received from Harris Corporation via Sandia Contract 54-7609

\section{References:}

E. G. Collins, L. D. Davis, S. Richter, "Homotopy Algorithms for $\mathrm{H}_{2}$ Optimal Reduced-Order Dynamic Compensation and Maximum Entropy Control," Harris Corporation Contract 54-7609 Report, November 1992.

Computer Language: Pro-Matlab Toolbox (m-files)

\section{Computer Platform:}

Runs on any Pro-Matlab implementation. However, computers with significant computational capability are frequently required, due to the significant computational burden.

Related Codes: Pro-Matlab

Key Words: Robust Control, Flexible Structure Control, Uncertain Systems, Homotopy 


\section{Sandia National Laboratories Analysis Code Data Base}

Code Name: $J A C 2 D$

Technical Competency/Capability Area: Structural Mechanics

Sandia Point of Contact:

John H. Biffle, 1503, (505) 844-5385 FAX (505) 844-9297, jhbiffl@sandia.gov

Technical Description of What the Code Does:

The nonlinear conjugate gradient procedure is employed in the computer program JAC2D to solve quasi-static nonlinear mechanics problems. A set of continuum equations which describes accurately nonlinear mechanics involving large rotation and strain is very conveniently used with the conjugate gradient method to solve the nonlinear problem. The method is exploited in a twodimensional setting while using various methods for accelerating convergence. Sliding interface condition are also implemented. A four-node Lagrangian uniform strain element is used with hourglass stiffness to control the zero energy nodes. Materials which can be modeled are elastic and isothermal elastic-plastic with combined kinematic and isotropic harding. The program is vectorized to perform very efficiently on CRAY computers. Sample problems described are the bending of a thin beam, the rotation of a unit cube, a pressurized and thermally loaded sphere and cylinder.

Original Developer of the Code: John H. Biffle, Sandia National Laboratories

Release Status: Available to government agencies and contractors, university research groups.

\section{References:}

J. H. Biffle, "A Two-Dimensional Finite Element Computer Program for the Non-Linear Quasistatic Response of Solids with the Conjugate Gradient Method," SAND93-1891, Sandia National Laboratories, Albuquerque, New Mexico, May 1994.

\section{Computer Language: ANSI Standard FORTRAN-77}

\section{Computer Platform:}

Code is written in as portable a form as possible and has been ported to several UNIX systems including Cray, HP, Sun, Dec, Stardent, Convex, and SGI platforms.

\section{Related Codes:}

GEN3D, GJOIN, GREPOS, GROPE, and NUMBERS, with Aprepro interface, can provide modifcations to the finite element mesh generated by FASTQ to construct the input finite element model. Output of analysis codes can be modified by ALGEBRA before running the postprocessing graphics code BLOT.

Key Words: Finite element analysis, structural mechanics, quasi-static mechanics, nonlinear mechanics, conjugate gradient, contact surfaces, elastic materials, elastic-plastic materials 


\section{Sandia National Laboratories Analysis Code Data Base}

Code Name: JAC3D

Technical Competency/Capability Area: Structural Mechanics

Sandia Point of Contact:

John H. Biffle, 1503, (505) 844-5385 FAX(505) 844-9297, jhbiffl@ sandia.gov

\section{Technical Description of What the Code Does:}

$J A C 3 D$ is a three-dimensional finite element program designed to solve quasi-static nonlinear mechanics problems. A set of continuum equations, which describe nonlinear mechanics involving large rotation and strain, is used. A nonlinear conjugate gradient method is used to solve the nonlinear equations. The method is implemented in a three-dimensional setting with various methods for accelerating convergence. Sliding interface conditions are also implemented. An eight-node Lagrangian uniform strain element is used with hourglass stiffness to control the zero energy modes. This release of the code contains elastic and isothermal elastic-plastic material models. Other material models can be added relatively easily. The program is vectorized to perform very efficiently on CRAY computers. Sample problems described are the bending of a thin beam, the rotation of a unit cube, a pressurized and thermally loaded sphere.

Original Developer of the Code: John H. Biffle, Sandia National Laboratories

Release Status: Available to government agencies and contractors, university research groups.

\section{References:}

J. H. Biffle, "JAC3D - A Three-Dimensional Finite Element Computer Program for the Nonlinear Quasi-Static Response of Solids with the Conjugate Gradient Method," SAND87-1305, Sandia National Laboratories, Albuquerque, New Mexico, February 1993.

Computer Language: ANSI Standard FORTRAN-77

\section{Computer Platform:}

Code is written in as portable a form as possible and has been ported to several UNIX systems including Cray, HP, Sun, Dec, Stardent, Convex, and SGI platforms.

\section{Related Codes:}

GEN3D, GJOIN, GREPOS, GROPE, and NUMBERS, with Aprepro interface, can provide modifications to the finite element mesh generated by FASTQ to construct the input finite element model. Output of analysis codes can be modified by ALGEBRA before running the postprocessing graphics code BLOT.

\section{Key Words:}

Finite element analysis, structural mechanics, quasi-static mechanics, nonlinear mechanics, conjugate gradient, contact surfaces, elastic materials, elastic-plastic materials 


\section{Sandia National Laboratories Analysis Code Data Base}

Code Name: MATLAB

Technical Competency/Capability Area: Numerical Computation, esp. Matrix Applications

Sandia Point of Contact:

Edward L. Marek, 1434, (505) 844-3966; FAX (505) 844-9297; elmarek@ sandia.gov

Technical Description of What the Code Does:

MATLAB is a general purpose numerical computation tool. It is particularly applicable to matrix formulations, containing many special operators and data structures to facilitate dimensioning, indexing, etc. MATLAB is a programming language which is easily extended. Many common functions are built-in, including sophisticated graphics. 'Vanilla' MATLAB includes many standard matrix functions such as equation solvers and eigensolvers, and a digital signal processing toolbar is bundled with the code. Many other toolboxes cover specific technical areas: Control, System ID, Robust Control, Optimization, Spline, Mu-Synthesis, Neural Network, Chemometrics, Simulink, Nonlinear Control, Image Processing, and Maple (symbolic computation).

Original Developer of the Code: Mathworks, Inc.

Release Status: Version 4.0

References:

Matlab Documentation, Mathworks, Inc., 1993

Computer Language: $C$

Computer Platform: HP 700 Unix Workstation, Cray YMP

Related Codes: Many internal and external tools are MATLAB based.

Key Words: Numerical computation, matrix analysis 


\section{Sandia National Laboratories Analysis Code Data Base}

Code Name: MERLIN II

Technical Competency/Capability Area:

Structural Mechanics, Fluid Mechanics and Heat Transfer

Sandia Point of Contact:

David K. Gartling, 1511, (505) 844-9150, FAX (505) 844-4523; dkgartli@ sandia.gov

Technical Description of What the Code Does:

The MERLIN II program is designed to transfer data between finite element meshes of arbitrary geometry. The program is structured to accurately interpolate previously computed solutions onto a given mesh and format the resulting data for immediate use in another analysis program. Data from either two-dimensional or three-dimensional meshes may be considered. The theoretical basis and computational algorithms used in the program are described and complete user instructions are presented. Several example problems are included to demonstrate program usage.

Original Developer of the Code: David K. Gartling, Sandia National Laboratories

Release Status: Available to government agencies and contractors, research groups

References:

D. K. Gartling, "MERLIN II - A Computer Program to Transfer Solution Data Between Finite Element Meshes," SAND89-2989, Sandia National Laboratories, Albuquerque, New Mexico, July 1991.

Computer Language: Fortran 77

Computer Platform: Any system with a Fortran Compiler

Related Codes: Requires SUPES Library

Key Words: Finite Element, Mesh Generation 


\section{Sandia National Laboratories Analysis Code Data Base}

Code Name: MIDAS - Multidisciplinary Integrated Dynamic Analysis System

Technical Competency/Capability Area: Structural Dynamics

Sandia Point of Contact:

Clark Dohrmann, 1434, (505) 844-8058; FAX (505) 844-7297,crdohrm@sandia.gov

\section{Technical Description of What the Code Does:}

MIDAS - Multidisciplinary Integrated Dynamic Analysis System - is a set of software tools to facilitate data transfer among various analysis codes. An application programmer interface (API) design is employed, which allows considerable re-use of common routines. A central MIDAS data set is defined, which is machine independent. The project is currently in prototype stage. A strawman implementation is currently in Beta test.

Original Developer of the Code: Ed Marek, 1434 (Project Mgr)

Release Status: Beta

References:

1. E. L. Marek, 1434, "MIDAS Development, Phase II," memo dated May 3, 1991.

2. Lynn Harris, Re/Spec, "Beta Release of Version 1.0 of MIDAS," memo dated May 15, 1993.

Computer Language: Fortran

Computer Platform:

Designed to be portable, currently implemented on HP 700 Unix workstations.

Related Codes: Nastran, IDEAS, Matlab, SSID, Exodus II

Key Words: Data transfer, translators 


\section{Sandia National Laboratories Analysis Code Data Base}

Code Name: MSCANASTRAN (MacNeal-Schwendler Corp./NASA STRuctural ANalaysis

Technical Competency/Capability Area:

General Purpose Structural Finite Element Analysis, Dynamics, Statics

Sandia Point of Contact:

Clay W. G. Fulcher, 1434, (505) 844-3899; FAX (505) 844-9297, cwfulch@ sandia.gov

Technical Description of What the Code Does:

NASTRAN, originally developed by NASA, is a general purpose structural finite element analysis code which is currently marketed, maintained, and enhanced by several scientific software vendors. Solution sequences include normal modes analysis, complex eigenvalue analysis, dynamic transient analysis, frequency and random response analysis, heat transfer, static analysis, and aeroelasticity. The code offers both linear and nonlinear constitutive modeling capabilities. MSC/NASTRAN provides a Design Sensitivity Analysis (DSA) module which computes the sensitivities of user-specified state variables (e.g., stresses, frequencies, eigenvectors) to model design parameters. The sensitivities may be used to correlate finite element model predictions with test data, or to optimize design parameters within the Design Optimization module. MSCNASTRAN offers model reduction capabilities via the Craig-Bampton, Guyan, and other well-known reduction techniques. Multi-level substructuring of large models is offered via user-defined "superelements." Users are provided the unique ability to extract and manipulate intermediate data (e.g., stiffness, mass matrices, reaction loads) generated during the solution sequences via the Direct Matrix Abstraction Programming (DMAP) language.

Original Developer of the Code: National Aeronautics and Space Administration

Release Status: MSC/NASTRAN Version 67.5

References:

1. "MSCANASTRAN User's Manual"

2. "MSC/NASTRAN Programmer's Manual"

3. "MSC/NASTRAN Applications Manual"

4. "MSC/NASTRAN Theoretical Manual"

5. "MSC/NASTRAN Primer. Static and Normal Modes Analysis" by Harry G. Schaeffer

6. "Introduction to Finite Element Analysis and MSC/NASTRAN Utilization" by L. I. Nagy

Computer Language: FORTRAN, DMAP

Computer Platform: Sandia's CRAY YMP-1 and YMP-2

Related Codes: PATRAN (PDA Engineering), CORDS (SDRC), PEGA (SNL)

Key Words:

Structures, structural dynamics, modal analysis, complex eigenvalue analysis, design sensitivity, optimization, heat transfer, finite element analysis, stress analysis, aeroelasticity, MacNeal-Schwendler Corporation 


\section{Sandia National Laboratories Analysis Code Data Base}

Code Name: NASMAT: MSC/NASTRAN ProMatlab Translator and Intrepretor

Technical Competency/Capability Area: Structural Analysis, Systems Theory

Sandia Point of Contact:

JamesJ.Allen, 2741, (505) 844-6764; FAX (505) 844-0078; jjallen@sandia.gov

Technical Description of What the Code Does:

NASMAT consists of software which can read a MSC/NASTRAN Output2 binary file and translate the data to a ProMatlab M-file (ascii) or mat-file (binary) formats. This package also consists of associated ProMatlab functions for interpreting the NASTRAN set table and partitioning the structural matrices based on this information. ProMatlab functions are also available for producing a state space model in ProMatlab using NASTRAN data. This code permits the direct coupling of control design software with structural finite element modeling software which is a valuable asset for structural control design.

Original Developer of the Code:

J. J. Allen, Sandia National Laboratories, Structural dynamics and Controls Department 1434, Albuquerque, NM 87185-5800

Release Status: Pre-release version 0.9

\section{References:}

1. "MSC/NASTRAN User's Manual," the MacNeal-Schwendler Corporation, Los Angeles, CA.

2. "MATLAB User's Guide," The MathWorks, Natick, MA.

Computer Language: Pro-Matlab Toolbox (m-files)

Computer Platform: Runs on any computer with a Pro-Matlab implementation.

Related Codes: Pro-Matlab, MSC/NASTRAN

Key Words: Structural Analysis, Systems Theory 


\section{Sandia National Laboratories Analysis Code Data Base}

Code Name: NUMBERS

Technical Competency/Capability Area: Structural Mechanics

Sandia Point of Contact:

Gregory D. Sjaardema, 1518, (505) 844-2701 FAX (505) 844-9297; gdsjaar@sandia.gov

\section{Technical Description of What the Code Does:}

NUMBERS is a program which reads and stores data from a finite element model described in the EXODUS database format. Within this program are several utility routines which generate information about the finite element model. The utilities currently implemented in NUMBERS allow the analyst to determine information such as (1) the volume and coordinate limits of each of the materials in the model; (2) the mass properties of the model; (3) the minimum, maximum, and average element volumes for each material; (4) the volume and change in volume of a cavity; (5) the nodes or elements that are within a specified distance from a user-defined point, line, or plane; (6) an estimate of the explicit central-difference timestep for each material; (7) the validity of contact surfaces or slidelines, that is, whether two surfaces overlap at any point; and (8) the distance between two surfaces.

Original Developer of the Code: Gregory D. Sjaardema, Sandia National Laboratories

Release Status: Available to government agencies and contractors, university research groups.

\section{References:}

G. D. Sjaardema, "NUMBERS: A Collection of Utilities for Pre-and Post-processing Two- and Three-Dimensional EXODUS Finite Element Models," SAND88-0737, Sandia National Laboratories, Albuquerque, New Mexico, March 1989.

\section{Computer Language: ANSI Standard FORTRAN-77}

\section{Computer Platform:}

Code is written in as portable a form as possible and has been ported to several UNIX systems including Cray, HP, Sun, Dec, Stardent, Convex, and SGI platforms.

\section{Related Codes:}

NUMBERS is one of the group of preprocessor codes -- GEN3D, GJOIN, GREPOS, GROPE, and NUMBERS, useful for manipulating finite element models for input to the analysis codes CONCHAS, SANCHO, PRONTO2D, PRONTO3D, JAC2D, and JAC3D.

Key Words: Mesh generation, finite elements 


\section{Sandia National Laboratories Analysis Code Data Base}

Code Name: OBSERVER/SYSTEM REALIZATION TOOLBOX for use with MATLAB

Technical Competency/Capability Area: System Identification and Control

Sandia Point of Contact:

James J. Allen, 2741, (505) 844-6764,FAX (505)844-0078;jjallen@sandia.gov;

Jeffrey L.Dohner, 1434, (505) 844-5757; FAX (505) 844-5017, jldohner@sandia.gov

Technical Description of What the Code Does:

The OBSERVER/SYSTEM REALIZATION TOOLBOX is a collection of functions, expressed in $M$ files, that implements a variety of modern system identification techniques. The central features of the OBSERVER/SYSTEM REALIZATION TOOLBOX are functions for identification of a system model and its corresponding observer directly from input and output data. The system and its observer are represented by either a discrete model or a continuous-time model. The identified model and observer may be used for controller design of linear systems as well as identification of modal parameters such as damping, frequency, and mode shapes. Both newly developed time domain and FFT-based frequency domain techniques are available for use in computing pulse response samples (Markov parameters) directly from input and output data.

\section{Original Developer of the Code:}

Jer-Nan Juang, Lucas G. Horta, Min Phan, Jiann-Shiun Lew, and Chung-Wen Chen, National Aeronautics and Space Administration, Langley Research Center, Hampton, Virginia

Release Status: Beta Version obtained from NASA Langley; this code has not been released

\section{References:}

1. J. N. Juang and R. S. Pappa, "An Eigen System Realization Algorithm for Modal Parameter Identification and Model Reduction," Journal of Guidance, Control and Dynamics, Vol. 8, No. 5, 1985, pp 620-627.

2. C. W. Chen, J. K. Huang, M. Phan and J. N. Juang, "Integrated System Identification and Modal State Estimation of Control of Large Flexible Space Structures," Journal of Guidance, Control and Dynamics, to appear.

Computer Language: MATLAB M-files

Computer Platform: MATLAB on Cray YMP, HP, IBM PC, Mac

Related Codes: Canonical Variance Analysis by Adaptics Inc.

Key Words: System Identification, Controls, Observer 


\section{Sandia National Laboratories Analysis Code Data Base}

Code Name: PEGA - Parameter Estimation by Genetic Algorithms

Technical Competency/Capability Area: Structural Mechanics

Sandia Point of Contact:

Garth M.Reese, 1434, (505) 845-8640; FAX (505) 844-9297, gmreese@sandia.gov

Technical Description of What the Code Does:

Parameter Estimation by Genetic Algorithms, PEGA, is a graphical user interface built on top of matlab 4.0. It permits use of the genetic algorithm $(G A)$ routines developed by the University of Florida in solution of parameter estimation problems. The primary applications are in correlation of finite element modal computations with test results. Input consists of test frequencies and frequencies, and design sensitivities from $F E$ analysis. Other tools exist for performing this correlation, but the flexibility, completeness and robustness of the GA solution technique is extremely valuable. The finite element code used to obtain design sensitivities is MSC/NASTRAN. Automatic routines will update a NASTRAN model.

The $C$ version of the code performs the same functions as the MATLAB version, with the exception of a lack of a least squares parameter estimation algorithm.

Original Developer of the Code: Garth Reese, Sandia National Laboratories

Release Status: Under Development

References:

PEGA Users Guide Version 1.0, January 1993.

\section{Computer Language:}

Matlab Version 4.0. The C version requires XI1R4 and Xaw.

\section{Computer Platform:}

The code has been written to Matlab standards for version 4. It has been tested on HP-Unix platforms only. The C code is portable to unix platforms and has been tested on hp-700, Sun Sparc and Cray-YMP.

Related Codes: MSCINASTRAN, MATLAB

Key Words: Parameter Estimation, System Identification 


\section{Sandia National Laboratories Analysis Code Data Base}

Code Name: $P R E G O$

Technical Competency/Capability Area: One-Dimensional Acoustics

Sandia Point of Contact:

Daniel J.Segalman, 1434, (505) 844-0972; FAX (505) 844-9297; djsegal@sandia.gov

Technical Description of What the Code Does:

PREGO calculates the one-dimensional wave propagation through linear elastic and viscoelastic materials with a variety of boundary conditions.

Original Developer of the Code: Daniel Segalman, Department 1434

Release Status: Research Code

\section{References:}

Daniel J. Segalman, "PREGO - A Simulation Code for One-Dimensional Viscoelastic Acoustics", Sandia Report: SAND90-0593, printed July 1990.

Computer Language: FORTRAN

Computer Platform: Portable among ANSI FORTRAN-77 compilers

Related Codes: None

Key Words: Viscoelastic, Viscoelasticity, Acoustics 


\section{Sandia National Laboratories Analysis Code Data Base}

Code Name: PRONTO2D

Technical Competency/Capability Area: Structural Mechanics

Sandia Point of Contact:

Stephen W. Attaway, 1425, (505) 844-9288 FAX (505) 844-9297; swattaw@sandia.gov

Technical Description of What the Code Does:

PRONTO2D is a two-dimensional transient solid dynamics code for analyzing large deformations of highly nonlinear materials subjected to extremely high strain rates. This Lagrangian finite element program uses an explicit time integration operator to integrate the equations of motion. Four-node uniform strain quadrilateral elements are used in the finite element formulation. A number of new numerical algorithms which have been developed for the code are described in this report. An adaptive time step control algorithm is described which greatly improves stability as well as performance in plasticity problems. A robust hourglass control scheme which eliminates hourglass distortions without disturbing the finite element solution is included. All constitutive models in PRONTO2D are cast in an unrotated configuration defined using the rotation determines from the polar decomposition of the deformation gradient. An accurate incremental algorithm was developed to determine this rotation and is described in detail. A robust contact algorithm was developed which allows for the impact and interaction of deforming contact surfaces of quite general geometry. A number of numerical examples are presented to demonstrate the utility of these algorithms.

Original Developer of the Code:

Lee M. Taylor and Dennis P. Flanagan, Sandia National Laboratories

Release Status: Export Controlled. Available to government agencies and contractors, univerReferences: $\quad$ sity research groups. Individuals having access to code must be U.S. citizens.

Lee M. Taylor and Dennis P. Flanagan, "PRONTO2D, a Two-Dimensional Transient Solid Dynamics Program," SAND86-0594, Sandia National Laboratories, Albuquerque, New Mexico, March 1987.

S. W. Attaway, "Update of PRONTO2D and PRONTO3D Transient Solid Dynamics Program," SAND90-0102, Sandia National Laboratories, Albuquerque, New Mexico, November 1990.

M. W. Heinstein, S. W. Attaway, J. W. Swegle, F. J. Mello, "A General-Purpose Contact Detection Algorithm for Nonlinear Structural Analysis Codes," SAND92-2141, Sandia National Laboratories, Albuquerque, New Mexico, May 1993.

Computer Language: ANSI Standard FORTRAN-77

Computer Platform:

Code is written in as portable a form as possible and has been ported to several UNIX systems including Cray, HP, Sun, Dec, Stardent, Convex, and SGI platforms.

Related Codes:

GEN3D, GJOIN, GREPOS, GROPE, and NUMBERS, with Aprepro interface, can provide modifcations to the finite element mesh generated by FASTQ to construct the input finite element model. Output of analysis codes can be modified by ALGEBRA before running the postprocessing graphics code BLOT.

Key Words: Finite element analysis, transient solid dynamics, structural mechanics, large deformation, nonlinear materials, plastic materials, contact surfaces, high strain rate, hourglass control 


\section{Sandia National Laboratories Analysis Code Data Base}

Code Name: PRONTO3D

Technical Competency/Capability Area: Structural Mechanics

Sandia Point of Contact:

Stephen W. Attaway, 1425, (505) 844-9288 FAX (505) 844-9297; swattaw@sandia.gov

\section{Technical Description of What the Code Does:}

PRONTO3D is a three-dimensional transient solid dynamics code for analyzing large deformations of highly nonlinear materials subjected to extremely high strain rates. This Lagrangian finite element program uses an explicit time integration operator to integrate the equations of motion. Eight-node uniform strain hexahedral elements are used in the finite element formulation. A number of new numerical algorithms which have been developed for the code are described in this report. An adaptive time step control algorithm is described which greatly improves stability as well as performance in plasticity problems. A robust hourglass control scheme which eliminates hourglass distortions without disturbing the finite element solution is included. All constitutive models in PRONTO3D are cast in an unrotated configuration defined using the rotation determined from the polar decomposition of the deformation gradient. An accurate incremental algorithm was developed to determine this rotation and is described in detail. A robust contact algorithm was developed which allows for the impact and interaction of deforming contact surfaces of quite general geometry. Numerical examples are presented to demonstrate the utility of these algorithms.

\section{Original Developer of the Code:}

Lee M. Taylor and Dennis P. Flanagan, Sandia National Laboratories

\section{Release Status:}

Export Controlled. Available to government agencies and contractors, university research groups. Individuals having access to code must be U.S. citizens.

\section{References:}

1. L. M. Taylor and D. P. Flanagan, "PRONTO3D, A Three-Dimensional Transient Solid Dynamics Program,” SAND87-1912, Sandia National Laboratories, Albuquerque, New Mexico, March 1989.

2. S. W. Attaway, "Update of PRONTO2D and PRONTO3D Transient Solid Dynamics Program," SAND90-0102, Sandia National Laboratories, Albuquerque, New Mexico, November 1990.

3. V. L. Bergmann, "Transient Dynamic Analysis of Plates and Shells with PRONTO3D," SAND91-1182, Sandia National Laboratories, Albuquerque, NewMexico, September 1991.

4. M. W. Heinstein, S. W. Attaway, J. W. Swegle, F. J. Mello, "A General-Purpose Contact Detection Algorithm for Nonlinear Structural Analysis Codes," SAND92-2141, Sandia National Laboratories, Albuquerque, New Mexico, May 1993. 
Computer Language: ANSI Standard'FORTRAN-77

\section{Computer Platform:}

Code is written in as portable a form as possible and has been ported to several UNIX systems including Cray, HP, Sun, Dec, Stardent, Convex, and SGI platforms.

\section{Related Codes:}

GEN3D, GJOIN, GREPOS, GROPE, and NUMBERS, with Aprepro interface, can provide modifcations to the finite element mesh generated by FASTQ to construct the input finite element model. Output of analysis codes can be modified by ALGEBRA before running the postprocessing graphics code BLOT.

\section{Key Words:}

Finite element analysis, transient solid dynamics, structural mechanics, large deformation, nonlinear materials, plastic materials, contact surfaces, high strain rate, hourglass control 


\section{Sandia National Laboratories Analysis Code Data Base}

Code Name: RASCAL: Robust Active Structural Control Algorithms

Technical Competency/Capability Area: Robust Control Design, Active Damping

Sandia Point of Contact:

JamesJ.Allen,2741, (505) 844-6764 FAX (505) 844-0078; jjallen@sandia.gov

Technical Description of What the Code Does:

This is a ProMatlab Toolbox which builds upon the control, mu-tools ProMatlab toolboxes, to implement methods unavailable or enhance the user interface for control simulation and design synthesis. The Multiple-Input/Multiple Output (MIMO) Robust Control and Single-Input/SingleOutput (SISO) active damping listed below are available.

MIMO Robust Control

- Frequency Weighted LQG

- $H_{\infty} / \mu$-Synthesis (enhanced user interface for $D-K$ iteration and controller robustness properties)

SISO Active Damping Methods

- Velocity Feedback

- Positive Position Feedback

- Impedance Matching

- Power-Flow Control

Original Developer of the Code:

J. J. Allen, Sandia National Laboratories, Structural Dynamics and Controls Department, 1434, Albuquerque, NM 87185-5800

Release Status: Pre-release version 0.9

References:

1. N. K. Gupta, "Frequency-Shaped Cost Functionals: Extension of Linear Quadratic Gaussian Design Methods," J. Guidance and Control, Vol. 3, No. 6, Nov.-Dec. 1980

2. M.J. Balas, "Direct Velocity Feedback Control of Large Space Structures," Journal of Guidance and Control, Vol. 2, No. 3, pp 252-253

3. J. L. Fanson, T. K. Caughey, "Positive Position Feedback Control for Large Space Structures," AIAA, Vol. 28, No. 4,pp 717-724

Computer Language: Pro-Matlab Toolbox (m-files)

Computer Platform:

Runs on any Pro-Matlab implementation. Depending on the problem size, computers with significant computational capability may be required.

Related Codes:

Pro-Matlab and the control and Mu-Tools Toolboxes

Key Words: Robust Control, Flexible Structures, Uncertain Systems, Active Damping, Vibration Suppression. 


\section{Sandia National Laboratories Analysis Code Data Base}

\section{Code Name: SANCHO}

Technical Competency/Capability Area: Structural Mechanics

Sandia Point of Contact:

Marilyn K.Smith, 1425, (505) 844-3082 FAX (50) 844-9297; mksmith@sandia.gov

Technical Description of What the Code Does:

SANCHO is a finite element computer program designed to compute the quasi-static, large deformation, inelastic response of planar or axisymmetric solids. Finite strain constitutive theories for plasticity, volumetric plasticity, and metallic creep behavior are included. A constant bulk strain, bilinear displacement isoparametric finite element is employed for the spatial discretization. The solution strategy used to generate the sequence of equilibrium solutions is a self-adaptive dynamic relaxation scheme which is based on explicit central difference pseudo-time integration and artificial damping. A master-slave algorithm for sliding interfaces is also implemented. A theoretical development of the appropriate governing equations and a description of the numerical algorithms are presented along with a user's guide which includes several sample problems and their solution.

\section{Original Developer of the Code:}

Charles M. Stone, Raymond D. Krieg, and Zelma E. Beisinger, Sandia National Laboratories

Release Status: Available to government agencies and contractors, university research groups.

\section{References:}

C. M. Stone, R. D. Krieg and Z. E. Beisinger, "SANCHO, A Finite Element Computer Program for the Quasi Static, Large Deformation, Inelastic Response of Two-Dimensional Solids," SAND842618, Sandia National Laboratories, Albuquerque, New Mexico, April 1985.

\section{Computer Language: ANSI Standard FORTRAN-77}

\section{Computer Platform:}

Code is written in as portable a form as possible and has been ported to several Unix systems including Cray, HP, Sun, Dec, Stardent, Convex, and SGI.

\section{Related Codes:}

GEN3D, GJOIN, GREPOS, GROPE, and NUMBERS, with Aprepro interface, can provide modifcations to the finite element mesh generated by FASTQ to construct the input finite element model. Output of analysis codes can be modified by ALGEBRA before running the postprocessing graphics code BLOT.

\section{Key Words:}

Finite element analysis, structural mechanics, quasi-static mechanics, inelastic response, metallic creep, dynamic relaxation, contact surfaces 


\section{Sandia National Laboratories Analysis Code Data Base}

Code Name: SANTOS3D

Technical Competency/Capability Area: Quasistatic, large deformation of solids

Sandia Point of Contact:

Technical Description of What the Code Does:

SANTOS is a finite element computer program designed to compute the quasistatic, large deformation, inelastic response of planar or axisymmetric solids. SANTOS is based on the dynamics program PRONTO2D by L. M. Taylor and D. P. Flanagan. SANTOS utilizes a self-adaptive dynamic relaxation algorithm to achieve a quasistatic solution. The efficiency, speed, through vectorization, and state-of-the-art algorithms that Taylor and Flanagan built into PRONTO2D are maintained in SANTOS. The architecture of the code as well as the user interface is similar for both codes which improves code reliability and encourages the use of both codes by analysts. By utilizing the same material interface, the same constitutive models may be utilized by both codes which allows for coupling of the two codes.

Original Developer of the Code:

Release Status:

References:

C. M. Stone, documentation not yet available.

Computer Language: FORTRAN 77

Computer Platform:

Cray

Related Codes:

Key Words: 


\section{Sandia National Laboratories Analysis Code Data Base}

Code Name: SARA 2D

Technical Competency/Capability Area: Two Dimensional Structural Acoustic Analysis

Sandia Point of Contact:

Donald W.Lobitz, 1434, (505) 844-9398; dwlobit@sandia.gov; Jeffrey L. Dohner, 1434, (505)

844-5757; FAX (505) 844-9297; jldohne@sandia.gov

\section{Technical Description of What the Code Does:}

SARA $2 D$ is a finite element program for computing the frequency response of plane and axi-symmetric structural acoustics problems. Non-symmetric response is included by a Fourier series approach. For structural models it is also possible to determine frequencies and mode shapes. Both internal and external fluids can be represented and an infinite element is available for truncating the exterior fluid field at a reasonable distance from the structure. Linear isotropic and othotropic materials can be modeled with isoparametric continuum and shell elements. Elements reformulated to permit modeling of incompressible or nearly incompressible isotropic materials are available for representing elastomeric materials, with visoelastic effects being included via a complex modulus approach. A piezoelectric finite element is included for modeling transducer structures.

Original Developer of the Code:

BBN Systems and Technologies, Union Station, New London, Connecticut 06320-6147

\section{Release Status:}

\section{References:}

1. H. Allik, "Infinite Elements in Structural Acoustics" Analysis \& Technology Inc. Report No. P-1689-1-83, March 1983

2. H. Allik and Haberman, "Accuracy of Infinite Elements in Structural Acoustics Modeling," presented at ASA Meeting, April 1985 (results available from authors at BBN Laboratories Inc.,New London, CT)

3. H. Allik and T.J.R. Hughes, "Finite Element Method for Piezoelectric Vibration", Int. J. Numer. Methods Eng., 1970, 2 pp. 151-157

Computer Language: Fortran 77

Computer Platform: Cray YMP

Related Codes: NASHUA, WASCAT, CHIEF

Key Words: Finite Elements, Structural Acoustics, Infinite Elements 


\section{Sandia National Laboratories Analysis Code Data Base}

Code Name: SSID

Technical Competency/Capability Area: Structural System Identification

Sandia Point of Contact:

John R. Red-Horse, 1434 (505)845-9190; FAX (505) 844-9297, jrredho@ @andia.gov

\section{Technical Description of What the Code Does:}

SSID employs an iterative Bayesian Estimation algorithm to provide physical parameter updates for structural dynamics finite element method (FEM) models. These updates seek to minimize the differences that exist between the FEM models and models extracted directly from experimental data. The comparison is based on user selected criteria from the results of modal tests. SSID has the capability to assemble systems composed of several components, again through user specified constraint definitions, where each component can be in the form of: (1) a physical model, (2) a modal model, or (3) a component modes (CMS) model. On each iteration SSID assembles the full system equations of motion, computes the eigensolution and sensitivity information appropriate to the specified criteria, and performs a parameter update. Finally, this new parameter set is employed in computing updated individual component models based on a truncated Taylor series expansion. (Note that for linear parametric models, the user is not required to return to the FEM code.) Although the data requirements are specified in such a way as to make the code viable for any commercial FEM software package, the current environment includes FEM model translation from MSC/NASTRAN via a utility known as NASSID.

Original Developer of the Code:

John Red-Horse, Sandia National Laboratories and Jon Chrostowski, Engineering Mechanics Associates, Inc.

Release Status: Beta

References:

SSID Theory Manual, Technical Report TR-91-1134-1, Engineering Mechanics Assoc., Inc., March 1991

Computer Language: FORTRAN

Computer Platform: Cray $Y / M P$

Related Codes: None

Key Words:

Structural System Identification, Parameter Estimation, Bayesian Estimation, Structural Dynamics 


\section{Sandia National Laboratories Analysis Code Data Base}

Code Name: $S U B W A Y 3 D$

Technical Competency/Capability Area: Transient Dynamic Electromechanical Responses

Sandia Point of Contact:

Stephen T. Montgomery, 2561(505) 844-9062; FAX(505) 844-2919, stmontg@sandia.gov

\section{Technical Description of What the Code Does:}

SUBWAY3D is a three-dimensional finite element code for numerical simulation of the transient electromechanical response of dielectric materials. The code uses a preconditioned conjugate gradient method to solve Poisson's equation governing the electric potential in the dielectrics. This field solver is embedded in a modified version of the finite element transient dynamics code PRONTO3D and allows solution for the electric response at each time step used in the explicit integration of the equations of motion. The code is structured to allow flexibility in formulation of initial-boundary value problems by permitting specification of electrical conductors and allowing these conductors to be connected to electrical circuits isolated from the mechanical deformations. An algorithm for solution of these initial-boundary value problems is incorporated into the code with special material models to represent the response of ordinary dielectrics and electromechanically active dielectrics like piezoelectric and ferroelectric ceramics. The code has a wide range of applications and, in particular, can be used to calculate responses of shock activated power supplies, impact gages, and the change in electrical capacitance due to deformations.

\section{Original Developer of the Code: \\ S. T. Montgomery, 2561, Sandia National Laboratories} Release Status:

\section{References:}

S. T. Montgomery, documentation in preparation

Computer Language: FORTRAN

Computer Platform: Cray, HP, SUN

Related Codes: PRONTO $3 D$

Key Words: Electromechanics, dielectric, transient dynamics 


\section{Sandia National Laboratories Analysis Code Data Base}

Code Name: SUPES Library

Technical Competency/Capability Area: Software Utilities Package

Sandia Point of Contact:

Technical Description of What the Code Does:

The Software Utilities Package for the Engineering Sciences (SUPES) is a collection of subprograms which perform frequently used non-numerical services for the engineering applications programmer. The three functional categories of SUPES are: (1) input command parsing, (2) dynamic memory management, and (3) system dependent utilities. The subprograms in categories one and two are written in standard FORTRAN-77, while the subprograms in category three are written to provide a standardized FORTRAN interface to several system dependent features.

Original Developer of the Code:

\section{Release Status:}

\section{References:}

J. H. Red-Horse, W. C. Mills-Curran, D. P. Flanagan, "SUPES Version 2.1, A Software Utilities Package for the Engineering Sciences," SAND90-0247, Sandia National Laboratories, Albuquerque, New Mexico, May 1990.

\section{Computer Language: \\ Computer Platform:}

\section{Related Codes:}

Key Wordș: 
Robotics Codes 
This page intentionally left blank 


\section{Sandia National Laboratories Analysis Code Data Base}

Code Name: SANDROS motion planner - Sequential and Non-uniform Dimension-deepening Refinement of Subgoals

Technical Competency/Capability Area: Automatic motion planning of robot manipulators

\section{Sandia Point of Contact:}

Yong K. Hwang, 2121 (505) 844-1336; FAX(505) 844-6161; ykhwang@sandia.gov

\section{Technical Description of What the Code Does:}

Given the description of a robot manipulator and objects in its environment, the SANDROS motion planner computes a collision-free motion between two configurations of the manipulator in terms of joint angles. The high-dimensional space of manipulator joint angles is searched in a hierarchical and structured manner to compute a safe and short path in a short time.

\section{Original Developer of the Code:}

Pang C. Chen and Yong K. Hwang, 1621, Sandia National Laboratories

\section{Release Status:}

This code is completed as a stand-alone code and ready for use. It has not been released to any organization.

\section{References:}

P. C. Chen and Y. K. Hwang, "SANDROS: A Motion Planner With Performance Proportional to Task Difficulty, " conference paper published in Proceedings of IEEE International Conference on Robotics and Automation, pp.2346-2353, Nice, France.

\section{Computer Language: $C$}

\section{Computer Platform:}

Any workstation with a native C compiler, such as SUN and Silicon Graphics

\section{Related Codes:}

Commercial robot simulation software IGRIP and Cimstation can be used to specify robot and object information. We are in the process of integrating the SANDROS motion planner into these software.

Key Words: Motion planning, path planning, collision avoidance, manipulators 
This page intentionally left blank 
Penetration Mechanics Codes 
This page intentionally left blank 


\section{Sandia National Laboratories Analysis Code Data Base}

Code Name: SAMPLL - Simplified Analytical Model of Penetration with Lateral Loading

Technical Competency/Capability Area: Earth Penetration

Sandia Point of Contact:

Ronald G. Lundgren, 9814, MS-0312, (505) 844-3404, FAX (505) 845-9319 (no e mail)

Technical Description of What the Code Does:

The code was developed as a fit to the vast experimental data base at Sandia and elsewhere. It is based on algorithms to match observed penetration phenomena, and basic kinematics. Specifically, SAMPLL predicts penetration performance of an intact earth penetrating weapon (EPW). It calculates both angular and translational motion (position, velocity, and acceleration) as a function of time, and calculates penetrator and structural damage to the case. The inputs are penetrator configuration (nose, weight, length, diameter, flares, wall thickness, material, etc.), impact conditions (velocity, angle and angle of attach), and target (soil, rock, concrete, ice, etc.). The sources of lateral loading are impact angle and angle of attack. Both a quasi-3D (planar motion and loading) and a true $3 D$ version exists.

Original Developer of the Code:

Sandia's Penetrator Technology Group developed SAMPLL. C. W. Young developed the concept and algorithms, and E. R. Young did the original coding.

Release Status:

SAMPLL is unclassified, but it is controlled by Export Control Information and Official Use Only. It has been released to (1) 20 private companies working on defense related programs, (2) 6 DoD laboratories, (3) 3 universities, (4) 5 DOE laboratories, (5) 6 other government organizations, and (6) Israel, as part of an Air Force weapon sales package.

References:

1. C. W. Young and E. R. Young, "Simplified Analytical Model of Penetration with Lateral Loading," SAND84-1635, Albuquerque, NM, May 1985.

2. C. W. Young, "A Simplified Analytical Model of Penetration with Lateral Loading (SAMPLL) An Update," SAND 91-2175, Albuquerque, NM, February 1992

Computer Language: Fortran

Computer Platform: Personal Computer, 486 or equivalent

Related Codes: None

Key Words:

EPW, Penetration, Structural damage, Lateral Loading, Penetrator, Penetrating Weapon 
This page intentionally left blank 
Flight Dynamics Codes 
This page intentionally left blank 


\section{Sandia National Laboratories Analysis Code Data Base}

Code Name: AIRSPD (Aircraft airspeed)

Technical Competency/Capability Area: Aircraft airspeed and fight conditions. Sandia Point of Contact:

Harold Spahr, 1515, (505) 844-4854; FAX (505) 844-8251, hrspahr@sandia.gov

Technical Description of What the Code Does:

Computes aircraft airspeeds and flight conditions for:

Different combinations of altitude, true airspeed, calibrated airspeed, Mach number, and dynamic pressure.

Both standard and MIL-STD 210 C nonstandard atmospheres.

Output variables include altitude, true airspeed, calibrated airspeed, Mach number, dynamic pressure, atmospheric static pressure, atmospheric static temperature, atmospheric density, and atmospheric total temperature.

Generates color computer generated plots showing the variation of atmospheric properties with altitude for the available atmospheres.

Used for:

Defining flight environment seen by aircraft delivered weapons.

Defining aircraft airspeeds and altitudes required to obtain necessary test conditions for weapon flight tests.

Original Developer of the Code: Harold Spahr, Department 1515, Sandia National Laboratories, New Mexico

Release Status: Development complete. Documentation started.

References: None.

Computer Language: ANSI Standard Fortran, with DISSPLA graphics language.

\section{Computer Platform:}

Currently operational on Sun 4 Sparcstation workstations. Has been operational on VAX computers. Can be used on any output device for which DISSPLA has a driver.

Related Codes: None.

Key Words: Aircraft airspeed, flight conditions, calibrated air speed, true air speed 


\section{Sandia National Laboratories Analysis Code Data Base}

Code Name: EJECTOR

Technical Competency/Capability Area: Analysis of performance of aircraft ejection racks.

Sandia Point of Contact:

Harold Spahr, 1515, (505) 844-4854; FAX (505) 844-8251, hrspahr@ sandia.gov

Technical Description of What the Code Does:

Computes velocity and angular rates for weapons ejected from aircraft weapons ejector racks.

These calculations:

Are available for the Rockwell 30 inch suspension rack, the BRU-44/A ejection rack, and the

$B R U-47 / A$ ejection rack. Code is easily extended to other ejection racks.

Include effects of climbing or diving aircraft.

Include effects of maneuvering aircraft at ejection.

Include the effects of changing pitch control orifices and ejection cartridges.

Include effects of tolerances in orifices used to control weapon pitch rate.

Use mass property models already defined for most weapons of interest to Sandia.

Currently do not include aerodynamic forces and moments in the nonuniform flow field below the aircraft.

Provide plots of pertinent variables as functions of time and distance during and after the ejection stroke.

Original Developer of the Code: Harold Spahr, Department 1515, Sandia National Laboratories/New Mexico

Release Status: Development almost complete.

References: None

Computer Language: ANSI Standard Fortran, with DISSPLA graphics language

Computer Platform:

EJECTOR is operational on Sun 4 Sparcstation workstations with Postscript graphics output devices. It can be used on any other output device for which DISSIPLA has a driver.

Related Codes: None

Key Words: Weapons, aircraft ejection racks, ejection rack performance, ejection velocity, ejection angular rate 


\section{Sandia National Laboratories Analysis Code Data Base}

Code Name: FLAER - Flight Dynamic and Aerodynamic Design Tool for Missiles and Re-Entry Vehicles

Technical Competency/Capability Area: Flight Dynamic and Aerodynamic Design

Sandia Point of Contact:

Kenneth V. Chavez, 1515, (844-3998) FAX (505) 844-8251, kvchave@sandia.gov

Technical Description of What the Code Does:

FLAER is an expeditious fight vehicle design software package which integrates aeroprediction, propulsion, and trajectory design tools into a single Graphical User Interface (GUI) which coordinates geometry definition, software execution, and result comparison. It utilizes the aerodynamic design code AeroTool, the solid rocket booster program Rocket, and the trajectory simulation code TSAP.

Original Developer of the Code: Kenneth V. Chavez, SNL 1515

Release Status: Under development

\section{References:}

1. D. E. Salguero, "Solid Rocket Motor Performance for Conceptual Design Studies," SAND891181, Sandia National Labs, May 1989.

2. D. E. Outka, "User's Manual for the Trajectory Simulation and Analysis Program (TSAP)," SNAD88-3158, Sandia National Labs, July 1990.

Computer Language: $C$ and Fortran

Computer Platform: SUN Workstations

Related Codes: Missile Datcom, HABA, SANDIAC

Key Words: Aerodynamic design, solid rocket booster design, trajectory simulation 


\section{Sandia National Laboratories Analysis Code Data Base}

Code Name: SOS (Sandia Orbital Simulator)

Technical Competency/Capability Area: Orbital simulation, mission analysis.

Sandia Point of Contact:

Harold Spahr, 1515, (505) 844-4854; FAX (505) 844-8251,hrspahr@sandia.gov

Technical Description of What the Code Does:

SOS is a multipurpose orbital simulation computer code which computes:

Orbital ground tracks and propulsive orbit modifications.

Regions of space covered by ground and space based tracking resources.

Orbital lifetimes.

Generates color computer generated maps and views of Earth as seen from space which show:

Orbital ground tracks.

Locations of and regions covered by ground and space based tracking resources.

Locations of daylight, moonlight, and darkness.

Regions of single and multiple coverage for satellite constellations in space.

Used for:

Analysis of foreign missile tests.

Analysis of reentering Russian satellites with reactors onboard.

Analysis of advanced strategic systems.

Original Developer of the Code:

Harold Spahr, Department 1551, Sandia National Laboratories/New Mexico

Release Status: Development almost complete. Documentation started.

References: None

Computer Language: ANSI Standard Fortran, with DISSPLA graphics language.

\section{Computer Platform:}

Currently, SOS is operational on Sun 4 Sparcstation workstations. SOS has been operational on VAX and Cray computers. It can be used on any output device for which DISSPLA has a driver.

Related Codes: None

Key Words:

Orbital simulation, mission analysis, tracking station coverage, ground tracks, satellite constellation coverage, orbital lifetime 


\section{Sandia National Laboratories Analysis Code Data Base}

Code Name: TSAP - Trajectory Simulation and Analysis Program

Technical Competency/Capability Area: Flight Dynamics

Sandia Point of Contact:

David E.Outka, 1513, (505) 844-8471; FAX (505) 844-4523; deoutka@sandia.gov

Technical Description of What the Code Does:

TSAP is a generalized software package for studying point mass trajectory problems. The flexible user interface, along with numerical analysis capabilities such as parameter surveys, boundary value problem solving, and parameter optimization make TSAP particularly useful for mission planning and performance capability predictions. Several types of targets trajectories can be modeled for use with intercept or flyby problems. Viewing angles and ranges from arbitrary ground stations are also available. A number of standard earth and atmosphere models are available, and wind fields may be included. Output can be both tabular and graphical. Examples of the types of programs to which TSAP has been applied include sounding rocket programs, the STARS rocket program, glide bombs, ASRAM, and maneuvering atmospheric entry vehicles in both earth and martian atmospheres.

Original Developer of the Code:

David E. Outka developed TSAP using as a basis the Point Mass Simulation Tool (PMAST), written at Sandia by David E. Salguero.

Release Status: Released to Sandia and several other organizations

\section{References:}

David E. Outka, "User's Manual for the Trajectory Simulation and Analysis Program (TSAP)," SAND88-3158 (Revised), July 1990.

Computer Language: Fortran, with (optionally) a command-line interpreter written in $C$.

Computer Platform: Sun, Silicon Graphics, DEC VAX, Cray, PC.

\section{Related Codes:}

MultiTsap: An extension to TSAP which include the capability to deploy objects; also provides the capability to model the STARS phase one guidance scheme.

Tsaptool: a graphical user interface for running MultiTsap on the 1550 LAN.

PMAST: the code from which TSAP was derived.

Key Words: Trajectory simulation, trajectory optimization 
This page intentionally left blank 


\section{Aerodynamics Codes}


This page intentionally left blank 


\section{Sandia National Laboratories Analysis Code Data Base}

Code Name: AeroTool-Aerodynamic Prediction Tool

Technical Competency/Capability Area: Aerodynamic Design

Sandia Point of Contact:

Kenneth Chavez, 1515, (505) 844-3998 FAX(505) 844-4523 kvchave@ sandia.gov; or David Salguero, 9811, (505) 845-9001, FAX (505)(505) 844-0094; desalgu@sandia.gov

\section{Technical Description of What the Code Does:}

AeroTool is an aerodynamic design tool that predicts the aerodynamic coefficients for missile and re-entry vehicle shapes in speed regimes ranging from subsonic to hypersonic. It integrates geometry definition, code setup and execution, and post processing and plotting into a single Graphical User Interface (GUI). AeroTool utilizes three major aeroprediction codes to obtain the aerodynamic coefficients:

1 Missile Datcom - Missile shapes, subsonic to supersonic speeds

I HABA - Missile and reentry vehicle shapes, supersonic to hypersonic speeds

I SANDIAC - Reentry vehicle shapes, supersonic to hypersonic speeds.

Original Developer of the Code: David E. Salguero, SNL 9811

Release Status: Under development

\section{References:}

1. S. R. Vukelich, et. al., "MISSILE DATCOM Volume I Final Report," AFWAL-TR-86-3091, McDonnell Douglas Missile Systems Company, December 1988.

2. D. E. Salguero, "Hypersonic Arbitrary-Body Aerodynamics (HABA) for Conceptual Design," SAND90-0078, Sandia National Labs, January 1990.

3. R. W. Noack and A. R. Lopez, "Inviscid Flow Field Analysis of Complex Reentry Vehicles: Volume I, Description of Numerical Methods," SAND87-0776, Sandia National Labs, October 1988 .

Computer Language: $C$ and Fortran

Computer Platform: SUN SPARCstations, Silicon Graphics Workstations

Related Codes: Missile Datcom, HABA, SANDIAC

Key Words:

Aerodynamic prediction; subsonic, transonic, supersonic, and hypersonic aerodynamics 


\section{Sandia National Laboratories Analysis Code Data Base}

Code Name: $A N G E S T$

Technical Competency/Capability Area: Aerodynamics, Flight Dynamics

Sandia Point of Contact:

Terry Jordan-Culler, 1515, (505) 844-2324 FAX (505) 844-8241; tmjorda@sandia.gov

Technical Description of What the Code Does:

The ANGEST code estimates angle of attack values from reentry vehicle (RV) fight test data and includes the flexibility to accept data from accelerometers not located at the RV mass center (cg). When accelerometers not located at the $R V \mathrm{cg}$, angle of attack can be determined from lateral accelerations, angular accelerations, and angular velocities. Fourier series approximations for angular accelerations are used to determine pitch, yaw and total angle of attack, and windward meridian throughout a trajectory.

Original Developer of the Code: Terry Jordan, Dept. 1515, Sandia National Laboratories

Release Status: Engineering Code used for flight test data reduction

References:

D. L. Keese and T. M. Jordan, "User's Guide for ANGEST Computer Code," Internal Memorandum, Sandia National Laboratories, Albuquerque, NM, August 1985.

Computer Language: Fortran

Computer Platform: SUN Workstation, VAX

Related Codes: None

Key Words: Angle of Attack, Windward Meridian, Accelerometers, Rate Gyros, Estimation 


\section{Sandia National Laboratories Analysis Code Data Base}

Code Name: $B L N C$

Technical Competency/Capability Area: Aerodynamics, Flight Dynamics

Sandia Point of Contact:

Terry Jordan-Culler, 1515, (505) 844-2324 FAX (505) 844-8241; tmjorda@sandia.gov

\section{Technical Description of What the Code Does:}

The BLNC code reduces flight test data from a six-component balance mounted in the nose of a reentry vehicle $(R V)$. The reduction process accounts for both inertial and atmospheric effects and assumes that the accelerometers are located at the $R V$ center of mass. The reduction equations are those used for a LTV Corp. six-component balance with separate equations for positive and negative load conditions. Primary program output includes values for forces, moments, and windward meridian as well as their respective coefficients.

Original Developer of the Code: Rick Eisler, 1434, and Terry Jordan, 1515, Sandia National Laboratories

Release Status: Engineering Code used for flight data reduction

References:

D. L. Keese and T. M. Jordan, "User's Guide for BLNC Computer Code," Internal Memorandum, Sandia National Laboratories, Albuquerque, NM, August 1985.

Computer Language: Fortran

Computer Platform: SUN Workstation, VAX

Related Codes: None

Key Words: Six-component force and moment balance, strain gauge, nose balance 


\section{Sandia National Laboratories Analysis Code Data Base}

Code Name: FLAWLES - FLight Analysis by Weighted Least Squares

Technical Competency/Capability Area:

Aerodynamics, Flight Dynamics, Parameter Estimation

Sandia Point of Contact:

Terry Jordan-Culler, 1515,(505) 844-2324 FAX (505) 844-8241; tmjorda@sandia.gov;

G. Richard Eisler, 1434, (505) 844-4838,FAX 844-9297; greisle@sandia.gov;

Jeffrey L.Payne, 1515, (505)844-4838,FAX 844-4523; jlpayne@sandia.gov

Technical Description of What the Code Does:

FLAWLES is an unconstrained weighted least-squares code for aerodynamic parameter estimation, used for postflight analysis of flight vehicles. The code provides a tool for nonlinear postflight analysis of multi-sensor flight vehicles. Vehicle initial conditions, mass properties, aerodynamic properties, and sensor parameters can be estimated from flight observations. The method of estimation is the Gauss estimation using the Levenberg-Marquardt algorithm, where a nonlinear-in-the-parameters weighted sum of squares is minimized. The code is written to model and fit multisensor data from the flight of an unpowered, constant-mass, asymmetric, aerodynamically-controlled or ballistic vehicle over a rotating, spherically-oblate earth.

Original Developer of the Code: G. Richard Eisler, 1434, Sandia National Laboratories

Release Status: Export Controlled Information, Official Use Only

References:

G. Richard Eisler, "FLAWLES: FLight Analysis by Weighted LEast Squares," SAND92-0123, Sandia National Laboratories, Albuquerque, NM, April, 1992.

Computer Language: Fortran 77

Computer Platform: SUN Workstation, Cray YMP

Related Codes: TRAP

Key Words: Weighted least-squares, parameter estimation, postflight analysis, aerodynamic parameter estimation, fight vehicles, multisensor data 


\section{Sandia National Laboratories Analysis Code Data Base}

Code Name: Hypersonic Arbitrary-Body Aerodynamics (HABA)

Technical Competency/Capability Area: Aerodynamic Design of Hypersonic Vehicles

\section{Sandia Point of Contact:}

Jeffrey L. Payne, 1515, (505) 844-4524, FAX (505) 844-4523; jlpayne@sandia.gov

David E. Salguero, 9811, (505) 845-9001; FAX(505) 844-0094, desalgu@sandia.gov

\section{Technical Description of What the Code Does:}

The HABA program predicts static and dynamic aerodynamics derivatives at hypersonic speeds for any vehicle geometry. The program uses local-slope pressure calculation methods that provide reasonable predictions at hypersonic speed also there are methods for predicting skin friction. HABA is intended to be used for conceptual design studies where fast computational speed is required. The program uses the same predictions methods in the Mark IV Supersonic/Hypersonic Arbitrary-Body Program (SHABP) developed under sponsorship of the Air Force Flight Dynamics Laboratory; however, the input and output have been improved.

Original Developer of the Code: David E. Salguero, Department 9811, Sandia National Laboratories

Release Status: Version 90.001

\section{References:}

1. Salguero, D. E., "Hypersonic Arbitrary-Body Aerodynamics (HABA) for Conceptual Design," SAND90-0078, Sandia National Laboratories, January 1990.

2. Gentry, A. E., Smyth, D. N., and Oliver, W. R., "The Mark IV Supersonic-Hypersonic Arbitrary-Body Program, Volume I, User's Manual," AFFDL-TR-73-159, November 1973.

3. Gentry, A. E., Smyth, D. N., and Oliver, W. R., "The Mark IV Supersonic-Hypersonic Arbitrary-Body Program, Volume II, Program Formulation," AFFDL-TR-73-159, November 1973.

Computer Language: $C$

Computer Platform: SUN, VAX, Silicon Graphics Workstations

Related Codes: $H A B A, S H A B P$

Key Words: Aerodynamic prediction, hypersonic 


\section{Sandia National Laboratories Analysis Code Data Base}

Code Name: HIBLARG

Technical Competency/Capability Area: Aerodynamic Heating and Force and Moments

Sandia Point of Contact:

David W. Kuntz, 1514, (505) 844-9690, FAX (505) 844-4523 dwkuntz@sandia.gov

Technical Description of What the Code Does:

HIBLARG solves the integral form of the momentum and energy equations along inviscid streamlines for a 30D flow field. It provides a boundary layer solution for an inviscid flow field solution from an inviscid flow field code. It is valid for Mach numbers 2-25 from sea level to $220 \mathrm{kft}$, and angles of attack from 0 to 30 degrees. It integrates the flow field data to provide aerodynamic and heating coefficient predictions.

Original Developer of the Code: Gary Polansky, Sandia National Laboratories - Aerodynamics Department

Release Status:

References:

G. F. Polansky, "Hypersonic Integral Boundary Layer Analysis of Reentry Geometries (HIBLARG) Code Description and User's Manual, Version 2.0," SAND89-0552, August 1989.

Computer Language: Standard Fortran 77

Computer Platform: SUN \& Cray UNIX

Related Codes: SANDIAC, MAGIC, POSTHEAT

Key Words: 


\section{Sandia National Laboratories Analysis Code Data Base}

Code Name: MISSILE DATCOM

Technical Competency/Capability Area: Aerodynamic Design

Sandia Point of Contact:

Kenneth V. Chavez, 1515,(505) 844-3998,FAX (505) 844-4523, kvchave@sandia.gov;

Jeffrey L.Payne, 1515, (505) 844-4524, FAX (505) 844-4523; jlpayne@sandia.gov

Technical Description of What the Code Does:

MISSILE DATCOM is an aerodynamic design code suitable for preliminary design of a wide variety of missile configurations with or without air-breathing inlets. It uses a component build-up method that incorporates empirical formulations and theoretical techniques for estimating static and dynamic aerodynamic coefficients at subsonic, transonic, and supersonic speeds.

\section{Original Developer of the Code:}

S. R. Vukelich, et. al., McDonnell Douglas Missile Systems Company, for the Flight Dynamics Laboratory of the Air Force Wright Aeronautical Laboratories, Wright-Patterson AFB.

Release Status: Under development

\section{References:}

1. S. R. Vukelich, et. al, "MISSILE DATCOM Volume I Final Report," AFWAL-TR-86-3091, McDonnell Douglas Missile Systems Company, December 1988.

2. S. R. Vukelich, et. al, "MISSILE DATCOM Volume II User's Manual," AFWAL-TR-86-3091, McDonnell Douglas Missile Systems Company, December 1988.

Computer Language: Fortran

Computer Platform:

MISSILE DATCOM runs on any machine with a standard Fortran compiler. It is currently running on SUN and Silicon Graphics Workstations.

\section{Related Codes:}

None

Key Words: Aerodynamic prediction, missile aerodynamics 


\title{
Sandia National Laboratories Analysis Code Data Base
}

\author{
Code Name: $R A M P A N T^{T M}$
}

Technical Competency/Capability Area: Computational Fluid Dynamics/Compressible Flow Sandia Point of Contact:

James M. Nelsen, 1516, MS-0836, (505) 844-8425, (505) 844-8251, jmnelse@sandia.gov

Technical Description of What the Code Does:

RAMPANT ${ }^{T M}$ is a three-dimensional, compressible, unstructured, finite volume code developed by Fluent Inc. The code can model two- and three-dimensional flows in the subsonic $\left(M_{\infty}>0.1\right)$, transonic, and supersonic $\left(M_{\infty}<6\right)$ regimes. The code solves the full Navier-Stokes equations and is sufficiently modularized to handle inviscid, laminar, or turbulent flows. The turbulent models used include the standard two-equation $k-\varepsilon$ model or the new renormalization group theory (RNG) model. RAMPANT ${ }^{T M}$ utitlizes an unstructured triangular (2-D) or tetrahedral (3-D) mesh which permits the use of solution adaptivity as the flow develops. The solution algorithm is based on an explicit, second-order finite volume discretization developed by Jameson with a blended first/third order dissipation to capture shocks and prevent pressure-velocity decoupling. To accelerate convergence, a novel multigrid solution technique is implemented which avoids the prohibitive storage and computational requirements of traditional finite element formulations. RAMPANT ${ }^{T M}$ has been extensively validated for both internal and external flows on 2-D and 3-D geometries.

Original Developer of the Code:

Wayne Smith, (603) 643-2600 or 1-800-445-4454

Fluent Inc., Centerra Resource Park, 10 Cavendish Court, Lebanon, NH 03766-1442

Release Status: Available to the public through Fluent Inc. licensing agreement

References:

RAMPANT 1.0 User's Guide, June 1992, Fluent Inc., Centerra Resource Park, 10 Cavendish Ct., Lebanon, NH 03766

Computer Language: $C$ and Scheme (variant of LISP)

Computer Platform:

Silicon Graphics, SUN, HP, Cray, Intel Paragon, and most Unix based systems

Related Codes:

Fluent, Nekton, FEFlo or ArcFlow

Key Words: CFD, compressible flow, unstructured grid, Navier-Stokes 


\section{Sandia National Laboratories Analysis Code Data Base}

Code Name: SANDIAC

Technical Competency/Capability Area: Aerodynamics

Sandia Point of Contact:

Amalia R. Lopez, Dept. 1515, (505) 845-8057, FAX(505) 844-4523, arlopez@sandia.gov

\section{Technical Description of What the Code Does:}

SANDIAC solves the supersonic and hypersonic inviscid flow field around reentry vehicle bodies providing flow field state variables and integrated force and moment data. The SANDIAC solution for a perfect or equilibrium real gas flow field is obtained by solving the 3-D, steady-state Euler equations in finite difference form using a second order accurate, explicit scheme. The flow field must consist of a supersonic freestream and no embedded subsonic regions. SANDIAC includes a grid generation module which can generate grids for the solution of the flow field around spherically blunted multi-conics, bent axis biconics, vehicles with slices and/or flaps and vehicles with wings and fins.

Original Developer of the Code: General Electric/Sandia National Laboratories

Release Status: Available for government use only.

\section{References:}

1. R. W. Noack and A. R. Lopez, "Inviscid Flow Field Analysis of Complex Reentry Vehicles: Volume 1, Description of Numerical Methods," SAND87-0776/1, October 1988.

2. R. W. Noack and A. R. Lopez, "Inviscid Flow Field Analysis of Complex Reentry Vehicles: Volume II, User's Manual," SAND87-0776/2, November 1988.

\section{Computer Language: FORTRAN}

\section{Computer Platform: SUN, Cray}

\section{Related Codes:}

1. PURMAGIC is a pre-and post-processor code for several of Sandia's inviscid and boundary layer hypersonic flow field codes including SANDIAC.

2. A SANDIAC solution can be used with the HIBLARG boundary layer code to predict surface heating, skin friction and viscous forces and moments.

Key Words: Inviscid aerodynamics, supersonic marching code 


\title{
Sandia National Laboratories Analysis Code Data Base
}

\author{
Code Name: SANDRAG
}

Technical Competency/Capability Area: Aerodynamic Prediction

\section{Sandia Point of Contact:}

William L. Oberkampf, 1515, (505) 844-3799,FAX(505)844-4523,wloberk@sandia.gov

Technical Description of What the Code Does:

SANDRAG calculates the flow field and drag of bodies of revolution, with and without lifting surfaces, at zero angle of attack in incompressible flow. The body pressure distribution, viscous shear stress, and boundary layer separation point are calculated by a combination of a potential flow method and boundary layer techniques. The potential solution is obtained by modeling the body with an axial distribution of source/sink elements whose strengths vary linearly along their length. Both the laminar and turbulent boundary layer solutions use momentum integral techniques which account for the effects of surface roughness. Empirical correlations are used to estimate the base pressure on a variety of boattailed geometries. Very good agreement with experiment has been obtained on a wide range of missiles, bombs, artillery shells, and small arms bullets for low speed flow.

Original Developers of the Code:

Walter P. Wolfe and William L. Oberkampf, Sandia National Laboratories

Release Status of Version Described:

Released to approved users.

\section{References:}

1. Wolfe, W. P., and Oberkampf, W. L., "SANDRAG - A Computer Code for Predication Drag of Bodies of Revolution at Zero Angle of Attack in Incompressible Flow," SAND85-0515, Sandia National Laboratories, April 1985.

2. Wolfe, W. P., and Oberkampf, W. L., "A Design Method for the Flow Field and Drag of Bodies of Revolution in Incompressible Flow, Paper No. AIAA-82-1359, August 1983.

3. Wolfe, W. P., and Oberkampf, W. L., "Drag Predictions for Projectiles and Finned Bodies in Incompressible Flow," Journal of Spacecraft and Rockets, vol. 24, no. 1, January 1987.

Computer Language: FORTRAN

Computer Platform:

UNIX, VMS, DOS, and Apple Operating Systems with FORTRAN compiler

Related Codes: None

Key Words: Drag Prediction, Flow Field, Incompressible Flow, Subsonic Flow, Bodies of Revolution, Finned Bodies, Winged Bodies, Missiles, Bombs, Projectiles, Bullets 
Parachute Technology Codes 
This page intentionally left blank 


\section{Sandia National Laboratories Analysis Code Data Base}

Code Name: AIVEL-PW (Aircraft Induced VELocity - Paneled Wing)

Technical Competency/Capability Area: Parachute Systems

Sandia Point of Contact:

W. D. Sundberg, 1516, (505) 844-5234, FAX(505) 844-4523,wdsundb@sandia.gov

\section{Technical Description of What the Code Does:}

A vortex panel method of calculating the wake velocities induced by specific delivering aircraft on parachute/payload trajectories has been developed. The aircraft is represented by a set of quadrilateral vortex panels which form a planar structure of the approximate size and shape of the aircraft's wing planform. The aircraft's wake is represented by vortex filaments which emanate continuously from the wing's trailing edge. Ground proximity effects are included. Input requirements are a panel description of the aircraft's wing, the aircraft's trajectory, and the payload's trajectory.

Original Developer of the Code: T. L. Fullerton, Sandia National Laboratories

Release Status: Research code

\section{References:}

T. L. Fullerton, J. H. Strickland and W. D. Sundberg, "A Vortex Panel Method for Calculating Air craft Downwash on Parachute Trajectories," AIAA Paper 91-0875, April 1991, San Diego, CA.

Computer Language: FORTRAN 77

Computer Platform: Personal computers running DOS with at least 640Kbyte of memory and a $80386 / 87$ or higher processor.

Related Codes: None

Key Words: Vortex panel method, aircraft downwash 


\section{Sandia National Laboratories Analysis Code Data Base}

Code Name: CALA (CAnopy Loads Analysis)

Technical Competency/Capability Area: Parachute Systems

Sandia Point of Contact:

W. D. Sundberg, 1516, (505) 844-5234, FAX (505) 844-4523,wdsundb@sandia.gov

\section{Technical Description of What the Code Does:}

CALA does a steady-state loads/stress analysis of a conventional ( $n$ symmetric gores) parachute. The code requires as input: coefficients for the pressure distribution, the constructed geometry of the parachute, and the elastic material properties used in the parachute. Either a fuxed dynamic pressure can be specified, or the dynamic pressure can be varied to match a specified load. The current version does not include strength in the vertical member direction.

Original Developer of the Code: W. D. Sundberg, Department 1516, Sandia National Laboratories

Release Status: Released (prior to licensing) to several installations

References:

Sundberg, W.D., "New Solution Method for Steady-State Canopy Structural Loads," Journal of Aircraft, Vol. 25, Nov. 1988, pp. 1045-1051.

Computer Language: FORTRAN 77

Computer Platform:

DEC VAX Sun SPARCstation, personal pomputers running DOS with at least 512 Kbyte memory and a $8086 / 87$ or higher processor.

Related Codes:

Key Words: Parachute canopy loads, stress 


\section{Sandia National Laboratories Analysis Code Data Base}

Code Name: LAPTAP (Low Altitude Parachute Trajectory Analysis Program)

Technical Competency/Capability Area: Parachute Systems

Sandia Point of Contact:

W. D. Sundberg, 1516, MS-0836, (505) 844-5234, FAX(505) 844-4523, wdsundb@sandia.gov

Technical Description of What the Code Does:

LAPTAP is a single point mass parachute trajectory code with a low altitude ( $<36 \mathrm{kft}$ ) atmosphere model. It has facilities for parachute included air mass. It has printout control based on parachute drag area table inflection points. The input is user friendly prompts.

Original Developer of the Code:

W. D. Sundberg, Department 1516, Sandia National Laboratories

Release Status: Research code

References: None

Computer Language: FORTRAN 77

\section{Computer Platform:}

Sun SPARCstation, personal computers with at least 640 Kbyte of memory and a $8386 / 87$ or higher processor.

\section{Related Codes:}

A DISSPLA based plotting code is available on the Sun. A code to generate columns of variables to be read by a commercial $x$-y plotting package is available on the Sun or PC.

Key Words: Parachute trajectories, point mass, included mass 


\section{Sandia National Laboratories Analysis Code Data Base}

Code Name: LINESAIL

Technical Competency/Capability Area: Parachute Systems

Sandia Point of Contact:

W. D. Sundberg, 1516, MS-0836, (505) 844-5234, FAX (505) 844-4523, wdsundb@ sandia.gov

Technical Description of What the Code Does:

LINESAIL models parachute line sail during high-speed lines-first parachute deployment when there is a component of cross flow velocity. A series of elastically connected mass points are used to model the parachute. Mass points become activated in the model as they leave the deployment bag. A line and canopy tie model is included.

Original Developer of the Code: J. W. Purvis, Department 9204, Sandia National Laboratories

Release Status: Research code

\section{References:}

J. W. Purvis, "Prediction of Parachute Line Sail During Lines-First Deployment," Journal of Aircraft, Vol. 20, Nov. 1983, pp. 940-945.

Computer Language: FORTRAN 77

\section{Computer Platform:}

Sun SPARCstation, IBM compatible personal computers with at least 640 Kbyte of memory and a $80386 / 87$ or higher processor. The Sun and PC versions of the code are different.

Related Codes: Two additional plot codes are used to plot results.

Key Words: Parachute deployment, suspension line sail, cross-flow 


\section{Sandia National Laboratories Analysis Code Data Base}

Code Name: MIMIC (MIke Macha's Inflation Code)

Technical Competency/Capability Area: Parachute Systems

Sandia Point of Contact:

W. D. Sundberg, 1516,(505) 844-5234 FAX(505) 844-4523,wdsundb@sandia.gov

Technical Description of What the Code Does:

MIMIC calculates parachute inflation total load and skirt diameter as a function of time for parachutes with canopy effective porosities between 15 and 25\%. The parachute and payload system is treated as a single point mass for calculation of the trajectory during the inflation. A single stage of reefing is allowed in the inflation model. The maximum deceleration of the system, in terms of initial velocity normalized by steady-state terminal velocity, is limited to be less than 19.

Original Developer of the Code:

Sandia National Laboratories, J. M. Macha, Department 1552

Release Status: Released to two installations with no-cost licensing agreements

References:

Macha, J. M., "Development and Experimental Verification of a Single-Degree-of-Freedom Inflation Model for Ribbon and Ringslot Parachutes," SAND92-1378, Sandia National Laboratories, October 1992.

\section{Computer Language: FORTRAN 77}

Computer Platform:

DEC VAX, Sun SPARCstation, Personal Computers with at least 512Kbyte memory and 8086/87 or higher processor. A Motif graphical user interface is available on the Sun SPARCstation.

Related Codes: None

Key Words: Parachute Inflation 


\section{Sandia National Laboratories Analysis Code Data Base}

Code Name: $M B O D Y$ (Multiple BODY trajectory code)

Technical Competency/Capability Area: Parachute Systems

Sandia Point of Contact:

W. D. Sundberg, 1516, MS-0836, (505) 844-5234, FAX (505) 844-4523, wdsundb@ sandia.gov

Technical Description of What the Code Does:

$M B O D Y$ is a multiple body trajectory code primarily designed for (but not limited to) parachute system analysis. Bodies can be a mix of point-mass, point-mass with orientation, or six-degreeof-freedom. Bodies can be elastically connected or not. Some cases which have been calculated ate (1) a payload being extracted from a cargo aircraft with payload tipoff, repositioning of the payload after extraction, and then trajectory to the ground, and (2) free flight of a payload, deployment of a parachute attached to the payload, inflation of the parachute using the MIMIC equations, and trajectory to the ground. The code is designed to be quite general so that many models can be included in it, and it can calculate trajectories from simple point-mass models to complex multiple six-degree-of freedom models or any mix in between. A general staging structure has been built in to allow the number of bodies and connectors to vary during a trajectory calculation.

Original Developer of the Code:

W. D. Sundberg, Department 1516, Sandia National Laboratories

Release Status: Under development

References: W. D. Sundberg, "Extraction, Tipoff, and Descent Modelling of the Air Launched Surface Craft Using the Multiple Body Trajectory Code," Sandia National Laboratories Report SAND94-1315, June 1994.

Computer Language: FORTRAN 77

\section{Computer Platform:}

Sun SPARCstation, Personal Computers with over 2Mbyte of memory and a 80386/87 or higher processor.

\section{Related Codes:}

Key Words:

Parachute systems, trajectories, multiple-body, six-degree-of-freedom, elastic connections 


\section{Sandia National Laboratories Analysis Code Data Base}

Code Name: $T W O B O D Y$ (TWO BODY parachute trajectory code)

Technical Competency/Capability Area: Parachute Systems

Sandia Point of Contact:

W. D. Sundberg, 1516, (505) 844-5234, MS-0836, FAX (505) 844-4523, wdsundb@ sandia.gov

Technical Description of What the Code Does:

TWOBODY calculates the trajectory of two point mass bodies connected by an elastic line. In terms of a parachute system, this means the start point has to be at canopy stretch or later. This code is intended to model systems where the length of the system is a significant fraction of the fall distance, such as low altitude deliveries of payloads, and the system is experiencing angular oscillations at pay-load impact. The angular orientation of each body is determined from the connecting line orientation. The connecting line axes are approximately non-rolling so the payload can have a specified pitch orientation with respect to the connecting line in a specified connecting line roll plane orientation. Point mass bodies simplify the input, but still give adequate angular motion for many situations. A version of the code is available where the parachute can have a trim angle (lift). The code has the facilities for the parachute included air mass. The aircraft induced velocity calculation from AIVEL-PW is included in the code, so that these effects on a trajectory can be modeled.

Original Developer of the Code:

W. D. Sundberg, Department 1552, Sandia National Laboratories

Release Status: Research code

References: None

Computer Language: FORTRAN 77

\section{Computer Platform:}

Sun SPARCstation, Personal Computers with at least 640 Kbyte of memory and a 80386/87 or higher processor.

Related Codes:

A DISSPLA-based plotting code is available on the Sun. A code to generate columns of variables to be read by a commercial $x-y$ plotting package is available on the Sun or PC.

Key Words: Parachute trajectories, two-body, included mass 
This page intentionally left blank 
Hydrology Codes 
This page intentionally left blank 


\section{Sandia National Laboratories Analysis Code Data Base}

Code Name: BLT (Breach, Leach and Transport)

Technical Competency/Capability Area: Hydrology

Sandia Point of Contact:

Technical Description of What the Code Does:

$B L T$ predicts the rate of radionuclde release from shallow land disposal of low-level waste. Source Term Analysis and Ground Water Flow and Transport.

Original Developer of the Code: T. M. Sullivan, C. J. Suen - Brookhaven National Laboratory

Release Status: First Version

References:

NUREG/CR-5387 BNL-NUREG-52206 Low-Level Waste Shallow Land Disposal Source Term Model: Data Input Guides, July 1989.

Computer Language: FORTRAN

Computer Platform: IBM PC

Related Codes: FEMWASTE, FEMWATER

Key Words: Breach, leach transport, low-level waste, shallow-land burial 


\section{Sandia National Laboratories Analysis Code Data Base}

Code Name: $D C M 3 D$

Technical Competency/Capability Area: Hydrology

Sandia Point of Contact:

David P. Gallegos, 6331, MS-1345,(505) 848-0761, FAX(505) 848-0764,dpgalle@sandia.gov

Technical Description of What the Code Does:

DCM3D solves three-dimensional, ground-water flow problems in variably saturated, fractured porous media.

Original Developer of the Code: C. D. Updegraff, C. E. Lee and D. P. Gallegos - SNL

Release Status: Version 1.0

References:

NUREG/CR-5536 DCM3D: A Dual-Continuum, Three-Dimensional, Ground-Water Flow Code for Unsaturated, Fractured, Porous Media, Feb. 1991

Computer Language: FORTRAN

Computer Platform: CRAY, IBM PC Compatible

Related Codes: None

Key Words: Ground-water flow, unsaturated, fractured, porous media, dual-continuum, hydrology 


\section{Sandia National Laboratories Analysis Code Data Base}

Code Name: FEMWASTE

Technical Competency/Capability Area: Hydrology

Sandia Point of Contact:

D.P. Gallegos,6331,(505) 848-0761,FAX (505) 848-0764,dpgalle@sandia.gov

Paul A.Davis,6307,(505) 848-0754,FAX(505)848-0764,padavis@sandia.gov

Technical Description of What the Code Does:

This is a two-dimensional transient model for the transport of dissolved constituents through porous media. Transport mechanisms include: convection, hydrodynamic dispersion, chemical sorption and first-order decay.

Original Developer of the Code: ORNL - G. T. Yeh and D. S. Ward

Release Status: April 1981

\section{References:}

ORNL-5601 - FEMWASTE: A Finite-Element Model of Waste Transport Through SaturatedI Unsaturated Porous Media, April 1981, Oak Ridge National Laboratory

Computer Language: FORTRAN

Computer Platform: None

Related Codes: None

Key Words: Finite, transport, waste, saturated, unsaturated, hydrology 


\section{Sandia National Laboratories Analysis Code Data Base}

Code Name: FEMWATER

Technical Competency/Capability Area: Hydrology

Sandia Point of Contact:

Paul A. Davis, 6307, MS-1345, (505) 848-0754, FAX(505)848-0764,padavis@sandia.gov

Technical Description of What the Code Does:

FEMWATER models finite element flow of water through saturated and unsaturated porous media.

Original Developer of the Code: $O R N L-G . T . Y e h$

Release Status: June 1982

References:

ORNL-5567, FEMWATER

Computer Language: FORTRAN

Computer Platform: CRAY, CDC, IBM PC Compatible

Related Codes: FEMWASTE

Key Words: Unsaturated, finite element, water flow, saturated 


\section{Sandia National Laboratories Analysis Code Data Base}

Code Name: $M O D F L O W$

Technical Competency/Capability Area: Hydrology

Sandia Point of Contact:

Paul A. Davis, 6307,MS-1345, (505) 848-0754, FAX (505) 848-0764, padavis@ sandia.gov

Technical Description of What the Code Does:

MODFLOW models saturated groundwater flow

Original Developer of the Code: USGS

Release Status:

References:

TWRI, Book 6, Chapter A1, Scientific Software Group, 1988

Computer Language: FORTRAN

Computer Platform: Sun Sparc-Station, VAX

Related Codes:

Key Words: Ground water, saturated, flow, hydrology 


\section{Sandia National Laboratories Analysis Code Data Base}

Code Name: $M O D P A T H$

Technical Competency/Capability Area: Hydrology

Sandia Point of Contact:

Paul A. Davis, 6307,MS-1345, (505) 848-0754, FAX(505) 848-0764, padavis@ sandia.gov

Technical Description of What the Code Does:

MODPATH is a modular three-dimensional finite-difference groundwater flow model.

Original Developer of the Code: USGS - David W. Pollock

Release Status: Version 1.2, April 27, 1990

References:

OFR 89-381 Computer Programs to Compute and Display Pathlines Using Results from USGS Modular Three-Dimensional Finite-Difference Groundwater Flow Model.

Computer Language: FORTRAN

Computer Platform: Sun Sparc-Station

Related Codes: PCG2, StR1 Source Codes

Key Words: Finite, ground water flow, hydrology 


\section{Sandia National Laboratories Analysis Code Data Base}

Code Name: NEFTRAN II

Technical Competency/Capability Area: Hydrology

Sandia Point of Contact:

Natalie E. Olague, 6201, MS-0704, (505) 844-2109, FAX (505) 844-7786, neolagu@ sandia.gov

Technical Description of What the Code Does:

A computer program which simulates flow and transport of high level radioactive waste in time dependent velocity fields in unsaturated, welded tuff.

Original Developer of the Code:

N. E. Olague, D. E. Longsine, J. E. Campbell, C. D. Leigh, Sandia National Laboratories/New Mexico

Release Status: February 1991

References:

NUREG/CR-5618 SAND90-2089, User's Manual for the NEFTRAN II Computer Code

Computer Language: FORTRAN

Computer Platform: Sun Sparc - Station and VAX

Related Codes: NEFTRAN, NWFT/DVM

Key Words: Flow, transport, hydrology, unsaturated, tuff, high level radioactive waste, hydrology 


\section{Sandia National Laboratories Analysis Code Data Base}

Code Name: NORIA

Technical Competency/Capability Area: Hydrology

Sandia Point of Contact:

Roger R. Eaton, 1511, MS-0828, (505) 844-4063, FAX (505) 844-4523, rreaton@ sandia.gov

Technical Description of What the Code Does:

NORIA solves two phase vapor, heat transport of water in unsaturated zone.

Original Developer of the Code: Nathan Bixler, $S N L$

Release Status: Version 1?

References:

N. E. Bixler, "A Finite Element Computer Program for Analyzing Water, Vapor, Air and Energy

Transport in Porous Media," NORIA: SAND84-2057, 1985.

Computer Language: FORTRAN

Computer Platform: Cray

Related Codes: None

Key Words: Transport, heat, hydrology, unsaturated, water 


\section{Sandia National Laboratories Analysis Code Data Base}

Code Name: PAGAN

Technical Competency/Capability Area: Hydrology

\section{Sandia Point of Contact:}

Matthew W. Kozak, 6331, MS-1345, (505) 848-0766, FAX (505)848-0764, mwkozak@sandia.gov Margaret S. Y. Chu, 6622, MS-0727, (505) 844-9931, FAX(505) 844-1480, msychu@sandia.gov

Technical Description of What the Code Does:

The code allows the analyst to perform systematic quantitative analyses of the radionuclide releases from a low-level waste disposal facility, the transport of radionuclides through the environment and biosphere, and the doses to man from various exposure pathways. The code is a performance assessment ground-water analysis of low-level nuclear waste.

Original Developer of the Code: Margaret Chu, Matt Kozak, J. E. Campbell, B. M. Thompson

Release Status: Version 1 (2)

References:

NUREG/CR-5539 SAND90-0585 A Self-Teaching Curriculum for the NRC/SNL Low-Level Waste Performance Assessment Methodology, January 1991.

\section{Computer Language: FORTRAN}

Computer Platform: $I B M-P C$

Related Codes: DISPERSE, SURFACE, VAM2D, GENII

Key Words: Radionuclide releases, low-level waste, transport, exposure pathways 


\section{Sandia National Laboratories Analysis Code Data Base}

Code Name: SWIFT

Technical Competency/Capability Area: Hydrology

Sandia Point of Contact:

Paul A. Davis, 6307, MS-1345, (505) 848-0754, FAX (505) 848-0764, padavis@sandia.gov

Technical Description of What the Code Does:

SWIFT simulates radioactive flow and transport of radionuclides from a hypothetical repository in fractured rocks or porous media. It includes effects of heat generation and brine flow.

Original Developer of the Code: Sandia - N. C. Finley and M. Reeves (INTERA)

Release Status: Version 1 - August 1986

References:

1. NUREG/CR-3162 SAND83-0242 Data Input Guide for SWIFTII, The Sandia Waste Isolation Flow and Transport Model for Fractured Media.

2. NUREG/CR-3328, SAND83-1159, Theory and Implementation for SWIFTII, The Sandia Waste Isolation Flow and Transport Model for Fractured Media

Computer Language: FORTRAN

Computer Platform: VAX

Related Codes:

Key Words: Fractured media, transport, flow, hydrology 


\section{Sandia National Laboratories Analysis Code Data Base}

Code Name: TOSPAC

Technical Competency/Capability Area: Rock Mass Analysis

Sandia Point of Contact:

John H. Gauthier, 6312, MS-1326, , (505) 848-0808, FAX (505) 848-0739, jhgauth@sandia.gov

Technical Description of What the Code Does:

TOSPAC models one-dimensional, vertical groundwater flow with transport of decaying contaminants through unsaturated, fractured, porous media.

Original Developer of the Code: Wilson/Gauthier, Sandia/SPECTRA

Release Status: Research code

References:

"Total System Performance Assessment Code, TOSPAC, Volume 2, User's Guide," SAND850004.

Computer Language: FORTRAN 77

Computer Platform: DEC VAX

Related Codes: None

Key Words: Groundwater flow, decay transport 


\section{Sandia National Laboratories Analysis Code Data Base}

Code Name: TOUGH2 - Transport Of Unsaturated Groundwater and Heat

Technical Competency/Capability Area:

Multiphase, Multicomponent Fluid and Heat Flow in Porous and Fractured Media. Reference code for Fluid Flow and Transport Dept. 6119 for the WIPP.

Sandia Point of Contact:

Stephen W. Webb, 6119, MS-1320, (505) 844-7037, FAX (505) 848-0622, swwebb@ sandia.gov

Technical Description of What the Code Does:

TOUGH2 is a numerical simulation program for multi-dimensional coupled fluid and heat flows of multiphase multicomponent fluid mixtures in porous and fractured media. TOUGH2 includes a number of different fluid property modules which make the code applicable to a variety of subsurface flow systems, including groundwater aquifers and unsaturated zones such as those encountered in nuclear waste repositories and geothermal reservoirs. Additional fluid property modules are under development at Lawrence Berkeley Laboratory $(L B L)$ for enhanced oil recovery, NAPL contaminant transport, and other applications. TOUGH2 uses the integrated finite difference method for spatial discretization which avoids any reference to a global system of coordinates and is applicable to regular and irregular discretizations in one, two, or three dimensions. Time is discretized in a fully implicit manner, and the resulting equations are solved by Newton-Raphson iteration. TOUGH2 is the successor to the TOUGH code.

Original Developer of the Code:

Karsten Pruess, Lawrence Berkeley Laboratory, Berkeley, California

Release Status: Released to Energy Science and Technology Software Center

References:

1. K. Pruess, "TOUGH2 - A General-Purpose Numerical Simulator for Multiphase Fluid and Heat Flow," LBL-29400, Lawrence Berkeley Laboratory, May 1991

2. K. Pruess, "TOUGH User's Guide," NUREG/CR-4645, SAND86-7104, LBL-20700, US Nuclear Regulatory Commission, August 1987.

Computer Language: FORTRAN

Computer Platform:

The original version was developed on $C D C-7600$ and Cray X-MP computers. The code has been modified at SNL to run on VAXs, IBM PCs, HP Workstations, Sun Workstations, and IBM Workstations.

Related Codes:

A postprocessor has been developed to provide contour and vector plots using the Tecplot plotting program.

Key Words:

Multiphase,multicomponent, porous media, fluid flow, heat flow, fractured porous media. 


\section{Sandia National Laboratories Analysis Code Data Base}

Code Name: UNSAT2

Technical Competency/Capability Area: Hydrology

Sandia Point of Contact:

Paul A. Davis, 6307, MS-1345, (505) 848-0754, FAX (505) 848-0764, padavis@sandia.gov

Technical Description of What the Code Does:

UNSAT2 analyzes flow in unsaturated, partially saturated, and fully saturated regions.

Original Developer of the Code: L. A. Davis and S. P. Neuman - WWL, Inc.

Release Status: December 1983

References:

"NUREG/CR-3390 WWL/TM-1791-1 Documentation and User's Guide UNSAT2 - Variably Saturated Flow Model Final Report," December 1983.

Computer Language: FORTRAN

Computer Platform: VAX, IBM PC Compatible

Related Codes: None

Key Words: Unsaturated, saturated, flow hydrology 


\section{Sandia National Laboratories Analysis Code Data Base}

Code Name: USGS3D

Technical Competency/Capability Area: Hydrology

Sandia Point of Contact:

Paul A. Davis, 6307, MS-1345, (505) 848-0754, FAX (505) 848-0764,padavis@sandia.gov

Technical Description of What the Code Does:

USGS3D is a computer program for simulating geohydraulic systems in three dimensions.

Original Developer of the Code:

USGS, D. R. Posson, G. A. Hearne, J. V. Tracy and P. F. Fenzel

Release Status: March 1980

References:

"USGS OFR-80-421, A Computer Program for Simulating Geohydraulic Systems in Three Dimensions."

Computer Language: FORTRAN

Computer Platform: Computers running FORTRAN

Related Codes: None

Key Words: Geohydraulic, hydrology, three dimensional 


\section{Sandia National Laboratories Analysis Code Data Base}

Code Name: $V A M 2 D$

Technical Competency/Capability Area: Health Physics, Hydrology

Sandia Point of Contact:

Matthew W. Kozak, 6331, MS-1345, (505) 848-0766, FAX(505)848-0764, mwkozak@sandia.gov

Technical Description of What the Code Does:

Two-dimensional finite element model developed to simulate water flow and solute transport in variably saturated porous media.

Original Developer of the Code:

HydroGeoLogic Inc., Herndon, Virginia - P. S. Hyakorn, J. B. Kool and J. B. Robinson

Release Status: Version 5.1

References:

NUREG/CR-5352 Documentation and User's Guide: VAM2D - Variably Saturated Analyses Model in Two Dimensions (Version 5.0 with Hysteresis and Chained Decay Transport), April 1989.

Computer Language: FORTRAN

Computer Platform: IBM PC Compatible or mainframe computer

Related Codes: None

Key Words: Finite element, solute transport, saturated, two-dimensional 


\section{Sandia National Laboratories Analysis Code Data Base}

Code Name: VS2D

Technical Competency/Capability Area: Hydrology

Sandia Point of Contact:

James T.McCord, 6622, MS-0727, (505) 844-5157, FAX (505) 844-1480, jtmccor@ sandia.gov

Technical Description of What the Code Does:

VS2D models unsaturated water flow and transport.

Original Developer of the Code: USGS

Release Status: Version 1

References:

WRI 83-4-99 - Documentation of Computer Program US2D to Solve the Equation of Fluid Flow in Variable Saturated Porous Media, Denver, CO 1987

Computer Language: FORTRAN

Computer Platform: $P C$

Related Codes: None

Key Words: Unsaturated, transport, hydrology 


\section{Geostatics Codes}


This page intentionally left blank 


\section{Sandia National Laboratories Analysis Code Data Base}

Code Name: GEOEASE

Technical Competency/Capability Area: Two Dimensional Geostatistical Analysis

Sandia Point of Contact:

Erik K. Webb, 6331, MS-1345, (505) 848-0760,FAX(505)848-0764, ekwebb@sandia.gov

Technical Description of What the Code Does:

Performs file management, statistics, variogram analysis, cross validations, kriging and plots.

Original Developer of the Code: E. Englund and A. Sparks

Release Status: Open public domain

References:

E. Englund and A. Sparks, "GEO-EPS, Geostatistical Environmental Assessment Software User's Guide". U.S. EPA EPA/600/4-88/-033, 1988.

Computer Language: FORTRAN

Computer Platform: DOS, IBM Compatible Computer

Related Codes: GEOPACK

Key Words: Geostatistics 


\section{Sandia National Laboratories Analysis Code Data Base}

Code Name: GEOPACK

Technical Competency/Capability Area: Geostatistical Analysis

Sandia Point of Contact:

Erik K. Webb, 6331, MS-1345, (505) 848-0760, FAX (505)848-0764, ekwebb@sandia.gov

Technical Description of What the Code Does:

Provides Fortran subroutines to calculate variograms, krig data, simulate numerical fields and plot the results.

Original Developer of the Code: S. R. Yates and M. V. Yates, RS KERR Environmental Resource Laboratories

Release Status: Version 1.0 Public Domain

\section{References:}

S. R. Yates and M. F. Yates, "Geostatistics for Waste Management: A User's Manual for the GEOPACK (Version 1.0) Geostatistical Software System," R. S. KERR Environmental Resource Laboratories, US EPA. EPA/600/8-90/004. 70p, 1990.

Computer Language: FORTRAN

Computer Platform: DOS-based IBM PC compatible

Related Codes: GSLIB

Key Words: Geostatistics, statistics, simulation 


\section{Sandia National Laboratories Analysis Code Data Base}

Code Name: Stanford Geostatistical Package - GSLIB

Technical Competency/Capability Area:

Geostatistical Simulation Algorithms, Variograms, Kriging, Conditional Simulation, Linear System Solvers, Plotting

Sandia Point of Contact:

Erik K. Webb, 6331, MS-1345, (505) 848-0760, FAX (505)848-0764, ekwebb@sandia.gov

Technical Description of What the Code Does:

Provides Fortran subroutines to calculate variograms, krig data, simulate numerical fields and plot the outcome.

Original Developer of the Code: C. V. Deutsch and A. G. Journel

Release Status: Version 1.0

\section{References:}

C. V. Deutsch and A. G. Journel, "GSLIB: Geostatistic Software Library, User's Guide", Stanford Center for Reservoir Forecasting, School of Earth Sciences, Stanford, California., 1991.

Computer Language: FORTRAN

Computer Platform: Sun Station, Unix - operator

Related Codes:

Key Words: Geostatistics, kriging, conditional simulation 
This page intentionally left blank 
Chemical Transport/Chemistry Codes 
This page intentionally left blank 


\section{Sandia National Laboratories Analysis Code Data Base}

Code Name: Fracture/Matrix Transport Code (FMT)

\section{Technical Competency/Capability Area:}

Chemical transport modeling with explicit representation of mineral dissolution/precipitation reactions, ion exchange, and speciation. Includes an option for the Pitzer activity model (Harvie et al., 1984) for brine reactions.

Sandia Point of Contact:

Craig F.Novak,6119,MS-1320, (505) 848-0619,FAX (505) 848-0622,cfnovak@sandia.gov

\section{Technical Description of What the Code Does:}

FMT is a FORTRAN computer code that solves the two-dimensional advection-dispersion equations coupled with mechanistic chemical reactions. The limits of advection-dominated transport, with only numerical dispersion, and diffusion-dominated transport are available. Currently, the velocity profile must be calculated externally and is assumed to be constant in time. However, a module for calculating velocities from pressure profiles as a function of permeability and porosity is under development. The porosity can be calculated as a function of chemical composition, and thus the dissolution and precipitation of minerals can affect velocity profiles. The user can specify any chemical database desired; the EQ3/6 database and the Harvie-Moller-Weare parameterization of the Pitzer activity model (Harvie et al., 1984) are available.

\section{Original Developer of the Code:}

FMT is the current incarnation of a code previously called GEOFLOW, which was initially developed by Craig. F. Novak in the Departments of Chemical and Petroleum Engineering at The University of Texas at Austin.

\section{Release Status:}

FMT has not been formally released. Development of FMT will likely continue as applications to additional systems require.

\section{References:}

1. C. E. Harvie, N. Moller, and J. H. Weare, 1984 "The Prediction of Mineral Solubilities in Natural Waters: The $\mathrm{Na}-\mathrm{K}-\mathrm{Mg}-\mathrm{Ca}-\mathrm{H}-\mathrm{CI}-\mathrm{SO}_{4}-\mathrm{OH}-\mathrm{HCO}_{3}-\mathrm{CO}_{3}-\mathrm{CO}_{2}-\mathrm{H}_{2} \mathrm{O}$ System to High Ionic Strength at $25^{\circ} \mathrm{C}, "$ Geochimica et Cosmochimica Acta vol. 48, 723-751.

2. C. F. Novak, 1990 "Metasomatic Patterns Produced by Infiltration or Diffusion in permeable Media. Doctoral Thesis," University of Texas at Austin. Ann Arbor, Michigan, Univer-sity Microfilms.

3. C. F. Novak, 1992, "Transport Modeling in a Finite Fractured Rock Domain," SAND920936C, in Proceedings of the Scientific Basis for Nuclear Waste Management XVI Conference, 30 November - 4 December 1992. 
4. C. F. Novak, and F. Gelbard, 1991, "Modeling Mineral Dissolution and Precipitation in DualPorosity System," SAND91-0430 Sandia National Laboratories, Albuquerque, New Mexico.

5. C. F. Novak, R. S. Schechter, and L. W. Lake, 1989, “Diffusion and Solid Dissolution/Precipitation in Permeable Media," American Institute of Chemical Engineers Journal vol. 35 \#7, 1057-1072

6. C. F. Novak and S. D. Sevougian, 1992, "Propagation of Dissolution/Precipitation Waves in Porous Media," SAND92-0364 Sandia National Laboratories, Albuquerque, New Mexico.

Computer Language: FORTRAN 77

Computer Platform: As of 10192, FMT has been run only on a VAX under VMS. The code is scheduled to be ported to and run on an HP workstation in 12/92.

Related Codes: A preprocessor is available to translate chemical equilibrium data from the EQ3/6 data format to that necessary for FMT.

Key Words: Transport modeling, geochemical modeling, double-porosity transport, local equilibrium, Pitzer activity model 


\section{Sandia National Laboratories Analysis Code Data Base}

Code Name: TIGER

Technical Competency/Capability Area: Nonideal chemical equilibrium

Sandia Point of Contact:

Michael L.Hobbs, 1512 MS-0834, (505) 844-5988,FAX (505) 844-8251,mlhobbs@sandia.gov

Technical Description of What the Code Does:

TIGER is a computer code used for calculating the thermodynamic state attained in a heterogeneous system of known atomic composition containing gases, liquids, and solids with arbitrary equations of state. The version of TIGER used at SNL can be applied to systems containing up to 400 gaseous and 100 condensed constituents composed of up to 50 chemical elements. The thermodynamic data base used in TIGER is based on the JANNAF thermochemical tables. Covolumes have been estimated for approximately 900 gaseous species for use with the BeckerKistiakowsky-Wilson equation of state (BKW-EOS). The BKW-EOS parameters have been optimized for CHNO explosives using measured detonation properties of HMX, PETN, RDX, TETRYL and TNT over a wide initial density range.

Original Developer of the Code:

Stanford Research Institute (SRI) located at Menlo Park, California, developed the code in the early 1970's for Lawrence Livermore Laboratory, Naval Ordnance Laboratory, and the U. S. Army Picatinny Arsenal.

\section{Release Status:}

Formally released with permission from Picatinny Arsenal at Battell (Columbus, Ohio), IIT Research Institute (Chicago, IL), and Naval Surface Warfare Center (Silver Spring, MD).

\section{References:}

1. M. L. Hobbs and M. R. Baer, "Nonideal Thermoequilibrium Calculations Using a Large Product Species Data Base," accepted for publication in Shock Waves (1992)

2. M. L. Hobbs and M. R. Baer, "Nonideal Thermoequilibrium Calculations Using a Large Product Species Data Base," SAND92-0482, UC-741, SNL, Albuquerque, NM (June 1992)

3. M. L. Hobbs and M. R. Baer, "Pyrotechnic Calculations Using the BKW-EOS with a Large Product Species Data Base," Proceedings of the Eighteenth International Pyrotechnics Seminar IIT Research Institute, Chicago, Illinois, 415 (1992)

\section{Computer Language: FORTRAN}

Computer Platform: Cray YMP, workstations

Related Codes: Output can be plotted with a variety of codes

\section{Key Words:}

$B K W$ equation of state, nonideal thermochemical equilibrium, $C-J$ states, Hugoniot calculations 
This page intentionally left blank 


\section{Environment Codes}


This page intentionally left blank 


\section{Sandia National Laboratories Analysis Code Data Base}

\section{Code Name: $L I Q D I F$}

Technical Competency/Capability Area: Subsurface Radionuclide Transport

Sandia Point of Contact:

Paul A.Davis,6307,MS-1345, (505) 848-0754,FAX (505) 848-0764,padavis@sandia.gov

Technical Description of What the Code Does:

A liquid diffusion model of radionuclide transport in the unsaturated zone is solved by an analytic solution. Discharges are computed and integrated over time to yield release values. Biological uptake, erosion and absorption are included.

Original Developer of the Code: Laura Price, Natalie Olague, Sandia National Laboratories

Release Status: Under Development

References: None

Computer Language: FORTRAN

Computer Platform: Sun Sparc-Station

Related Codes: None

Key Words: Liquid diffusion, radionuclide transport, vadose zone 


\section{Sandia National Laboratories Analysis Code Data Base}

Code Name: $M M 4 B A T$

Technical Competency/Capability Area: Climate modeling

Sandia Point of Contact:

Robert J. Sandoval, 6316,MS 9902,(510) 294-2908,FAX (510) 294-3320,rjsando@sandia.gov

Technical Description of What the Code Does:

Adaptation of the Penn State/NCAR Meso-scale Model including the Biosphere-Atmosphere Transfer Scheme (BATS). This model will be used for regional climate simulation.

Original Developer of the Code: Penn State - National Center for Atmospheric Research

Release Status: Research code

References:

Haagenson, P. L. "Penn State/NCAR Mesoscale Model User's Manual" - Version 8. NCAR.

Computer Language: Fortran 77

Computer Platform: Cray YMP

Related Codes: TERRAIN, MM4CCM, BDYOUT, INBATS, MM4PROC

Key Words: Climate simulation, atmospheric modeling 


\section{Sandia National Laboratories Analysis Code Data Base}

Code Name: PATH1

Technical Competency/Capability Area: Sensitivity analyses, environmental transport routes

\section{Sandia Point of Contact:}

Jon C. Helton, 6341, MS-1341, (505) 848-0701,FAX (505) 848-0705, jchelto@sandia.gov

Technical Description of What the Code Does:

PATH1 describes environmental movement and pathways to human uptake of radionuclides.

Original Developer of the Code: J.C. Helton and N. C. Finley, Sandia National Laboratories

Release Status: Version 1, 1982

References:

NUREG/CR-2394, SAND81-2377 PATH1 Self Teaching Curriculum: Example Problems for Pathways-to-Man Model

Computer Language: FORTRAN

Computer Platform: VAX

Related Codes: None

Key Words: Surface hydrology, one sell partitioning, sensitivity analysis, radionuclides, pathways 


\section{Sandia National Laboratories Analysis Code Data Base}

Code Name: Vapor Test (VaporTest System for Surface Acoustic Wave Sensors)

Technical Competency/Capability Area:

Developers and manufacturers of sensors (chemical, environmental, etc.) could use the enabling technology provided by VaporTest to evaluate, calibrate and optimize their devices.

\section{Sandia Point of Contact:}

Gregory C. Frye, 1315, MS-0351, (505) 844-0787, FAX (505) 844-1198, gcfrye@sandia.gov; Joel O. Stevenson, 1841,MS-0609, 845-8652, FAX (505) 844-2974, josteve@sandia.gov; Peggy J. Clews, 1841, MS-0609, (505) 844-3498, FAX (505) 844-2974, pjclews@sandia.gov; Gary T. Cordes, 1846 MS- 0607, (505) 844-9686, FAX (505) 844-2974,gtcorde@sandia.gov

\section{Technical Description of What the Code Does:}

The Vapor Test System is a data acquisition and experimental control system designed to acquire data from an acoustic wave device while the device is exposed to user-specified solvent profiles controlled by the Vapor Test System. The system is used to investigate and calibrate sensor behavior in the laboratory before the sensors are deployed in the field. Chemical sensors have been produced and optimized using the enabling technology provided by the Vapor Test System. The potential benefits of this sensor technology include waste minimization and process optimization, compliance with state and federal regulations concerning emissions, environmental monitoring during site remediation, and protection of the environment and personnel.

\section{Original Developer of the Code:}

Joel O. Stevenson, Peggy J. Clews, Gary T. Cordes, Department 1846, Gregory C. Frye

\section{Release Status:}

Research code - Industrial and/or commercial partners may be sought for distribution. The code has not been released at this time.

\section{References:}

Planned presentation/publication at The Pittsburgh Conference (March, 1993). SAND Report in Preparation

\section{Computer Language:}

The source code is written in Microsoft QuickBasic and National Instruments LabWindows QuickBasic. There are approximately 10,000 lines of source code in VaporTest

\section{Computer Platform:}

VaporTest is a DOS application that runs on the IBM architecture (386 machine or better)

Related Codes: None

Key Words: Chemical sensors, environmental sensors, acoustic wave devices 
Nuclear Reactor Technologies Codes 
This page intentionally left blank 


\section{Sandia National Laboratories Analysis Code Data Base}

Code Name: USINT

Technical Competency/Capability Area:

Reactor Safety: USINT was developed to predict the thermal decomposition of concretes commonly used for reactor containment.

\section{Sandia Point of Contact:}

Ned R. Keltner, 2761,MS-1135, (505) 845-3189,FAX (505) 845-3151,nrkeltn@sandia.gov

Technical Description of What the Code Does:

The code models the heat and mass transfer events inside porous concrete when it is exposed to a high temperature environment. The code calculates temperature and pressure profiles as a function of time and water release rates at the concrete boundaries.

Original Developer of the Code: J.F.Beck ${ }^{I}$ and R. L. Knight ${ }^{2}$

Release Status: This code is in the National Energy Software Center, Argonne National Lab

\section{References:}

SAND79-1694

Computer Language: FORTRAN

Computer Platform: Various

Related Codes: None

Key Words:

Concrete, high temperature, heat transfer, mass transfer, water release, pore pressure

\footnotetext{
${ }^{1}$ Former Sandian, now Professor at Michigan State University
}

${ }^{2}$ Former Sandian 


\section{Sandia National Laboratories Analysis Code Data Base}

\section{Code Name: VICTORIA-92}

\section{Technical Competency/Capability Area:}

VICTORIA-92 is a computer model of radionuclide behavior in the reactor coolant system of a light water reactor during a severe nuclear accident. It mechanistically models fission product chemistry (thermodynamic equilibrium), some kinetically limited processes, transport, aerosol physics, and decay heating.

Sandia Point of Contact:

Nathan E. Bixler, 6422, MS-1137, (505) 845-3144, FAX (505) 845-3435, nebixle@ sandia.gov

\section{Technical Description of What the Code Does:}

VICTORIA-92 is a mechanistic computer code designed to analyze fission product behavior within the reactor coolant system $(R C S)$ during a severe reactor accident. It provides detailed prediction of the release from the fuel and transport in the $R C S$ of radionuclides and non-radioactive materials during core degradation. These predictions account for the chemical and aerosol processes that affect radionuclide behavior. Coupling of detailed chemistry and aerosol packages is a unique feature of VICTORIA: it allows exploration of issues involving deposition, revaporization, and re-entrainment that cannot be resolved with other codes. Development and validation of VICTORIA are international efforts, involving three countries (US, UK, and Canada) and six laboratories (Sandia, Argonne, Oak Ridge, Battelle Columbus, Winfrith, and Chalk River). Complementary efforts are ongoing at the six locations; the overall effort is being coordinated by Sandia. New models in VICTORIA-92 account for the following effects: (1) decay-heat induced structural heat-up and its effect on revaporization and structure failure; (2) aerosol re-entrainment; (3) deposition of aerosols in sudden contractions, steam separators, and steam dryers; (4) $\mathrm{UO}_{2}$ oxidation and oxidative volatilization; (5) enhanced diffusion of fission products within the fuel due to oxidation; (6) porous flow of fission products through fuel rods; (7) release of vapors and aerosols from control rods; (8) mechanistic release from fuel; (9) release from degraded fuel geometries, i.e., rubble beds and molten pools; and (10) kinetically limited surface reactions, i.e., chemisorption. In addition, the chemistry package in now more robust and inclusive.

Original Developer of the Code:

N. E. Bixler, 6422, T., J. Heames, 6422, and D. A. Williams, Winfrith Technology Centre, UK

\section{Release Status:}

VICTORIA-92 was released to the public in March 1993.

\section{References:}

T. J. Heames, D. A. Williams, N. E. Bixler, A. J. Grimley, C. J. Wheatley, N. A. Johns, P. Domagala, L. W. Dickson, C. A. Alexander, I. Osborn-Lee, S. Zawadzki, J. Rest, A. Mason, R.. Y. Lee, "VICTORIA: A Mechanistic Model of Radionuclide Behavior in the Reactor Coolant System Under Severe Accident Conditions," NUREG/CR-5545, SAND90-0756 Rev. 1, Sandia National Laboratories, Albuquerque, NM, 87185, December, 1992. 
Computer Language: FORTRAN-77

Computer Platform: SPARCstation, HP Workstation, IBM RS-6000, CRAY, and IBM PC

\section{Related Codes:}

ALBERT - Preprocessor to add or delete chemical elements and species from the VICTORIA-92 database.

EDWARD - Graphics postprocessor.

\section{Key Words}

Source term, fission products, radionuclides, severe accidents, transport, decay heating, thermodynamic equilibrium, fuel oxidation, aerosol physics 
This page intentionally left blank 
Health Physics Codes 
This page intentionally left blank 


\section{Sandia National Laboratories Analysis Code Data Base}

Code Name: GENII

Technical Competency/Capability Area: Health Physics

Sandia Point of Contact:

MatthewW.Kozak,6331,MS-1345,(505) 848-0766,FAX (505) 848-0764 mwkozak@sandia.gov

Technical Description of What the Code Does:

Performs dose analysis from multiple pathway analyses.

Original Developer of the Code: Bruce Napier - PNL

Release Status: Version 1 (?)

References:

1. PNL-5684 GENII - The Hanford Environmental Radiation Dosimetry Software System Vol 1: Conceptual Representation Dec. 1988

2. PNL-6584 GENII - The Hanford Environmental Radiation Dosimetry Software System Vol 2: User's Manual Nov. 1988

Computer Language: FORTRAN

Computer Platform: IBM PC Compatible

Related Codes: None

Key Words: Dosimetry, pathway analysis, environmental contamination, radiation doses 


\section{Sandia National Laboratories Analysis Code Data Base}

Code Name: IMPACTS-BRC

Technical Competency/Capability Area: Health Physics

Sandia Point of Contact:

Matthew W. Kozak, 6331,MS-1345, (505) 848-0766,FAX (505) 848-0764 mwkozak@sandia.gov

Technical Description of What the Code Does:

Calculation of multi-pathway doses for de miniumus wastes.

Original Developer of the Code: Dames and Moore

Release Status: Version 2.1

References:

NUREG/CR-5797 SAND91-2226 - IMPACTS-BRC, Version 2.1, April 1992.

Computer Language: FORTRAN

Computer Platform: IBM PC

Related Codes: None

Key Words: Radioactive waste, regulatory, radiologic assessment, low-level waste 
Shock Physics Codes 
This page intentionally left blank 


\title{
Sandia National Laboratories Analysis Code Data Base
}

\author{
Code Name: $C T H$
}

Technical Competency/Capability Area: Shock Physics

Sandia Point of Contact:

E.S. Hertel, Jr., 1431,MS-0819, (505) 844-5364,FAX (505) 844-0918, esherte@sandia.gov

\section{Technical Description of What the Code Does:}

The $C T H^{1,2}$ software family is a complete package for the initialization, integration through time, and examination of complex phenomena surrounding shock physics. The classes of problems that can be analyzed with CTH include penetration and perforation, compression, high explosive detonation and initiation phenomena, and hypervelocity impacts. The software family currently consists of six major components along with several graphics post-processing tools.

CTH uses an Eulerian mesh to solve the conservation equations. Six geometry options are available in CTH: one-dimensional rectangular, cylindrical, and spherical; two-dimensional rectangular, and cylindrical; and three-dimensional rectangular. Up to ten materials and void can occupy a computational cell, although the maximum number of materials can be changed by modifying $a$ single Fortran parameter statement. In general, all internal dimensions are controlled by Fortran parameter statements and can be easily modified by rebuilding the appropriate program or programs.

Original Developer of the Code: J.M. McGlaun, S. L. Thompson and a cast of TEN'S

Release Status: Export controlled, available to government agencies and contractors.

\section{References:}

1. J. M. McGlaun, S. L. Thompson, L. N. Kmetyk and M. G. Elrick, "A Brief Description of the Three-Dimensional Shock Wave Physics Code CTH," Sandia National Laboratories report SAND89-0607, July 1990.

2. J. M. McGlaun, S. L. Thompson, L. N. Kmetyk and M. G. Elrick, "CTH: A Three-Dimensional Shock Wave Physics Code," Int. J. Impact Engng. 10, 351-360, 1990.

3. J. M. McGlaun, "CTH Reference Manual: Lagrangian Step for Hydrodynamic Materials, Sandia National Laboratories report SAND90-2645, December 1990.

4. S. A. Silling, "Stability and Accuracy of Differencing Schemes for Viscoplastic Models in Wavecodes," Sandia National Laboratories report SAND91-0141, 1991.

5. S. A. Silling, "CTH Reference Manual: Viscoplastic Models," Sandia National Laboratories report SAND91-0292, September 1991.

6. P. A. Taylor, "CTH Reference Manual: The Steinberg-Guinan-Lund Viscoplastic Model," Sandia National Laboratories report SAND92-0716, September 1992. 
7. S. A. Silling, "CTH Reference Manual: Johnson-Holmquist Ceramic Model," Sandia National Laboratories report SAND92-0576, September 1992.

8. E. S. Hertel, Jr., "The CTH Data Interface for Equation-of-State and Constitutive Model Parameters," Sandia National Laboratories report SAND92-0553, September 1992.

9. G. I. Kerley, "CTH Equation of State Manual: .Porosity and Reactive Burn Models," Sandia National Laboratories report SAND92-0553, July 1992.

10. R. L. Bell and E. S. Hertel, Jr., "A Improved Material Interface Reconstruction Algorithm for Eulerian Codes," Sandia National Laboratories report SAND92-1716, September 1992.

11. G. I. Kerley, "CTH Reference Manual: .The Equation-of-State Package," Sandia National Laboratories report SAND91-0344, May 1991.

12. J.M. McGlaun, "CTH Reference Manual: .Cell Thermodynamics," Sandia National Laboratories report SAND91-0002.

Computer Language: FORTRAN, C

Computer Platform: CRAY/UNICOS, HP/HP-UX, IBM RS6000/AIX, SUN/UNIX, SGI/UNIX, DEC/ULTRIX, CONVEX/UNIX

Related Codes: CTHGEN, CTHED, CTHPLT, HISPLT, CSQ, CHARTD

Key Words: Shock physics, Eulerian, large deformation, high strain rate, hydrocode 


\section{Sandia National Laboratories Analysis Code Data Base}

\section{Code Name: $P C T H$, for "Parallel CTH"}

\section{Technical Competency/Capability Area:}

PCTH is a portable, massively parallel computer code which models one-, two-, and three-dimensional phenomena arising from very rapid release of large amounts of energy. These events melt or vaporize solid materials, generate strong shock waves, and fracture much of the material. Events which can be modeled include the impacts of meteorites, collisions of orbital debris with space vehicle hull protectors, acceleration of hypervelocity projectiles, explosive forging, and armor/projectile interactions.

\section{Sandia Point of Contact:}

David R. Gardner, 1421,:MS-1111, (505) 845-7875; FAX: (505) 845-7871; drgardn@cs.sandia.gov

\section{Technical Description of What the Code Does:}

PCTH is a massively parallel hydrocode which models multi-dimensional, multi-material, largedeformation, strong-shock wave physics. A wide variety of phenomena may be modeled including high explosives, energy sources, elastic-plastic materials, and fracture. The code is based on the algorithms found in the CTH hydrocode developed at Sandia National Laboratories. It is designed for an MIMD computer architecture model whose nodes may have vector processing or SIMD characteristics.

\section{Original Developer of the Code:}

PCTH is being developed at Sandia National Laboratories by David R. Gardner, Allen C. Robinson, Courtenay T. Vaughan, H. Eliot Fang, Arlo L. Ames, Dino Pavlakos, Michael Wong, James S. Peery and Douglas Cline, all of Sandia; and Philip Campbell of Cray Research Inc.

Release Status: Under development

\section{References:}

A. C. Robinson, A. L. Ames, H. Eliot Fang, D. Pavlakos, C. T. Vaughan and P. Campbell, "Massively Parallel Computing, $C++$ and Hydrocode Algorithms," Proceedings of the 8 th Conference for Computing in Civil Engineering, 519-526 (June 1992)

\section{Computer Language: $\mathrm{C}++$}

Computer Platform: The nCUBE 2, the Intel iPSC/860, and Sun Workstations

\section{Related Codes:}

PCTH_GUI (PCTH Graphical User Interface), VFGEN (volume fraction generator), hisplt (history plotting program)

Key Words: Massively parallel, object-oriented programming, shock physics, hydrocode 
This page intentionally left blank 
Spectral Analysis Codes 
This page intentionally left blank 


\section{Sandia National Laboratories Analysis Code Data Base}

Code Name: CARSFT (Coherent Anti-Stokes Raman Spectroscopy Fitting Code)

Technical Competency/Capability Area:

Remote sensing (nonintrusive measurements of temperature, pressure, species concentrations in homogeneous and heterogeneous mixtures and flows)

\section{Sandia Point of Contact:}

Richard E.Palmer, 8901, (510) 294-3126 FAX (510) 294-1225, repalme@sandia.gov

Technical Description of What the Code Does:

CARSFT calculates coherent anti-Stokes Raman (CARS) spectra, and allows least-squares fitting to experimental spectra. Several options are available, including collisional narrowing, double convolutions, and multiple resonant species.

Original Developer of the Code: Gary L. Clark (originally at Sandia, now at Los Alamos National Laboratory, Los Alamos, NM 87544)

Release Status: Research code, but informally released to over twenty laboratories

\section{References:}

1. R. L. Farrow, R. P. Lucht, G. L. Clark, and R. E. Palmer, "Species Concentration Measurements using CARS with Nonresonant Susceptibility Normalization, "Appl. Opt. 24, 2241 (1985)

2. R. E. Palmer, "The CARSFT Computer Code for Calculating Coherent Anti-Stokes Raman Spectra: User and Programmer Information," Sandia Technical Report SAND89-8206, Feruary 1989.

Computer Language: FORTRAN 77

Computer Platform:

VAX (VMS), Cray Y-MP (UNICOS), most UNIX platforms, IBM PC and Compatibles (Intel 486)

\section{Related Codes:}

FTCARS, a quick-fitter that determines temperatures by interpolating from spectral libraries precalculated by CARSFT

Key Words: Raman, CARS, least-squares fit, spectroscopy 


\section{Sandia National Laboratories Analysis Code Data Base}

Code Name: PLSSNL, Partial Least Squares - Sandia National Laboratories

Technical Competency/Capability Area:

Chemometric multivariate calibration software for quantitative spectral analyses.

Sandia Point of Contact:

David M. Haaland, 1823 (505) 844-5292,FAX (505) 844-7910,dmhaala@sandia.gov

Technical Description of What the Code Does:

This software performs the chemometric multivariate calibration methods of partial least squares $(P L S)$ and principal component regression $(P C R)$ to quantitatively analyze spectral data. It includes data preprocessing, calibration, prediction, and has extensive graphics capabilities and outlier detection diagnostics. The intermediate calibration results for qualitative analysis are also available for examination. The software is menu driven and includes batch mode processing.

Original Developer of the Code:

David M. Haaland, Department 1823, and David K. Melgaard, J \& M Systems under contract to Sandia National Laboratories

\section{Release Status:}

Released to all SEMATECH member companies and is available under nonexclusive licensing from Sandia National Laboratories.

\section{References:}

Manual to PLSSNL is available from David M. Haaland

\section{Computer Language:}

Array Basic based upon Galactic Industries Lab Calc software. Also requires Galactic's PLSPLUS software.

Computer Platform: Runs on any PC compatible computer with co-processor installed.

Related Codes: Lab Calc and PLSPLUS from Galactic Industries as indicated above.

\section{Key Words:}

Chemometrics, multivariate calibration, quantitative spectral analysis, partial least squares, principal component regression 


\section{Sandia National Laboratories Analysis Code Data Base}

Code Name: SiFTIR (Silicon Fourier Transform Infrared Spectroscopy)

\section{Technical Competency/Capability Area:}

Manufacturers of device silicon could use the enabling technology provided by the SiFTIR code to monitor their products for interstitial oxygen impurities. Early detection of oxygen impurities using this diagnostic could minimize costly device failure downstream.

Sandia Point of Contact:

John W. Medernach,1332,MS-1083, (505) 845-9179 FAX (505) 844-2991, jwmeder@sandia.gov; Joel O. Stevenson, 1841, MS-0609,(505) 845-8652 FAX (505) 844-2974 josteve@sandia.gov; Mark A.Grohman, 9127, (505) 844-0350,FAX (505) 844-7020, magrohhm@sandia.gov

\section{Technical Description of What the Code Does:}

Software implements three independent oxygen analysis methods in a single integrated package. The concentration of interstitial oxygen in silicon is an important parameter for microelectronic device manufacture because oxygen impurities affectg the mechanical, electrical and gettering properties of silicon. Routine oxygen measurements are desirable over a wide range of silicon resistivities, but there has been confusion concerning which of the three numerical methods is most suitable for the high resistivity portion of the continuum. A major strength of the software is an ability to rapidly produce results for all three methods using only a single FTIR spectrum as input. This ability to perform three analyses on a single data set allows a detailed comparison of the three methods across the entire range of resistivities.

\section{Original Developer of the Code:}

Joel O. Stevenson, Department 1841 and John W. Medernach, Department 1323, Sandia National Laboratories; Eglin Air Force Base, Florida; Wright Laboratory

\section{Release Status:}

Research code - Industrial andlor commercial partners may be sought for distribution. The code has not been released at this time.

\section{References:}

1. J. W. Medernach, H. J. Stein, J. O. Stevenson, "The Application of Selective Electrochemical Wafer Thinning for Silicon Characterization," Extended Abstracts of the 179th Meeting of the Electrochcmical Society, Washington, DC, May 5-10, 1991, SAND90-3090EA.

2. J.W. Medernach, H.J. Stein and J. O. Stevenson, "The Application of Selective Electrochemical Wafer Thinning for Silicon Characterization," Proceedings of Defects in Silicon II Symposium, The Electrochemical Society, Washington, DC, May 5-10, 1991, SAND90-3090C.

3. J. W. Medernach and J. O. Stevenson, "A Comparison of Interstitial Oxygen Calculated by Different Techniques," Extended Abstracts of the 181 st Meeting of the Electrochemical Society, St. Louis, MO, May 17-22, 1992, SAND91-2693EA.

4. SAND Report in preparation. 


\section{Computer Language:}

The source code is written in FORTRAN. There are approximately 2000 lines of source code in SiFTIR.

\section{Computer Platform:}

SiFTIR is a DOS application that runs on the IBM architecture (386) machine). The code has also been successfully ported to a DEC (VAX/VMS) machine.Any Computer with ANSI Fortran 77 Compatible Compiler.

Related Codes: None

Key Words: Interstitial oxygen analysis in silicon, impurities in silicon, device silicon 


\section{Sandia National Laboratories Analysis Code Data Base}

Code Name: $S N L-N J O Y$

Technical Competency/Capability Area: $P K A$ recoil spectrum, cross section processing Sandia Point of Contact:

Patrick J.Griffin, 8534-1, MS-1145, (505) 845-9121 FAX (505) 845-3115, pjgriff@sandia.gov

\section{Technical Description of What the Code Does:}

This is a modified version of the NJOY code which allows the user to extract the primary knock-on atom $(P K A)$ recoil spectrum. Reaction-dependent recoil spectrum or integrals over all neutroninduced reactions for a given incident energy neutron are available.

This code was used to apply PKA-energy weighing functions to the displacement kerma in preparing the GaAs damage function that is being accepted by the ASTM community as part of the E722 Standard.

Original Developer of the Code: R. E. MacFarlane, Los Alamos National Laboratory

\section{Release Status:}

Research code only, not intended for release. Most users should use the LANL supported versions of NJOY.

References:

R. E. MacFarlane, D. W. Muir, R. M. Boicourt, "The NJOY Nuclear Data Processing System, Volume I: User's Manual," Los Alamos National Laboratory, LA-9303-M (ENDF-324), May 1982.

Computer Language: FORTRAN

Computer Platform: VAX VMS, UNIX on SUN Sparc

Related Codes: PKA_SPECTRUM

Key Words: PKA, recoil spectra, neutron cross sections 


\section{Sandia National Laboratories Analysis Code Data Base}

Code Name: SNLRML, Sandia National Laboratories Radiation Metrology Library

Technical Competency/Capability Area: Spectrum Unfolding, Reactor Dosimetry

Sandia Point of Contact:

Patrick J. Griffin, 8534-1, MS-1145, (505) 845-9121, FAX (505) 845-3115, pjgriff@ sandia.gov

Technical Description of What the Code Does:

This is a library of neutron dosimetry cross sections and covariance matrices. The cross sections represent the best reactions for neutron reactor dosimetry and have been drawn from the ENDF/ $B$-VI, IRDF-90, GLUCS, JENDL-3, JEF-2.2, and FENDL-2 libraries. The data is presented in multigroup format in the SAND-II 640 group energy structure. The library format is designed for easy interface with the SAND-II and LSL spectrum unfold codes.

Original Developer of the Code:

P. J. Griffin - The library is intended as a replacement for the DOSCROS84 library developed by W. L. Zijp of the Netherlands Energy Research Foundation, Petten, Netherlands

Release Status: Pending completion of documentation to release through RSIC

\section{References:}

1. P. J. Griffin, J. G. Kelly, T. F. Luera, "Effect of New Cross Section Evaluations on Spectrum Determinations," SAND92-0093, Sandia National Laboratories, presented at the 29th International Nuclear and Space Radiation Effects Conference held on July 13-17, 1992, in New Orleans, LA. Conference proceedings will be published in the December 1992 IEEE Transactions on Nuclear Science.

2. P. J. Griffin, J. G. Kelly, T. F. Luera, J. B. VanDenburg, "SNLRML Recommended Dosimetry Cross Section Compendium," SAND 92-0094, SNL, publication pending peer review of draft documentation.

Computer Language: ASCII format database - Interfaced with SNL-SAND-II Fortran code

Computer Platform:

ASCII format applicable to all platforms. Interfaced with SUN Sparc version of SNL-SAND-II.

Related Codes: SNL-SAND-II

Key Words:

Neutron dosimetry, spectrum unfolding, neutron cross sections reactor spectra, neutron spectrum, foil activation 


\section{Sandia National Laboratories Analysis Code Data Base}

Code Name: SNL-SAND-II, Sandia National Laboratories version of SAND-II (Spectrum Analysis by Neutron Detectors-II)

Technical Competency/Capability Area: Spectrum Unfolding, Reactor Dosimetry

Sandia Point of Contact:

Patrick J. Griffin, 8534-1, MS-1145, (505) 845-9121, FAX (505) 845-3115, pjgriff@sandia.gov

Technical Description of What the Code Does:

This is an updated version of the SAND-II code designed for iterative determination of neutron spectra. The major code improvements include:

1 Interfaces to aid in the outer iteration methodology detailed in reference 3. Includes a multiple iteration option, plots of resonances and areas of contribution by specific reactions.

1 UNIX port of code, automatic Make interface for file building for all support codes (SLTAPE, CSTAPE, and SLACTS).

1 Automatic interface of support codes in the preparation of a SAND-II library.

$1 \quad A C E / g r$ graphics interface.

1 Improved user input and output interface.

1 Summaries of spectral characteristics including 1-MeV(Si) and 1-MeV(GaAs) fluence in accordance with ASTM E722 Standard Fluence, tissue dose, SI, and HP characterition.

1 Interface with SNLRML library of dosimetry cross sections.

1 User definition of foil combinations to account for contaminant reactions (e.g. ${ }^{235} U$ in ${ }^{238} U$ fission foil or ${ }^{55} \mathrm{Mn}$ in ${ }^{56} \mathrm{Fe}$ foil).

Original Developer of the Code: W. N. McElroy, Atomics International

Release Status: User interface still being enhanced. Release through RSIC anticipated.

\section{References:}

1. J. G. Kelly, D. W. Vehar, "Measurement of Neutron Spectra in Varied Environments by the Foil Activation Method With Arbitrary Trials," SAND-87-1330, Sandia National Laboratories, December 1987.

2. J. G. Kelly, "Neutron Spectrum Adjustment with SAND-II Using Arbitrary Trial Functions," in Reactor Dosimetry, Methods, Applications, and Standardizations, edited by H. Farrar, E. P. Lippincott, STP 1001, American Society for Testing and Materials, 1989, Paper from the Sixth ASTM-Euratom Symposium held in Jackson Hole, Wyoming from 31 May to 5 June 1987. 
3. P. J. Griffin, J. G. Kelly, T. F. Luera, "Effect of New Cross Section Evaluations on Spectrum Determinations," SAND92-0093, Sandia National Laboratories, presented at the 29th International Nuclear and Space Radiation Effects Conference held on July 13-17, 1992 in New Orleans, Louisiana. Conference proceedings will be published in the December 1992 IEEE Transactions on Nuclear Science.

4. P. J. Griffin, J. G. Kelly, T. F. Luera, J. B. VanDenburg, "SNLRML Recommended Dosimetry Cross Section Compendium," SAND92-0094, Sandia National Laboratories, publication pending peer review of draft documentation.

5. P.J.Turner, “ACE/gr User's Manual, Graphics for exploratory data analysis, Software Documentation Series," SDS3, 91-3, 1992.

Computer Language: FORTRAN

Computer Platform: UNIX on SUN Sparc II - should easily port to any UNIX system

Related Codes: SNLRML, ACE/gr, SLTAPE, CSTAPE, SLACTS

\section{Key Words:}

Neutron dosimetry, spectrum unfolding, neutron cross sections reactor spectra, neutron spectrum, foil activation 
Surface Physics and Microscopy Codes 
This page intentionally left blank 


\section{Sandia National Laboratories Analysis Code Data Base}

Code Name: IMPCODE

Technical Competency/Capability Area: Surface Science, Quantum Chemistry

\section{Sandia Point of Contact:}

Peter J. Feibelman, 1114, MS-0344, (505) 844-6706, FAX(505) 844-5470, pjfeibe@sandia.gov

Technical Description of What the Code Does:

Computes the electronic structure of a two dimensionally periodic solid using a local orbital basis, within the Local Density Functional Approximation. Computes the total energy of the twodimensional crystal, the forces on the nuclei in the unit cell and the surface stress. Also computes the crystal electronic Green's function and other necessary information for use in IMPCODE.

Original Developer of the Code: Peter J. Feibelman, Sandia National Laboratories, Dept. 1114

Release Status: Research code. Parallel version under development.

\section{References:}

This program has not been documented in the scientific literature. It has generally been used as a preprocessor for IMPCODE, although its use as a free-standing code for molecular and ordered surface calculations is contemplated.

\section{Computer Language: Fortran}

\section{Computer Platform:}

The full code has been run on the Cray XMP, YMP, Cray-2 and C-90 machines. A version has been prepared for UNIX work stations, not yet including all the output features. $A$ version for the NCUBE massively parallel computer is in preparation.

\section{Related Codes:}

SLABCODE is designed to provide input in the necessary format for IMPCODE, a scattering theory program for surface impurity calculations. It makes use of codes to generate pseudopotentials, to develop adequate orbital basis sets and integration meshes. Analysis is greatly aided by a set of graphics codes.

Key Words: Electronic Structure, Density Functional, Surface, Crystal, First-Principles, Quantum Chemistry 


\section{Sandia National Laboratories Analysis Code Data Base}

Code Name: SLABCODE

Technical Competency/Capability Area: Surface Science, Quantum Chemistry

Sandia Point of Contact:

Peter J. Feibelman, 1114, MS-0344, (505) 844-6706, FAX(505) 844-5470, pjfeibe@ sandia.gov

\section{Technical Description of What the Code Does:}

SLABCODE computes the electronic structure of a two dimensionally periodic solid using a local orbital basis, within the Local Density Functional Approximation. It computes the total energy of the two-dimensional crystal, the forces on the nuclei in the unit cell and the surface stress. SLAB$C O D E$ also computes the crystal electronic Green's function and other necessary information for use in IMPCODE.

Original Developer of the Code:

Peter J. Feibelman, Sandia National Laboratories, Dept. 1114

Release Status: Research code. Parallel version under development.

\section{References:}

This program has not been documented in the scientific literature. It has generally been used as a preprocessor for IMPCODE, although its use as a free-standing code for molecular and ordered surface calculations is contemplated.

\section{Computer Language: Fortran}

\section{Computer Platform:}

The full code has been run on the Cray XMP, YMP, Cray-2 and C-90 machines. A version has been prepared for UNIX work stations, not yet including all the output features. A version for the NCUBE massively parallel computer is in preparation.

\section{Related Codes:}

SLABCODE is designed to provide input in the necessary format for IMPCODE, a scattering theory program for surface impurity calculations. It makes use of codes to generate pseudopotentials, to develop adequate orbital basis sets and integration meshes. Analysis is greatly aided by a set 9 of graphics codes.

Key Words: Electronic Structure, Density Functional Surface, Crystal, First-Principles, SelfConsistent, Local Orbital Basis, Quantum Chemistry 


\section{Sandia National Laboratories Analysis Code Data Base}

Code Name: TFA - Thin Film Analysis

Technical Competency/Capability Area: Analytical Electron Microscopy

\section{Sandia Point of Contact:}

Martin J. Carr, 1822, MS-0342, (505) 844-0993, FAX (505) 844-7910, mjcarr@ sandia.gov

Technical Description of What the Code Does:

Executes a Cliff-Lorimer type thin-film quantitative $x$-ray EDS analysis. Absorption correction optional.

Original Developer of the Code: M. J. Carr \& A. D. Romig, SNL

Release Status: Version 1.3, released in compiled form only

References: None

Computer Language: Fortran, $C, C++$, Turbo Pascal

Computer Platform: Macintosh

Related Codes: None

Key Words: Cliff-Lorimer, thin film analysis, EDS, AEM 
This page intentionally left blank 
Pulsed Power Devices Codes 
This page intentionally left blank 


\section{Sandia National Laboratories Analysis Code Data Base}

Code Name: ATHETA, DATHETA

Technical Competency/Capability Area: Pulsed Power, Magnetostatics, Magnetic Diffusion

Sandia Point of Contact:

JeffreyP.Quintenz, 1203, MS 1195, (505) 845-7245,FAX (505)845-7864,jpquint@sandia.gov

Technical Description of What the Code Does:

ATHETA and its companion code DATHETA compute magnetic fields in $2 D$ cylindrically symmetric geometries using finite-difference techniques. ATHETA solves for the magnetic fields in regions consisting at arbitrarily shaped perfectly conducting materials and current carrying coils. DATHETA uses ATHETA generated model geometries to compute the magnetic field diffusion into resistive materials. ATHETA is an interactive code and prompts the user for input. A variety of graphical outputs are generated.

Original Developer of the Code: J.P. Quintenz

Release Status: Research code used extensively at Sandia and released to NRL and Cornell University.

References: In line documentation and on line help

Computer Language: FORTRĀN

Computer Platform: VAX/VMS, HP Unix, Cray UNICOS

Related Codes: N/A

Key Words: Magnetic field diffusion 


\section{Sandia National Laboratories Analysis Code Data Base}

\section{Code Name: QUICKSILVER}

Technical Competency/Capability Area: Design of Pulsed Power Devices - Plasma Physics

Sandia Point of Contact:

David B. Seidel,1242, MS-1182, (505) 845-8355, FAX(505) 845-7890, dbseide@sandia.gov

Technical Description of What the Code Does:

QUICKSILVER is a 3-dimensional, finite-difference, relativistic, electromagnetic, particle-in-cell (PIC) simulation code, used to self-consistently advance interacting electromagnetic fields and charged particles forward in time. The electric and magnetic fields are advanced using Maxwell's equations, with currents computed from the particles. The particles use a fully relativistic algorithm to advance their position and momentum under the action of the Lorentz force. Perfectly conducting, mirror and periodic boundaries are available for both particles and fields. Fields are driven with input TEM wave and circuit models. Particles can be preloaded, or dynamically created during the simulation with either field emission or beam injection algorithms.

Original Developer of the Code:

David B. Seidel, Mark L. Kiefer, Rebecca S. Coats, Timothy D. Pointon, W. A. Johnson, and Jeffrey P. Quintenz, Pulsed Power Sciences Center, Sandia National Laboratories

Release Status: Version 2.35 is available under licensing agreement with Sandia National Laboratories. The code remains under development.

References:

1. D. B. Seidel, M. L. Kiefer, R./ S. Coats, A. L. Siegel, and J. P. Quintenz, Proc. 12th Conf. on Numerical Simulation of Plasmas, San Francisco, CA, paper PT-24 (1987).

2. M. L. Kiefer, D. B. Seidel, R. S. Coats, J. P. Quintenz, T. D. Pointon, and W. A. Johnson, Proc. Conf. on Codes and the Linear Accelerator Community, Los Alamos National Laboratory, (1990).

3. D. B. Seidel, M. L. Kiefer, R. S. Coats, T. D. Pointon, J. P. Quintenz, and W. A. Johnson, in Computational PHysics, edited by A. Tenner (World Scientific, Singapore, 1991), pp. 475-482.

Computer Language: ANSI FORTRAN77 (some of QUICKSILVER's underlying libraries and some of the post-processors are written in ANSI C).

Computer Platform: Cray computers running UNICOS. The pre-and post-processing tools described below run on UNIX workstations and VMS computers.

\section{Related Codes:}

QUICKSILVER is the workhorse of a suite of codes (the QUICKSILVER suite). The other codes in the suite provide extensive pre- and post-processing functionality. The MERCURY preprocessor provides an easy-to-use interface for problem description and setup, including extensive grid generation tools. The suite contains several post-processors that fully support QUICKSILVER output. QSAVS provides an interface to the commercially available AVS $3 D$ visualization software. PLOTPFF is a design for quantitative analysis and manipulation of $3 D$ field and particle snapshot data. The IDR code provides similar capability for the analysis of time waveform data. The Sandia-developed Portable File Format (PFF) is used to facilitate the efficient transport of data between various codes running on various platforms.

Key Words: Particle-In-Cell (PIC), finite-difference time-domain (FDTD), pulsed power, plasma physics, particle beams, microwave devices 


\section{Sandia National Laboratories Analysis Code Data Base}

Code Name: SCREAMER

Technical Competency/Capability Area:

Design of Pulsed Power Devices, Electrical Circuit Modeling

\section{Sandia Point of Contact:}

Mark L. Kiefer, 1242, MA-1186, (505) 845-7271, FAX(505) 845-7890 mlkiefe@sandia.gov

Technical Description of What the Code Does:

SCREAMER simulates electrical circuits which may contain nonlinear resistance, capacistance and inductance. The user may add nonlinear elements in a simulation by choosing from a library of models or by writing a function describing the element. Transmission lines, magnetically insulated transmission lines (MITL) and arbitrary voltage and current sources may also be included. Transmission lines are modeled using pi-sections connected in series. For simulations with only nonvarying circuit elements, the SCREAMER circuit solver is completely implicit. By restricting the topology of circuits modeled by SCREAMER, a nearly tridiagonal matrix results. Such a matrix is inverted with little computation and the computational time scales nearly linearly with the number of circuit elements.

Original Developer of the Code:

Mark L. Kiefer (Sandia), Mel W. Widner (formerly Sandia) and Kelley L. Fugelso (SEA)

\section{Release Status:}

SCREAMER is available for release to $U$. S. companies, universities and government agencies only, but may be released to non-U.S. entities on a case-by-case basis. It has been released to over 30 sites. It is not currently under active development.

\section{References:}

1. "SCREAMER -- A Single-Line Pulsed Power Design Tool," p.685, Proceedings of the 5th IEEE Pulsed Power Conference, Arlington, VA, 1985

2. A User's Manual is available from the POC.

Computer Language: FORTRAN

Computer Platform: VAXNMS, UNIX, MacIntosh, PC version is planned

Related Codes: None

Key Words: Pulsed power, circuit analysis, transmission lines, MITL 


\section{Sandia National Laboratories Analysis Code Data Base}

\section{Code Name: $\quad T W O Q U I C K$}

Technical Competency/Capability Area: Design of Pulsed Power Devices - Plasma Physics

\section{Sandia Point of Contact:}

Timothy D. Pointon, 1242, MS-I193, (505) 845-7261, FAX (505) 845-7890, tdpoint@ sandia.gov

\section{Technical Description of What the Code Does:}

TWOQUICK is a 2--dimensional, finite-difference, relativistic, electromagnetic, particle-in-cell (EM PIC) simulation code, used to self-consistently advance interacting electromagnetic fields and charged particles forward in time. By 2-D, we mean that all thee field and particle momentum components are present, but only on a 2-D spatial grid, i.e., the system is invariant in the third spatial coordinate. The electric and magnetic fields are advanced using Maxwell's equations, with currents computed from the particles. The particles use a fully relativistic algorithm to advance their two spatial coordinates and three momentum components under the action of the Lorentz force. Perfectly conducting, mirror and periodic boundaries are available for both particles and fields. Fields are driven with input TEM wave and circuit models. Particles can be preloaded, or dynamically created during the simulation with either field emission or beam injection algorithms.

Original Developer of the Code:

Timothy D. Pointon (Sandia), and David B. Seidel (Sandia). TWOQUICK is a derivative of the MAGIC code, originally developed for Sandia National Laboratories under contract by Mission Research Corporation (Bruce Goplen, and Robert E. Clark).

Release Status:

Version 1.0 will soon be available under a licensing agreement with Sandia National Laboratories. The code is currently undergoing major development.

References: None

\section{Computer Language: FORTRAN}

Computer Platform: HP and Sun UNIX workstations, Cray computers running UNICOS

\section{Related Codes:}

TWOQUICK is a recent addition to the QUICKSILVER code suite (QUICKSILVER is the full 3-D EM PIC simulation code). The MERCURY preprocessor, originally designed for QUICKSILVER, currently provides little support for TWOQUICK itself. However, the post-processors in the suite, $P L O T P F F, Q S A V S$, and IDR, fully support TWOQUICK output.

Key Words: Particle-In-Cell (PIC), finite-difference-time domain (FDTD), pulsed power, plasma physics, particle beams, microwave devices 
Electromagnetic Phenomena Codes 
This page intentionally left blank 


\section{Sandia National Laboratories Analysis Code Data Base}

Code Name: SLINGSHOT

Technical Competency/Capability Area:

Electromagnetic launchers, magnetic field diffusion into conductors

Sandia Point of Contact:

Barry Marder, 1241, S-1186, (505) 845-7274, FAX (505) 845-7890,bmmarde@sandia.gov

Technical Description of What the Code Does:

SLINGSHOT computes the production and diffusion of a magnetic field in an axially symmetric geometry by subdividing conductors into concentric hoops with rectangular cross-section and solving the circuit equation for the current in each element. External circuits, such as for providing power, can be incorporated into selected elements. The code was written to stimulate the behavior of a coilgun, an inductive electromagnetic launcher. It finds the forces produced by the interaction of currents in the elements and moves the armature in response. The code computes, as functions of time, the self inductance, temperature, specific heat, and resistivity for all elements, as well as the mutual inductance (plus spatial derivatives) for all element pairs. Since no partial differential field equations are solved, no numerical mesh is needed. The magnetic field is not explicitly computed, but can be easily obtained at any location from the distribution of current.

Original Developer of the Code:

SLINGSHOT is a follow on to the code WARP-10. It was developed to be user friendly and have easy to use input and output files, as well as to incorporate several features specific to coilgun design.

Release Status: None

References:

M. M. Widner, "WARP-10: A Numerical Simulation Model for the Cylindrical Reconnection Launcher," 5th Symposium on Electromagnetic Launch Technology, Destin, Florida, April 2-5, 1990.

Computer Language: Standard FORTRAN

Computer Platform: Any platform with FORTRAN.

\section{Related Codes:}

The code is completely self-contained. Several post-processors have been written to plot information and examine the stresses and strains on the conductors.

Key Words: Electromagnetic launcher, coilgun, magnetic diffusion. 
This page intentionally left blank 
Mathematics and Statistics Codes 
This page intentionally left blank 


\section{Sandia National Laboratories Analysis Code Data Base}

Code Name: CCDFTRUIIFI

Technical Competency/Capability Area: Statistical Analysis

Sandia Point of Contact:

Paul A. Davis, 6307, MS-1345, (505) 848-0754, FAX (505) 848-0764, padavis@sandia.gov

Thomas A Baer, 6331, MS-1345, (505) 848-0748, FAX (505) 848-0764, tabaer@ sandia.gov

Technical Description of What the Code Does:

CCDTRUIIFI will calculate and display the complementary cumulative distribution function using integrated discharge data from a Monte Carlo Procedure.

Original Developer of the Code: Sandia, Felix Liard

Release Status: Under Development

References: None

Computer Language: FORTRAN

Computer Platform: Sun Sparc-Station

Related Codes: NEFTRANII, LIQDIF3

Key Words: Complementary cumulative distribution function 


\section{Sandia National Laboratories Analysis Code Data Base}

Code Name: $S A S$

Technical Competency/Capability Area: Statistics

Sandia Point of Contact:

Paul A.Davis, 6307, MS-1345, (505) 848-0754,FAX (505) 848-0764, padavis@sandia.gov;

Technical Description of What the Code Does:

SAS consists of a large number of procedures used in statistical data handling and analyses.

Original Developer of the Code:

SAS Institute Inc., SAS Campus Drive, Cary, North Carolina 27513-2414

Release Status: Version 6.07

References:

SAS Language and User's Guides Version 6

Computer Language: FORTRAN

Computer Platform: Sun Sparc-Station

Related Codes: None

Key Words: Statistics, analyses 


\section{Sandia National Laboratories Analysis Code Data Base}

Code Name: STEPWISE

Technical Competency/Capability Area: Regression Analysis

Sandia Point of Contact:

Ronald L.Iman, 6613, MS-0746, (505) 844-8834, FAX (505) 844-3321, rliman@sandia.gov

Technical Description of What the Code Does: Performs stepwise linear regression analyses

Original Developer of the Code:

Ronald L. Iman, James M. Davenport, Elizabeth L. Frost, Michael Shortencarier, Sandia National Laboratories

Release Status: Version 1

References:

SAND79-1472, Stepwise Regression with PRESS and Rank Regression (Program User's Guide)

Computer Language: FORTRAN

Computer Platform: VAX

Related Codes: PRESS

Key Words: Stepwise, linear, regression 
This page intentionally left blank 
Weapons Effectiveness Simulation Codes 
This page intentionally left blank 


\section{Sandia National Laboratories Analysis Code Data Base}

Code Name: FRAGBOM

Technical Competency/Capability Area: Fragmentation weapon design

Sandia Point of Contact:

Ronald L.Woodfin, 9122,MS-0860, (505) 844-3111,FAX (505) 844-7020, rlwoodf@sandia.gov

Technical Description of What the Code Does:

FRAGBOM predicts the impact patterns on a flat earth of the fragments produced by a munition bursting above the ground. It considers the ballistics of an aerodynamically retarded, cylindrical munition of reasonably arbitrary nose shape. The fragment patterns produced may be specified. These fragments are then assumed to fly on line-of-sight paths in the directions specified by the half angles of bounding cones. Fragment velocities are pre-computed off-line as a function of range. Blast-kill ranges are handled in "cookie-cutter" fashion. Specified degrees of randomness may be assigned for each parameter of the munition, delivery condition and atmosphere. Targets are defined by "vulnerable areas" taken from the Joint Munitions Effectiveness Manuals (JMEMs). Probabilities of kill or damage are calculated. FRAGBOM may be used for bombs, artillery projectiles, stabilized grenades, etc., but no specific maneuver capability is included.

Original Developer of the Code: Ronald L. Woodfin, SandialNM, 97238

Release Status: Available on license basis to US only; export restrictions apply

\section{References:}

Ronald L. Woodfin, "FRAGBOM, An Engineering Design Tool for Enhancing General Purpose Bomb Performance," SAND89-1568, UC-741, May 1991.

Computer Language: FORTRAN 77

Computer Platform: VAX, SUN SPARC

Related Codes: DISSPLA, User-supplied code for integration of 1st order, non-linear, ordinary differential equation for input data preparation.

Key Words: Fragments, munitions, bombs, Pk, projectiles 


\title{
Sandia National Laboratories Analysis Code Data Base
}

\author{
Code Name: SHAZAM
}

\section{Technical Competency/Capability Area:}

Shazam is an air-to-air interceptor effectiveness evaluation code, with the ability to model warhead, target detection device, and endgame kinematics, using Monte Carlo simulation techniques to produce probability of kill statistics for an interceptor against an airborne target.

\section{Sandia Point of Contact:}

Mark A. Grohman, 9127,MS-0859, (505) 844-0350,FAX (505)844-1673,magrohm@sandia.gov

Technical Description of What the Code Does:

SHAZAM utilizes user supplied data which models physical characteristics of an air-to-air interceptor, an airborne target, and terminal encounter geometry, with Monte Carlo random sampling techniques in order to obtain approximate solutions for probability of kill of the target by the interceptor.

The user supplies terminal encounter geometry data to indicate the relative interaction of the interceptor with the target. SHAZAM generates a random intercept geometry sample within the users guidelines to produce a slightly different scenerioi for each encounter. During the encounter, SHAZAM increments the interceptor position along the trajectory path. At each increment, elements of the interceptor fuze model determine what extent of the target is observable. As the interceptor moves along the trajectory path, the fuze re-evaluates the target signature until conditions specific to the fuze indicate that warhead detonation should commence. SHAZAM utilizes the user supplied warhead data in conjunction with target vulnerabilities to evaluate the ability of warhead fragments to cause failure in target structures and systems. The contribution of each fragment on the target is used in conjunction with a target fault tree to determine an overall probability of effectiveness. These probabilities over an iteration set produces a statistical probability, to some measure of surety, of the interceptor performance against a target for a specific encounter geometry.

Original Developer of the Code:

Eglin Air Force Base, Florida - Wright Laboratory

Release Status: Unclassified/Unlimited; distribution limited to Government agencies only.

References:

1. User Manual for the Air-to-Air Missile Effectiveness Program SHAZAM, AFATL-TR-86-32.

2. Vulnerability Model Standardization and SHAZAM Endgame Model Modification, AFATL$T R-86-32$.

3. User Manual for Construction SHAZAM Vulnerability Models, AFATL-TR-86-23.

4. Addendum to SHAZAM User Manual, AFATL-TR-86-27.

5. Vulnerability Input File Generator for SHAZAM, AFATL-TR-25. 
Computer Language: FORTRAN 77

Computer Platform: Any Computer with ANSI Fortran 77 Compatible Compiler

Related Codes:

BEEST - Backscatter and Electronic Event Simulation Technique, AD/EN-TR-88-1002 COVART, Dept. 4065

Key Words: SHAZAM, air-to-air interceptor, Monte Carlo 
This page intentionally left blank 
Optics Codes 
This page intentionally left blank 


\section{Sandia National Laboratories Analysis Code Data Base}

Code Name: CIRCE2 -- Convolution of Incident Radiation with Concentrator Errors

Technical Competency/Capability Area: Solar Concentrator/Receiver Optical Modelling

Sandia Point of Contact:

Vincente J.Romero, 1513,MS-0835,(505) 844-5890,FAX (505) 844-8251,vjromer@sandia.gov

Technical Description of What the Code Does:

CIRCE2 is a cone-optics code for determining the flux distribution and total power incident upon a receiver. Statistical methods are used to model the angular distribution of reflected sunlight from any point on the concentrator. This angular distribution is a result of the variation in brightness across the sun, coupled with reflector imperfections such as surface roughness and random deviations in curvature. Incident flux is calculated at a regular grid of points on the target surface, and this discrete distribution is numerically integrated to determine total collected power. $A$ broad variety of concentrator/receiver configurations can be modelled. Among the more advanced features are the capabilities to model faceted concentrators, reflectors with custom curvature such as stretched-membrane dishes, and 3-D internal or external receivers. Provisions for shading, blocking, and aperture specification also exist. CIRCE2 is paired with an interactive preprocessor, DEKGEN2, that facilitates the specification of geometry, sun models, and concentrator imperfections. The software package exhibits convenient features for modelling "conventional" concentrators, and has the generality required to model complex and unconventional designs.

Original Developer of the Code: Arthur C.Ratzel, Sandia National Laboratories

Release Status: Ratzel's version released 1986, Romero's version released 1993.

References:

1. V.J. Romero, "CIRCE2/DEKGEN2: A Software Package for Facilitated Optical analysis of 3-D Distributed Solar Energy Concentrators -- Theory and User Manual," Sandia National Laboratories report SAND91-2238, to be printed Spring, 1993.

2. A. C. Ratzel, and B. D. Bpughton, "CIRCE.001: A computer Code for Analysis of Point-2. Focus Concentrators with Flat Targets," Sandia National Laboratories report SAND86-1866, printed Feb. 1987.

Computer Language: FORTRAN

Computer Platform:

1. PC, requirements: $640 \mathrm{~Kb} R A M, 5 \mathrm{MB}$ hard disk, MS-DOS 3.0, Microsoft Fortran 4.0

2. VAX/VMS systems

3. Sun SPARCstations

Related Codes:

DEKGEN2 -- preprocessor for CIRCE2, V.J. Romero.

AEETES -- cavity receiver thermal modelling code, Roy Hogan, Dept. 1513.

FACALGN -- facet alignment, focusing of faceted concentrators, Rich Diver, Dept. 6216.

RECWICK -- flow of liquid metals through wick structure of heat-pipe receivers, Doug Adkins.

Key Words: Solar energy, optics, concentrator/receiver modelling, stochastic processes 
Distribution:

\begin{tabular}{|c|c|c|c|c|c|c|}
\hline MS0102 & 2 & J. A. Tegnelia & & MS0507 & 2700 & K. G. McCaughey \\
\hline MS0360 & 1000 & A.R.C. Westwood & & MS0630 & 2800 & J. F. Jones \\
\hline MS0320 & 1010 & P. L. Mattern & & MS0953 & 2900 & W. E. Alzheimer \\
\hline MS0336 & 1100 & R. J. Eagan & & MS1017 & 3000 & C. E. Emery \\
\hline MS1190 & 1200 & D. L. Cook & & MS0149 & 4000 & C. P. Robinson \\
\hline MS1195 & 1202 & J. P. Quintenez & & MS0149 & 4000 & J. C. Cummings (10) \\
\hline MS1186 & 1242 & J. P. Quintenez & & MS0455 & 4100 & G. R. Otey \\
\hline MS1079 & 1300 & P. S. Peercy & & MS1380 & 4200 & W. D. Siemens \\
\hline MS0321 & 1400 & E. H. Barsis & & MS1380 & 4202 & O. D. Thompson \\
\hline MS1111 & 1402 & S. S. Dosanjh & & MS1380 & 4211 & M. S. Allen (10) \\
\hline MS0821 & 1404 & J. A. Ang & & MS1375 & 4400 & L. D. Bertholf \\
\hline MS1110 & 1405 & R. C. Allen & & MS0131 & 4500 & J. A. Weiss \\
\hline MS0318 & 1415 & G. S. Davidson & & MS1368 & 4700 & J. P. Vandevender \\
\hline MS1111 & 1421 & Actg & & MS0463 & 5000 & R. L. Hagengruber \\
\hline MS1110 & 1422 & R. C. Allen & & MS0429 & 5100 & W. C. Nickell \\
\hline MS1110 & 1423 & E. F. Brickell & & MS0469 & 5200 & E. E. Ives \\
\hline MS1109 & 1424 & A. L. Hale & & MS9005 & 5300 & J. B. Wright \\
\hline MS0441 & 1425 & Actg & & MSO473 & 5400 & H. J. Saxton \\
\hline MS0819 & 1431 & J. M. McGlaun & & MS0461 & 5500 & C. A. Yarnall \\
\hline MS0820 & 1432 & P. J. Yarrinton & & MS0457 & 5600 & D. B. Hayes \\
\hline MS0821 & 1433 & P. L. Stanton & & MS0457 & 5601 & J. B. Gerardo \\
\hline MS0439 & 1434 & D. R. Martinez & & MS0458 & 5602 & J. R. Asay \\
\hline MS0841 & 1500 & D. J. McCloskey & & MS0457 & 5603 & L. R. Gillion \\
\hline MS0836 & 1516 & C. W. Peterson (25) & & MS0769 & 5800 & D. S. Miyoshi \\
\hline MS0827 & 1502 & P. J. Hommert & & MS0570 & 5900 & C. W. Childers \\
\hline MS0441 & 1503 & J. H. Biffle & & MS0724 & 6000 & D. L. Hartley \\
\hline MS0827 & 1504 & E. D. Gorham & & MS0701 & 6100 & R. W. Lynch \\
\hline MS0827 & 1511 & J. S. Rottler & & MS0706 & 6113 & J. K. Linn \\
\hline MS0834 & 1512 & A. C. Ratzel & & MS1324 & 6115 & P. B. Davies \\
\hline MS0835 & 1513 & R. D. Skocypec & & MS0751 & 6117 & W. R. Wawersik \\
\hline MS0832 & 1516 & W. P. Wolfe & & MS0735 & 6200 & D. E. Arvisu \\
\hline MS0836 & 1516 & C.E. Hailey & & MS0708 & 6214 & H. M. Dodd \\
\hline MS0826 & 1514 & W. L. Hermina & & MS0703 & 6216 & C. E. Tyner \\
\hline MS0825 & 1515 & W. H. Rutledge & & MS1337 & 6300 & D. E. Ellis \\
\hline MS0443 & 1517 & H. S. Morgan & & MS1345 & 6331 & D. P. Gallegos \\
\hline MS0437 & 1518 & R. K. Thomas & & MS1343 & 6351 & R. E. Thompson \\
\hline MS0337 & 1800 & A. D. Romig & & MS0736 & 6400 & N. R. Ortiz \\
\hline MS0803 & 1900 & D. L. Crawford & & MS0405 & 6411 & D. D. Carlson \\
\hline MS9011 & 1901 & R. E. Palmer & & MS0747 & 6412 & A. L. Camp \\
\hline MS0803 & 1902 & R. M. Cahoon & & MSO745 & 6418 & S. L. Thompson \\
\hline MS0805 & 1904 & A. R. Iacoletti & & MS0739 & 6429 & K. E. Washington \\
\hline MS9011 & 1952 & R. E. Cline, Jr. & & MS1143 & 6500 & J. K. Rice \\
\hline MS0806 & 1957 & W. D. Swartz & & MS0726 & 6600 & J. B. Woodard \\
\hline MS0513 & 2000 & H. W. Schmitt & & MSO725 & 6900 & T. O. Hunter \\
\hline MS0322 & 2100 & P. J. Eicker & & MS1067 & 7000 & M. L. Jones \\
\hline MS0509 & 2300 & R. D. Andreas & & MS9001 & 8000 & J. C. Crawford \\
\hline MS0960 & 2400 & J. Q. Searcy & & MS9004 & 8100 & M. E. John \\
\hline MS0511 & 2500 & G. N. Beeler & & MS9037 & 8200 & R. J. Detry \\
\hline MS0985 & 2600 & J. H. Stichman & & MS9054 & 8300 & W. J. McLean \\
\hline
\end{tabular}




$\begin{array}{lrl}\text { MS9161 } & 8341 & \text { W. G. Wolfer } \\ \text { MS9053 } & 8366 & \text { C. M. Hartwig } \\ \text { MS9105 } & 8400 & \text { L. A. Hiles } \\ \text { MS9401 } & 8700 & \text { R. C. Wayne } \\ \text { MS9405 } & 8701 & \text { D. L. Lindner } \\ \text { MS9401 } & 8702 & \text { C. W. Robinson } \\ \text { MS9403 } & 8712 & \text { M. I. Baskes } \\ \text { MS9404 } & 8713 & \text { J. C. F. Wang } \\ \text { MS9404 } & 8714 & \text { M. W. Perra } \\ \text { MS9402 } & 8715 & \text { G. J. Thomas } \\ \text { MS9403 } & 8716 & \text { J. M. Hruby } \\ \text { MS9042 } & 8741 & \text { G. A.Benedetti } \\ \text { MS9042 } & 8742 & \text { P. E. Nielan } \\ \text { MS9043 } & 8743 & \text { M. A. Callabaresi } \\ \text { MS9043 } & 8745 & \text { R. J. Kee } \\ \text { MS9044 } & 8746 & \text { W. A. Kawahara } \\ \text { MS9007 } & 8800 & \text { M. Dyer } \\ \text { MS0151 } & 9000 & \text { G. Yonas } \\ \text { MS0842 } & 9100 & \text { C. M. Hart } \\ \text { MS0970 } & 9200 & \text { T. A. Sellers } \\ \text { MS1165 } & 9300 & \text { J. E. Powell } \\ \text { MS0431 } & 9400 & \text { M. J. Eaton } \\ \text { MS0766 } & 9600 & \text { J. R. Kelsey } \\ \text { MS0301 } & 9800 & \text { D.J. Rigali } \\ \text { MS0163 } & 9900 & \text { S. G. Varnado } \\ \text { MS0801 } & 10300 & \text { M. J. Murphy } \\ \text { MS0161 } & 11500 & \text { K. C. Olsen } \\ \text { MS0161 } & 11510 & \text { C. W. Sumpter } \\ \text { MS0631 } & 12300 & \text { R. L. Schwoebel } \\ \text { MS0131 } & 12600 & \text { G. R. Langheim } \\ \text { MS0129 } & 12611 & \text { J. A. Leonard } \\ \text { MS9018 } & 8523-2 & \text { Central Technical Files } \\ \text { MS0899 } & 13414 & \text { Technical Library (7) } \\ \text { MS0619 } & 13416 & \text { Technical Publications } \\ \text { MS0100 } & 7613-2 & \text { Document Processing for } \\ & & \text { DOE/OSTI (10) } \\ & & \end{array}$

